Pacific Northwest

National Laboratory

Operated by Battelle for the

U.S. Department of Energy

\title{
Experimental Design for the INL Sample Collection Operational Test
}

B. G. Amidan, G. F. Piepel, and B. D. Matzke

Statistics and Sensor Analytics

Pacific Northwest National Laboratory

Richland, WA

J. J. Filliben, Statistical Engineering Division

B. J. Jones, Biochemical Science Division

National Institute of Standards and Technology

Gaithersburg, MD

December 2007

Prepared for

U.S. Department of Homeland Security

Science and Technology Directorate

Test and Evaluation/Standards Division

Standards Office

Prepared for the U.S. Department of Energy

under Contract DE-AC05-76RL01830 


\title{
UNCLASSIFIED
}

\section{DISCLAIMER}

This report was prepared as an account of work sponsored by an agency of the United States Government. Neither the United States Government nor any agency thereof, nor Battelle Memorial Institute, nor any of their employees, makes any warranty, express or implied, or assumes any legal liability or responsibility for the accuracy, completeness, or usefulness of any information, apparatus, product, or process disclosed, or represents that its use would not infringe privately owned rights. Reference herein to any specific commercial product, process, or service by trade name, trademark, manufacturer, or otherwise does not necessarily constitute or imply its endorsement, recommendation, or favoring by the United States Government or any agency thereof, or Battelle Memorial Institute. The views and opinions of authors expressed herein do not necessarily state or reflect those of the United States Government or any agency thereof.

\author{
PACIFIC NORTHWEST NATIONAL LABORATORY \\ operated by \\ BATTELLE \\ for the \\ UNITED STATES DEPARTMENT OF ENERGY \\ under Contract DE-AC05-76RL01830
}

Printed in the United States of America
Available to DOE and DOE contractors from the
Office of Scientific and Technical Information,
P.O. Box 62, Oak Ridge, TN 37831-0062;
ph: (865) 576-8401
fax: (865) 576-5728
email: reports@adonis.osti.gov

\footnotetext{
Available to the public from the National Technical Information Service, U.S. Department of Commerce, 5285 Port Royal Rd., Springfield, VA 22161 ph: (800) 553-6847 fax: (703) 605-6900

email: orders@ntis.fedworld.gov

online ordering: http://www.ntis.gov/ordering.htm
} 


\section{Experimental Design for the INL Sample Collection Operational Test}

B. G. Amidan, G. F. Piepel, and B. D. Matzke

Statistics and Sensor Analytics

Pacific Northwest National Laboratory

Richland, WA

J. J. Filliben, Statistical Engineering Division

B. J. Jones, Biochemical Science Division

National Institute of Standards and Technology

Gaithersburg, MD

December 2007

Prepared for

U.S. Department of Homeland Security

Science and Technology Directorate

Test and Evaluation/Standards Division

Standards Office

Prepared for the U.S. Department of Energy

under Contract DE-AC05-76RL01830

Pacific Northwest National Laboratory

Richland, WA 99352

UNCLASSIFIED 


\section{Executive Summary}

This report describes the test events and numbers of samples comprising an experimental design developed to assess sampling strategies and methods for detecting contamination in a building and releasing the building for use after decontamination. Idaho National Laboratory (INL) identified Building PBF-632 as a test bed facility for evaluating protocols for response to potential contamination by biological agents. Building PBF-632 is an unoccupied, two-story office building with each floor having an area of $4025 \mathrm{ft}^{2}$. The first floor has 11 offices, a reception area, men's and women's restrooms, and a mechanical room. The second floor has 15 offices, two storage rooms, men's and women's restrooms, and a mechanical room. Building PBF-632 will be contaminated with BG (Bacillus globigii, subsequently Bacillus subtilis var. niger, and recently renamed Bacillus atrophaeus), a simulant for Bacillus anthracis (BA). The contamination, sampling, decontamination, and re-sampling will occur as specified by the experimental design. This study is referred to as the INL Sample Collection Operational Test.

Two objectives were developed to guide the construction of the experimental design for the INL Sample Collection Operational Test. The first objective is to assess the relative abilities of judgmental and probabilistic sampling strategies to detect contamination (or the extent of contamination) in individual rooms or on a whole floor of the INL PBF-632 building. The second objective is to assess the use of traditional probabilistic sampling strategies and a Bayesian sampling strategy (which combines judgmental and probabilistic samples) to make clearance statements of the form " $\mathrm{X} \%$ confidence that at least $\mathrm{Y} \%$ of a room (or floor of the building) does not contain detectable contamination." These are referred to as $\mathrm{X} \% / \mathrm{Y} \%$ clearance statements. ${ }^{\left({ }^{a}\right)}$

The experimental design described in this report includes five test events, the first of which is an Operational Readiness Inspection (ORI). The test events 1) vary the floor of the building on which the contaminant will be released, 2) provide for varying or adjusting the concentration of contaminant released to obtain the ideal concentration gradient across a floor of the building, and 3) investigate overt as well as covert release of contaminants (i.e., the responders either know or do not know the release point of the contaminant). The ideal contaminant gradient would have high concentrations of contaminant in rooms near the release point, with concentrations decreasing toward zero (i.e., not contaminated) in rooms at the opposite end of the building floor. Such a gradient would be ideal because it provides a range of contamination levels (from high to low) to challenge the sampling, sample extraction, and analytical methods.

For each of the five test events, the specified floor of the INL PBF-632 building will be contaminated with BG. The BG contaminant will be disseminated from a point-release device located in the room specified in the experimental design for each test event. Then judgmental and probabilistic samples will be collected according to the pre-specified sampling plan. Judgmental samples will be selected based on professional judgment and prior information. Probabilistic samples will be selected with a random aspect and in sufficient numbers to provide desired confidence for detecting contamination or clearing

(a) $\mathrm{The} \mathrm{X} \% / \mathrm{Y} \%$ clearance statements are based on the statistical theory for $\mathrm{X} \% / \mathrm{Y} \%$ tolerance intervals (see Hahn and Meeker 1991).

\section{UNCLASSIFIED}


uncontaminated (or decontaminated) areas. Following sample collection for a given test event, the INL PBF-632 building will be decontaminated using $\mathrm{Cl}_{2} \mathrm{O}$ gas.

For possibly contaminated areas (which may be individual rooms or the whole floor of the INL PBF632 building), the numbers of probabilistic samples were chosen to provide $95 \%$ confidence of detecting contaminated areas of specified sizes. The numbers of judgmental samples were chosen based on guidance from experts in judgmental sampling. For rooms that may be uncontaminated following a contamination event, or for whole floors after decontamination, the numbers of judgmental and probabilistic samples were chosen using a Bayesian approach that combines judgmental and probabilistic samples to make a clearance statement of the form " $95 \%$ confidence that at least $99 \%$ of the room (or floor) does not contain detectable contamination." The experimental design also provides for making $95 \% / Y \%$ clearance statements using only probabilistic samples, where $\mathrm{Y}<99$.

For each test event, the numbers of samples were selected for a minimal plan (containing fewer samples) and a preferred plan (containing more samples). The preferred plan is recommended over the minimal plan for the following reasons. The larger numbers of characterization samples increase the probability of detecting contamination if 1) it occurs in a smaller area, and/or 2) the false negative rate is higher. The larger numbers of clearance samples 1) increase the percentage of an area (floor or rooms) that can be declared not contaminated with a given confidence, and/or 2) protect against judgmental sample locations being equally likely $(1 \times)$ to contain detectable contamination as probabilistic sample locations, versus the assumption that judgmental sample locations are three times as likely $(3 \times)$ to contain detectable contamination as probabilistic sample locations in the Bayesian approach to clearance sampling.

The preferred plan specifies a total of 1452 samples, 912 after contamination and 540 after decontamination. The minimal plan specifies a total of 1119 samples, 744 after contamination and 375 after decontamination. If the advantages of the "after decontamination" portion of the preferred plan are judged to be small compared to the "after decontamination" portion of the minimal plan, it is an option to combine the "after contamination" portion of the preferred plan (912 samples) with the "after decontamination" portion of the minimal plan (375 samples). This hybrid plan would involve a total of 1287 samples.

The experimental design and numbers of referee ${ }^{(a)}$, judgmental, and probabilistic samples specified in this report provide a good statistical foundation for achieving the objectives of the INL Sample Collection Operational Test, despite some limitations of the experimental design (discussed in Section 6).

In general, it is recommended that statisticians be involved in planning, experimental and sampling design, and data analyses of future validation work such as is described in the Interagency Strategic

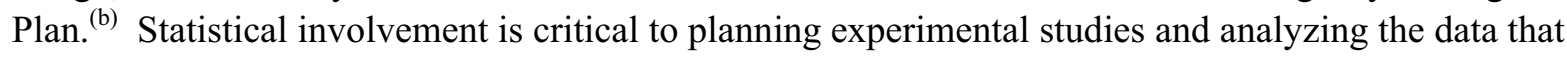
result from them. It helps verify that resources are used efficiently, testing and analytical uncertainties are accounted for, and conclusions can be made with the desired statistical confidence. Statistical planning

(a) Referee samples are samples collected by referee systems, which include various methods (e.g., air samplers, collection plates) to determine the extent to which a given room or location within the room is contaminated.

(b) Interagency Strategic Plan for Validation of Environmental Sampling Methods Used in Detection and Cleanup of B. Anthracis Contamination in Facilities, June 29, 2007.

\section{UNCLASSIFIED}




\section{UNCLASSIFIED}

combined with proper statistical analysis of data leads to defensible conclusions that satisfy the research objectives.

\section{UNCLASSIFIED}





\section{Acronyms}

BA

BG

CDC

CFU

DHS

DoD

DOE

EPA

FBI

FNR

GAO

HVAC

INL

JHU-APL

JPEO-CBD

LLNL

NIST

ORI

PNNL

RV-PCR

S\&T

VSP

VSPWG
Bacillus anthracis

Bacillus globigii, subsequently Bacillus subtilis var. niger (recently renamed Bacillus atrophaeus)

Centers for Disease Control and Prevention

Colony Forming Unit

U. S. Department of Homeland Security

U. S. Department of Defense

U. S. Department of Energy

Environmental Protection Agency

Federal Bureau of Investigation

False Negative Rate

Government Accountability Office

Heating, Ventilation, and Air Conditioning

Idaho National Laboratory

Johns Hopkins University Applied Physics Laboratory

Joint Program Executive Office for Chemical and Biological Defense

Lawrence Livermore National Laboratory

National Institute of Standards and Technology

Operational Readiness Inspection

Pacific Northwest National Laboratory

Rapid Viability Polymerase Chain Reaction

Science and Technology Directorate

Visual Sample Plan (software)

Validated Sampling Plan Working Group 



\section{Acknowledgments}

The Pacific Northwest National Laboratory (PNNL) work summarized in this report was funded by the Standards Office of the Test and Evaluation/Standards Division in the Science and Technology Directorate (S\&T) of the United States Department of Homeland Security (DHS). The interest of Dr. Bert Coursey (Standards Portfolio Executive) in the experimental design and sampling design capabilities of the Statistics and Sensor Analytics group at PNNL (which led to this work) is gratefully acknowledged.

Although there were many good suggestions offered by several members of the Validated Sampling Plan Working Group (VSPWG), there were a few who contributed directly to the necessary inputs and direction of this work. The authors would like to specifically thank the following: Dino Mattorano for his willingness to share his sampling expertise and to provide the necessary inputs related to sampling; Ken Martinez for his sampling expertise and direction in clearance sampling; Michael Walter for his guidance and inputs during initial planning as well as throughout the work; and Randy Long for his leadership in keeping this project on track and manageable.

The authors acknowledge and thank the following PNNL staff members: 1) Landon Sego for discussions about the capabilities and statistical basis for the Bayesian clearance capabilities of the Visual Sample Plan software, and for reviewing and providing comments on the draft report, and 2) Wayne Cosby for editing, formatting, and preparing the report for publication. 



\section{Contents}

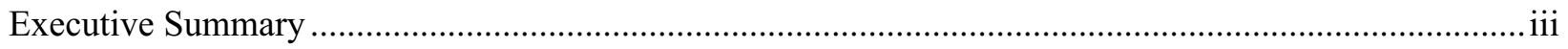

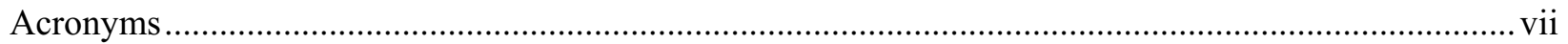

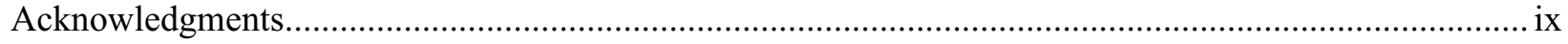

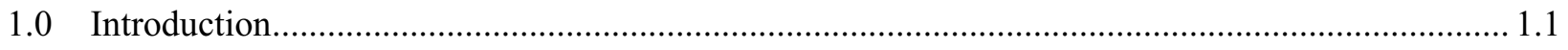

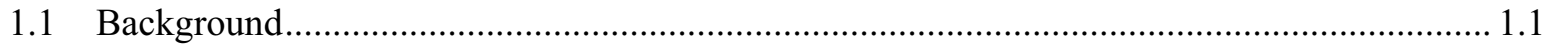

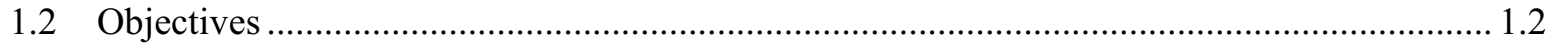

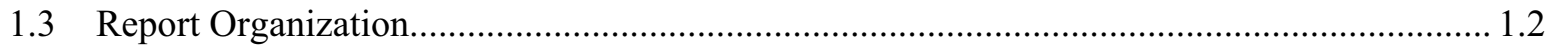

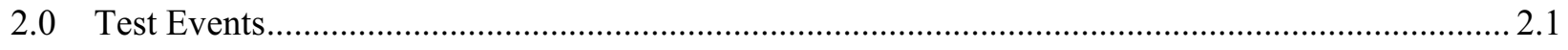

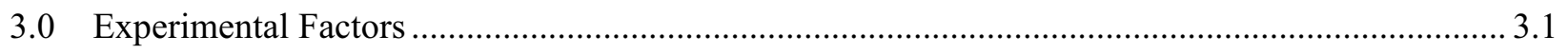

3.1 Factors Controlled During the Experiment.................................................................... 3.1

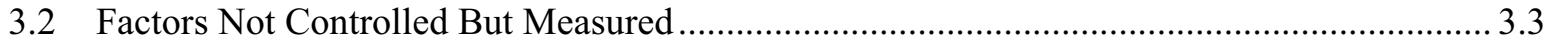

3.3 Factors Fixed During the Experiment............................................................................ 3.3

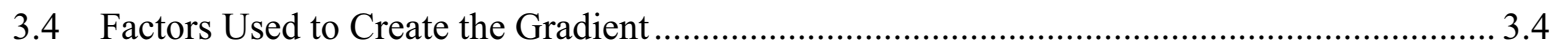

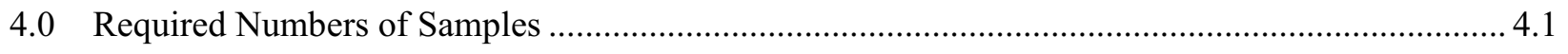

4.1 Characterization of Contamination in a Possibly Contaminated Area .................................. 4.1

4.2 Clearance of a Non-Contaminated or Decontaminated Area ................................................ 4.4

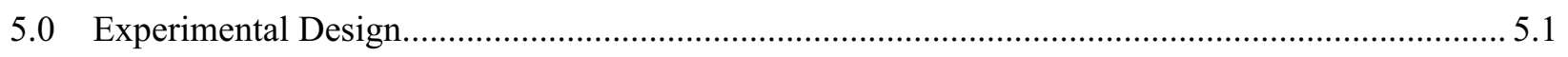

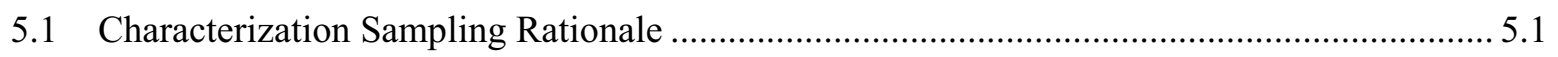

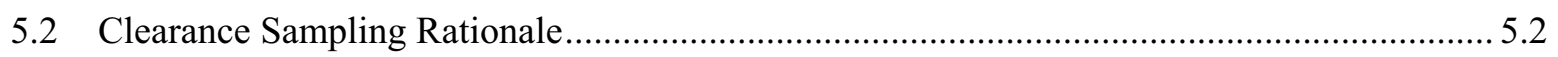

5.3 Operational Readiness Inspection (Test Event 1) ............................................................. 5.3

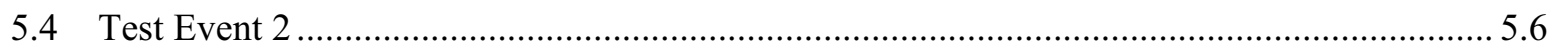

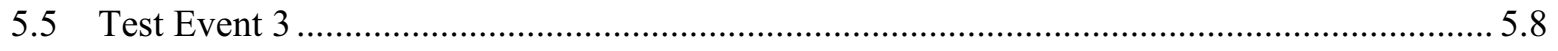

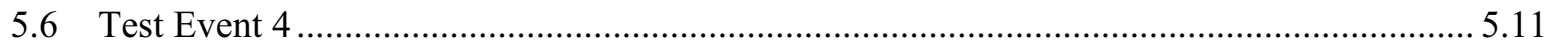

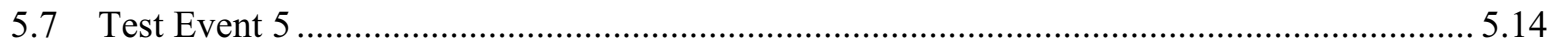

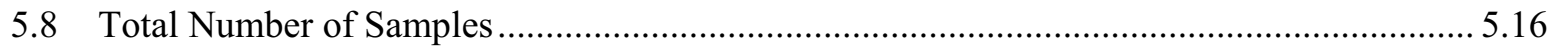

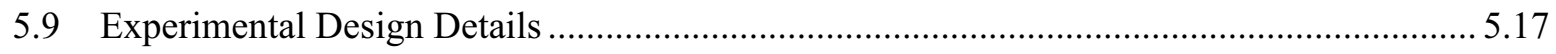

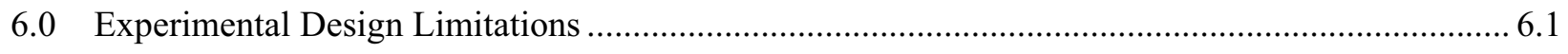

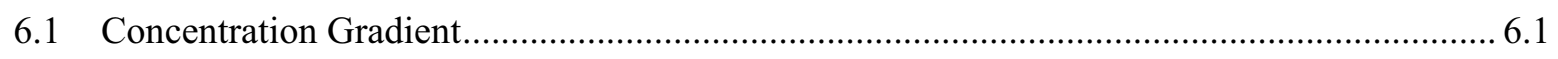

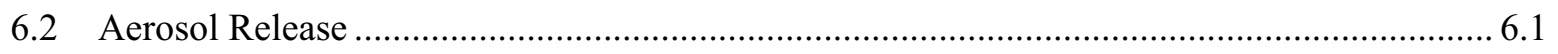

6.3 Probabilistic Sampling of Horizontal Surfaces .................................................................. 6.1

\section{UNCLASSIFIED}


6.4 Limited Knowledge of Information Required to Calculate Numbers of Samples .................. 6.2

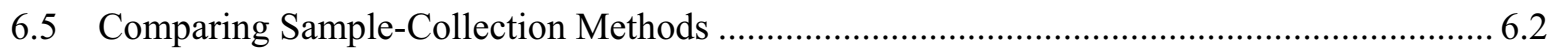

6.6 Comparing Judgmental and Probabilistic Samples to Referee Samples ............................... 6.2

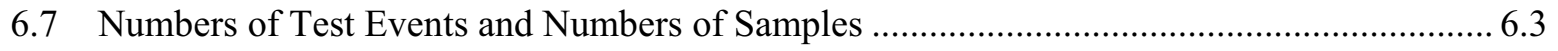

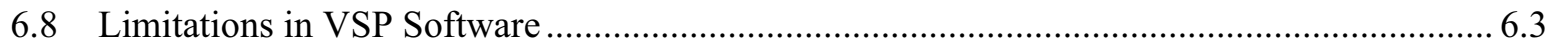

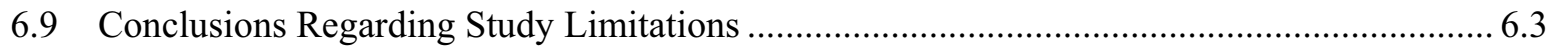

7.0 Summary and Recommendations for Any Future Studies..................................................... 7.1

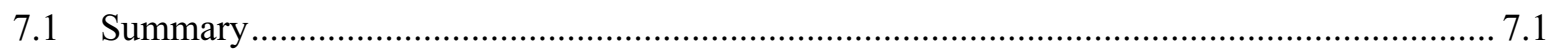

7.2 Recommendations for any Future Studies ..................................................................... 7.4

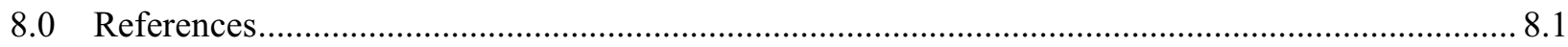

Appendix A: Numbers of Probabilistic Samples ............................................................................... A.1

Appendix B: Details to be Contained in the Eventual Complete Test Matrix ...........................................1

\section{Figures}

4.1. Number of Probabilistic Samples Required to Detect with 95\% Confidence a Circular Contaminated Area of a Given Diameter (represented by the colored lines) within a Typical Room of the INL PBF-632 Building....

4.2. Number of Probabilistic Samples Required to Detect with $95 \%$ Confidence a Circular Contaminated Area of a Given Diameter (represented by the colored lines) within a Single Floor of the INL PBF-632 Building.

4.3. Number of Negative Probabilistic Samples Required to be $95 \%$ Confident that Two Rooms in the INL PBF-632 Building Do Not Contain Detectable Contamination Given Various Numbers of Negative Judgmental Samples

4.4. Number of Negative Probabilistic Samples Required to be $95 \%$ Confident that at Least $99 \%$ of a Typical Floor in the INL PBF-632 Building Does Not Contain Detectable Contamination Given Various Numbers of Negative Judgmental Samples.

4.5. Number of Probabilistic Samples Required to Determine if a Given Percent of Two Typical Rooms in the INL PBF-632 Building Does Not Contain Detectable Contamination (x-axis) with a Given Level of Confidence (color lines).

4.6. Number of Probabilistic Samples Required to Determine if a Given Percent of a Typical Floor in the INL PBF-632 Building Does Not Contain Detectable Contamination (x-axis) with a Given Level of Confidence (color lines).

\section{UNCLASSIFIED}


5.1. Numbers of Samples in the Preferred Plan to be Taken After Contamination During the Operational Readiness Inspection (Test Event 1) on the First Floor of the INL PBF-632 Building

5.2. Numbers of Samples in the Preferred Plan to be Taken After Contamination During Test Event 2 on the First Floor of the INL PBF-632 Building....

5.3. Numbers of Samples in the Preferred Plan to be Taken After Contamination During Test Event 3 on the Second Floor of the INL PBF-632 Building.

5.4. Numbers of Samples in the Preferred Plan to be Taken After Contamination During Test Event 4 on the First Floor of the INL PBF-632 Building.

5.5. Numbers of Samples in the Preferred Plan to be Taken After Contamination During Test Event 5 on the Second Floor of the INL PBF-632 Building.

\section{Tables}

2.1. Test Events of the Experimental Design for Contamination-Decontamination Testing of the INL PBF-632 Building

3.1. Experimental Factors in the Experimental Design for Contamination-Decontamination Testing of the INL PGF-632 Building.....

4.1. Implications Given the Number of Probabilistic Samples Per Room and Per Floor for Characterizing the INL PGF-632 Building.

4.2. Implications Given the Number of Probabilistic and Judgmental Samples for Clearance of a Decontaminated or Non-Contaminated Area in the INL PBF-632 Building

5.1. Numbers of Samples for the Operational Readiness Inspection (Test Event 1) on the First Floor of the INL PBF-632 Building.

5.2. Numbers of Samples for Test Event 2 on the First Floor of the INL PBF-632 Building......

5.3. Numbers of Samples for Test Event 3 on the Second Floor of the INL PBF-632 Building

5.4. Numbers of Samples for Test Event 4 on the First Floor of the INL PBF-632 Building

5.5. Numbers of Samples for Test Event 5 on the Second Floor of the INL PBF-632 Building

5.6. Summary of the Numbers of Samples Needed for All Test Events in the INL PBF-632 Building 


\subsection{Introduction}

This report describes the final experimental design for a contamination and decontamination exercise conducted in an unoccupied building at the Idaho National Laboratory (INL). The experimental design consists of the scenarios for five test events, as well as the numbers of referee, judgmental, and probabilistic samples for characterization and clearance sampling in each test event.

The experimental design was developed by staff in the Statistics and Sensor Analytics group at the Pacific Northwest National Laboratory (PNNL), with contributions from staff at the National Institute of Standards and Technology (NIST). The specific contributors are listed as authors of this report.

Members of the Validated Sampling Plan Working Group (VSPWG) provided guidance and input needed to develop the experimental design. Specific individuals who provided inputs or guidance are listed in the Acknowledgments.

The PNNL work was funded by the Standards Office of the Test and Evaluation/Standards Division in the Science and Technology Directorate (S\&T) of the U.S. Department of Homeland Security (DHS). The work was funded under the prime contract between the U.S. Department of Energy (DOE) and the operator of the PNNL for research, testing, evaluation, and/or development activities and pursuant to Section 309(a)(1)(c) of the Homeland Security Act of 2002 (Public Law 107-296), which authorizes DHS to task the DOE national laboratories on a "work for others" basis.

\subsection{Background}

The experience with Bacillus anthracis (BA) contamination of the Hart Senate office building in Washington, DC and postal facilities that processed the mail containing BA demonstrated weaknesses in the procedures and methods used to characterize and clear buildings contaminated by BA. A congressional inquiry as well as the Government Accountability Office (GAO) identified two main weaknesses (GAO 2005a, 2005b). One weakness was the reliance on sampling specific areas in postal facilities where it was thought BA would be found. This type of sampling strategy is referred to as targeted sampling or judgmental sampling. The GAO reports identified the need to use probabilistic sampling so that when all results are negative, a building (or area within a building) can be cleared with a known level of statistical confidence. The second main weakness was that the sample collection and analytical methods used were not validated, which raised questions about the reliability of the negative results from sampling the postal facilities.

The VSPWG was formed in July 2006 in response to the congressional inquiry and GAO reports. The VSPWG is headed by DHS S\&T and includes experts from the Department of Defense (DoD), the Environmental Protection Agency (EPA), the Centers for Disease Control and Prevention (CDC), NIST, and the Federal Bureau of Investigation (FBI). The VSPWG is working towards the overall validation of sampling plans, including 1) sampling strategy (e.g., appropriate uses of judgmental and probabilistic sampling), 2) sample collection methods, 3) transportation of samples, 4) sample extraction methods (i.e., extraction of the contaminant from samples), and 5) sample analysis (i.e., analytical methods).

An interagency testing effort led by the DoD, Joint Program Executive Office for Chemical and Biological Defense (JPEO-CBD) and DHS S\&T was planned to partially address some of these concerns.

\section{UNCLASSIFIED}


This testing effort will consist of a series of contamination, sampling and sample analysis, and decontamination events in an unoccupied two-story office building at INL facilities located outside of Idaho Falls, ID. The INL testing is referred to as the INL Sample Collection Operational Test. The INL testing leverages work performed by Johns Hopkins University Applied Physics Laboratory (JHU-APL) for the JPEO-CBD to test sample-collection methods in a large-scale operational environment. ${ }^{\text {(a) }}$

\subsection{Objectives}

Two objectives were developed to guide the construction of the experimental design for the INL Sample Collection Operational Test. The first objective is to assess the relative abilities of judgmental and probabilistic sampling strategies to detect contamination (or the extent of contamination) in individual rooms or on a whole floor of the INL PBF-632 building. The second objective is to assess the use of traditional probabilistic sampling strategies and a Bayesian sampling strategy (which combines judgmental and probabilistic samples) to make clearance statements of the form " $\mathrm{X} \%$ confidence that at least $\mathrm{Y} \%$ of a room (or floor of the building) does not contain detectable contamination." These are referred to as $\mathrm{X} \% / \mathrm{Y} \%$ clearance statements ${ }^{(\mathrm{b})}$ in the rest of the report.

\subsection{Report Organization}

The remainder of this report describes the experimental design of the INL Sample Collection Operational Test and the basis for its development. The report is organized as follows. The five test events that form the main structure for the experimental design are discussed in Section 2. The experimental factors that will be varied or held fixed (constant) in the experimental design are discussed in Section 3. The methods used to determine the number of samples required are presented in Section 4. The experimental design and the basis for its development are presented in Section 5. The limitations of the experimental design for the INL Sample Collection Operational Test are discussed in Section 6. The conclusions for the work and recommendations for any future studies are presented in Section 7. The references cited in describing the experimental design and methods used to generate it are listed in Section 8 .

(a) Test and Evaluation of Surface Sampling Approaches Before and After Small-Scale Fumigation-Based Decontamination Events, NSTD-07-0592 (July 10, 2007 draft), John Hopkins University-Applied Physics Laboratory.

(b) The $\mathrm{X} \% / \mathrm{Y} \%$ clearance statements are based on the statistical theory for $\mathrm{X} \% / \mathrm{Y} \%$ tolerance intervals (see Hahn and Meeker 1991). 


\subsection{Test Events}

The test events were designed based on the dissemination characteristics of the BG contaminant rather than basing the design on specific of terrorist event scenarios. Many contamination motivations or "background stories" could be described to fit the proposed test events. The test-event characteristics include contaminant concentration, point of dissemination, type of dissemination (only aerosol releases will be performed during the INL Sample Collection Operational Test), and knowledge of the point of dissemination.

The experimental design developed for the INL Sample Collection Operational Test includes five test events, the first of which is an Operational Readiness Inspection (ORI). Table 2.1 shows the contamination characteristics for each of the proposed test events. The purpose of the ORI is to provide a complete run that can be used to make any necessary adjustments before the remaining four test events. If the ORI run is completed without any issues, it is possible that its data will be analyzed along with the data from the other four test events. The five test events will each consist of

1. a separate contamination on one of the two floors of the INL building, ${ }^{(a)}$

2. sampling in selected rooms or the complete floor,

3. decontamination, and

4. sampling of the complete floor to determine clearance.

Test Event 1 (the ORI) and Test Event 2 involve a single-source aerosol release of the contaminant from the lobby of the first floor, which is on one end of the building. Test Event 3 involves a similar release from Room 201 on the second floor, which is at the same end of the building. These first three test events are intended to provide a concentration gradient of contamination across each floor of the building, thereby providing a range of contamination conditions (from highly contaminated to possibly not contaminated at all) to challenge the sampling strategies as well as the sampling and analytical methods. With each of these events, the sampling team will be informed of the location of the dissemination.

Test Events 4 and 5 are planned as covert releases in which the sampling team will not know the location of the single-source aerosol dissemination. The specific locations of the contaminant releases are listed in Table 2.1, but were not listed in preliminary versions of this report because VSPWG reviewers might ultimately have been involved in selecting sample locations. Covert test events make it possible to assess the relative performance of the sampling strategies under different conditions than the overt test events.

Finally, an important aspect of the test events is the concentration of contaminant that is disseminated. Too high of a concentration may result in easy detection of contamination in every room on a floor. Too low of a concentration may result in too many rooms on a floor being lightly contaminated or not contaminated at all. The ideal concentration gradient will provide concentrations ranging from

(a) It is assumed that the first and second floors of the INL building will be "sealed" to prevent crosscontamination. In earlier discussions, the INL staff responsible for preparing the INL building mentioned that this was feasible.

\section{UNCLASSIFIED}


sufficiently contaminated (i.e., easily detected by sampling and analytical methods given their respective efficiencies) near the release location, to lightly or even uncontaminated (i.e., near or below the detection limit) at locations most remote from the release location. Such a contamination gradient is ideal for the purposes of assessing the performance of sampling strategies (judgmental, probabilistic, and Bayesian), sampling methods, sample extraction methods, and analytical methods. It is understood that air-flow modeling and tracer studies in the INL building are planned to aid in selecting the initial contaminant concentration. The ORI (Test Event 1) will also be used to determine the concentration and dissemination factors necessary to create the desired gradient. Dissemination factors may include 1) time from dissemination until response, 2) heating, ventilation and air conditioning (HVAC) being on or off, and 3) the contaminant release location. The experimental design allows for adjustments to be made to the concentration or to dissemination factors after each event, based on what is learned from each test.

Table 2.1. Test Events of the Experimental Design for Contamination-Decontamination Testing of the INL PBF-632 Building

\begin{tabular}{|c|c|c|c|}
\hline $\begin{array}{c}\text { Test } \\
\text { Event ID }\end{array}$ & Test Event Name & Floor & $\begin{array}{c}\text { Point of } \\
\text { Dissemination }\end{array}$ \\
\hline 1 & Operational Readiness Inspection (ORI) & 1 & lobby $^{(a)}$ \\
\hline 2 & Lobby dissemination on $1^{\text {st }}$ floor & 1 & lobby ${ }^{(a)}$ \\
\hline 3 & Room 201 dissemination on 2nd floor & 2 & $\operatorname{Rm} 201^{(a)}$ \\
\hline 4 & Covert dissemination on $1^{\text {st }}$ floor & 1 & lobby $^{(b),(c)}$ \\
\hline 5 & Covert dissemination on 2 nd floor & 2 & $\mathrm{Rm} 201^{(\mathrm{b}),(\mathrm{c})}$ \\
\hline
\end{tabular}

(a) These contaminant release locations will be known to the sampling team.

(b) These contaminant release locations were not revealed to the sampling team. The covert contaminant release locations are were not listed in preliminary versions of this table because of the possibility that reviewers would be among those determining sample locations or performing the sampling.

(c) Early discussions in planning the experimental design considered changing the contaminant release locations for the covert test events compared to the overt test events. However, it was ultimately decided to use the same release locations to allow direct comparison of the results from the covert and overt sampling plans, which are different. 


\subsection{Experimental Factors}

The experimental factors are the variables that will be varied or held constant during the experiment. The experiment is designed to determine whether changes to the levels (i.e., values or settings) of the factors that will be varied affect the detection (absence/presence) or the amount (number of colony forming units, CFUs) of the contaminant. One objective of the INL Sample Collection Operational Test is to examine the relative performance of the sampling strategies when contamination is likely. Characteristics of the test events are allowed to vary so that the relative performance of the sampling strategies can be assessed over a range of conditions. Other factors not varied in the test events should ideally be held as constant as possible.

After contamination, both judgmental and probabilistic sampling will occur in each room or floor where sampling is planned. In rooms that are expected to have high contamination (in the overt test events), fewer judgmental and probabilistic samples will be taken. Numbers of samples taken will increase as the distance from the contaminant release location increases. Up to 6 judgmental samples per room will be taken in rooms where contamination is probable, based on input from experienced samplers concerning rooms of the size in the INL PBF-632 building.

After decontamination, as well as in rooms that may not be contaminated because of the distance from the contaminant release location, a comparison between Bayesian and probabilistic sampling strategies will be made. A Bayesian sampling strategy that combines judgmental and probabilistic samples is an option available in Visual Sampling Plan 5.0 (VSP) software (Matzke et al. 2007). The Bayesian strategy allows for an $\mathrm{X} \% / \mathrm{Y} \%$ clearance statement to be made that would be stronger than the statement that could be made from probabilistic sampling alone. This comparison will focus on the advantages of adding judgmental samples to probabilistic samples.

To best study the sampling strategies, the experimental factors should be identified and their roles in the experiment defined as well as possible. Table 3.1 lists the experimental factors and places them into one of four categories (factors controlled during the experiment, factors not controlled but measured, factors fixed during the experiment, factors used to create the gradient). The Table 3.1 entries in each of these four categories are discussed in Sections 3.1 to 3.4.

\subsection{Factors Controlled During the Experiment}

The main factors that are varied in the experimental design are 1) the sampling strategy (judgmental, probabilistic, and Bayesian), 2) the floor of the INL PBF-632 building on which the testing will occur and 3 ) the type of sampling (covert or overt). Other factors that will be controlled during the experiment (which are related to creating a concentration gradient of the contaminant) are discussed in Section 3.4.

Another factor that must be controlled is the sampling team. It is important that the judgmental samples are not collected by one sampling team, while the probabilistic samples are collected by another sampling team. The location of each judgmental and probabilistic sample in each of the pre-determined rooms or floors should be selected prior to the sampling teams collecting the samples, and provided to the sampling teams in a test matrix (see Appendix B). Only the sample locations should be given to the teams collecting the samples so that they would be "blind" as to whether any given sample is a

\section{UNCLASSIFIED}


judgmental or probabilistic sample. This would minimize any bias that could be caused by the teams collecting samples. The specific test matrix (see Appendix B) corresponding to the experimental design will need to identify the sampling team that is assigned to collect each sample. That way, the sampled rooms can be balanced across the number of sampling teams collecting samples so that any systematic or random differences between sample collectors are spread over the collected samples in a controlled manner. The sampler ID should be recorded with the data so that 1) any systematic or random differences in teams that collected the samples can be assessed and 2) it can be verified that such differences do not impact the comparisons of sampling strategies.

Table 3.1. Experimental Factors in the Experimental Design for Contamination-Decontamination Testing of the INL PGF-632 Building

\begin{tabular}{|c|c|c|c|}
\hline $\begin{array}{c}\text { Factors Controlled } \\
\text { During the Experiment }\end{array}$ & $\begin{array}{c}\text { Factors Not } \\
\text { Controlled, but } \\
\text { Measured }\end{array}$ & $\begin{array}{c}\text { Factors Fixed During the } \\
\text { Experiment }\end{array}$ & $\begin{array}{c}\text { Factors Used to Create } \\
\text { the Gradient }\end{array}$ \\
\hline $\begin{array}{l}\text { - Sampling strategy } \\
\text { - Floor of the building } \\
\text { - Type of sampling } \\
\text { (covert or overt) } \\
\text { - Sampling team } \\
\text { collecting samples } \\
\text { - Order samples are } \\
\text { collected in a room }\end{array}$ & $\begin{array}{l}\text { - Temperature } \\
\text { - Humidity }\end{array}$ & $\begin{array}{l}\text { - } \text { Furniture configuration } \\
\text { - Contaminant release } \\
\text { method (aerosol) } \\
\text { - Sample collection } \\
\text { method for a given } \\
\text { sampling surface } \\
\text { - Sample area (size) } \\
\text { - Sample analytical } \\
\text { method } \\
\text { - Decontamination } \\
\text { method }\end{array}$ & $\begin{array}{l}\text { - Contaminant } \\
\text { concentration } \\
\text { - Length of HVAC } \\
\text { operation after } \\
\text { contaminant release } \\
\text { - Location of } \\
\text { contaminant release }\end{array}$ \\
\hline
\end{tabular}

Finally, the order in which the sampling team should collect samples within each room must be controlled. Having the sampling team collect the judgmental samples first, the probabilistic samples next, and finally the referee samples (or any permutation of these) should be avoided. From a statistical standpoint, it would be ideal to collect all samples (judgmental, probabilistic, and referee) within a room in a random order. Doing so would protect against confounding the effects of any uncontrolled variables that may change over time with the effects of factors of interest (i.e., probabilistic versus judgmental sampling). However, it is recognized that randomizing the order of all judgmental, probabilistic, and referee samples in a room is not feasible because of time constraints and the need to minimize movement within a room that might redistribute or transfer contamination from one location to another. Thus, it is recommended that a "sampling path" be determined for each room that minimizes unnecessary movements within the room, but still allows for sufficient intermingling of the order in which referee, judgmental, and probabilistic samples are collected. All samples (referee, judgmental, and probabilistic) that will be taken in a room should be listed in the test matrix (see Appendix B) in the order they are to be collected so that this factor is controlled. 


\subsection{Factors Not Controlled But Measured}

Temperature and humidity should remain constant during the sampling as much as possible. The temperature and humidity should be recorded at selected locations on each floor of the building a few times a day during every day of testing.

\subsection{Factors Fixed During the Experiment}

Table 3.1 identifies certain factors that will either be held fixed (constant) during the experiment or determined by other factors. These are discussed in the following paragraphs.

One consistent furniture configuration should be used in each room if possible. This could possibly be a chair and desk, with a monitor placed on the desk. The chair should be out from under the desk so that the BG contaminant can settle on its whole surface. If there is room, a table should also be placed in each room. This would increase the chance that probabilistic samples would select sampling positions with non-porous surfaces. Otherwise, the majority of probabilistic samples may be dominated by vacuum samples of the floors (which are mostly carpeted in the INL PBF-632 building). If it is not possible to use a single furniture configuration in every room, the number of configurations should be limited to two. In that case, the furniture configuration would need to become a controlled factor (the first column of Table 3.1, as discussed in Section 3.1). The two configurations would need to be assigned so as not to confound the effects of this factor with other factors of interest (e.g., the contamination gradient).

The contaminant release method will be the same for all test events, namely, an aerosol release from a single point (location) on a floor of the INL building. Other contaminant-release methods were discussed and even proposed in early drafts of the experimental design. One such release method was to contaminate only smaller areas (so-called "hot spots") of varying size in selected rooms, which would pose a much different situation for comparing judgmental and probabilistic samples (see Section 6.1 for more discussion of this). However, it was decided for this first real-world contamination exercise to limit the contaminant-release method to an aerosol release from a single location (point release).

The sample-collection method (swab, wipe, or vacuum) will be chosen according to the sampling surface that corresponds to each location to be sampled. The appropriate collection method will be applied to the appropriate sampling surface. The test plan should define which collection method should be applied for each of the possible surfaces. The specific test matrix (see Appendix B) for each room should specify the method to be used for each sample (whether judgmental or probabilistic) according to the nature of the surface to be sampled. This will require selecting the locations of judgmental samples in advance so that the sampling method as well as sampling order (see Section 3.1) can be included in the specific test matrix for each room. However, if it is decided to have the sampling team select the locations of judgmental samples at the time they enter a room, there will need to be a system in place to document the specific locations where judgmental samples were collected. This approach would also require the sampling team to be responsible for selecting the intermingling of judgmental and probabilistic samples and documenting the order of sample collection. This latter approach, although possibly more realistic, is far more complicated for the sampling team and could impact the ability to compare judgmental and probabilistic samples.

For probabilistic sampling, it has been assumed that samples will be collected from horizontal surfaces only. Horizontal positions of probabilistic samples selected by the Visual Sample Plan (VSP)

UNCLASSIFIED 
software (Matzke et al. 2007) may allow for the choice of the sample location. For example, a horizontal position might correspond to the floor, a table, or a vent in the ceiling. The specific sample location for a given horizontal sample position will need to be determined prior to sample collection by the sampling team and be included in the specific test matrix (see Appendix B) for each room. VSP allows for sampling from all surfaces of a room instead of just horizontal surfaces, but that increases the surface area of each room and floor of the building. That in turn increases the number of samples needed to detect contamination or clear a decontaminated floor. However, sampling from horizontal surfaces is the typical practice for $\mathrm{BA} / \mathrm{BG}$ contamination released as an aerosol. Hence, in constructing the experimental design for the INL Sample Collection Operational Test, it was assumed that only horizontal surfaces would be sampled.

It is important to note that the size (or area) of each sample should be held constant (per the procedure for each sampling method), independent of whether it is a judgmental or probabilistic sample. If the sampling team determines that a larger area should be sampled with a given sampling method for judgmental samples, then multiple samples should be taken to sample the larger area (rather than collecting a single sample from the larger area).

Culture has been determined to be the only analytical method that will be applied to every sample. It is possible that a few RV-PCR analyses will be made, but it was decided that this will not be factored into the experimental design. Hence, the choice of samples to analyze by RV-PCR is not addressed in this document. It is also assumed that the extraction method will be fixed and performed according to a set procedure for each sampling method, regardless of whether a given sample-collection method is used to collect a judgmental or probabilistic sample. The extraction method also should not change over the gradient of contamination, because changes in the extraction method could negate differences due to the contamination gradient.

It is expected that the decontamination method will be aggressive (i.e., the concentration of $\mathrm{ClO}_{2}$ gas will be sufficient to easily decontaminate contaminated areas). Because contamination will be occurring after all but the last decontamination, it is important to make sure that decontamination is sufficient so that there is no residual contamination that could become an uncontrolled factor that affects testing results.

\subsection{Factors Used to Create the Gradient}

The concentration of contaminant released and the HVAC system will be used to create a gradient of the contaminant across a floor of the INL building. Modeling and pre-testing work should be used to determine the amount of time the HVAC should remain on after contaminant release to achieve the desired concentration gradient. If the desired concentration gradient is not achieved in the ORI, then adjustments could be made to the concentration of contaminant released, while holding constant the postrelease running time of the HVAC system. However, the amount of time the HVAC system is run after contaminant release, along with the contaminant concentration and within-room location of the contaminant release, ${ }^{(a)}$ could be used to improve the concentration gradient if needed.

(a) The room of a building floor in which the contaminant will be released is specified as part of each test event. However, if the location of the release within the specified room (e.g., proximity to return air vents) affects the dissemination, the location of release within a room could be modified.

UNCLASSIFIED 


\subsection{Required Numbers of Samples}

The required numbers of samples depends on the sampling goal. This goal is formulated using 1) information that is known about an event and 2) the objectives that must be achieved when responding to the event. In an area where contamination is expected, sampling is performed to confirm/detect that contamination is present. In an area that may not be contaminated or after decontamination, sampling can be performed to clear the area. Each situation and the appropriate numbers of samples are discussed in the following subsections. Individual room calculations are based on a typical room for the INL PBF-632 building (Room 108), while calculations for a single floor are based on the first floor (considering it as a "typical" floor). Calculations associated with clearing two rooms together as a "zone" are based on Rooms 109 and 110.

Section 4.1 discusses the methods used to calculate the number of samples needed to detect contamination in a possibly contaminated area. Section 4.2 discusses the methods used to calculate the number of samples needed to clear an uncontaminated or decontaminated area.

\subsection{Characterization of Contamination in a Possibly Contaminated Area}

There are many variables that affect the number of probabilistic samples that should be taken in a room or on a floor to detect contamination in a possibly contaminated area. These variables include 1) percent confidence of detecting contamination, 2) the size of the contaminated area (assumed in this case to be circular, quantified by its diameter) ${ }^{(a)}$ one wishes to be able to detect with high confidence, and 3 ) the false-negative rate (FNR). ${ }^{(b)}$ More samples are required to have a higher confidence, detect a smaller diameter of contamination, or when the FNR is higher. Unfortunately, there is not enough information to quantify what the size of the contaminated area is likely to be for the INL Sample Collection Operational Test. Similarly, there is not much information on the expected FNR. For this reason, the numbers of samples were calculated for confidence levels ranging from $50 \%$ to $95 \%$, contaminated areas ranging from 1 foot to 10 feet in diameter, and FNRs ranging from $0 \%$ to $50 \%$. Sample sizes were calculated using triangular grid patterns where samples are spread out in a relatively uniform manner. This implies that no two samples are bunched together and there is no large unsampled portion of the room or floor. Actual samples should be placed using either a grid pattern or an adaptive fill algorithm that spaces out samples in a manner similar to a grid. Results of these calculations are provided in subsequent figures and tables for $95 \%$ confidence. The results for the smaller diameters of

(a) Statistical formulas for calculating numbers of samples required to detect a contaminated area with specified confidence exist for circular or elliptical contamination shapes using square, rectangular, and triangular contamination shapes (Sego and Wilson 2007; Gilbert 1987, Chapter 10). The formula for a circular contaminated area is used most frequently in practice, and thus was the basis for calculations used to develop the experimental design for the INL exercise.

(b) The false-negative rate is specified as the percentage of times a contaminated sample is erroneously declared to be "uncontaminated." False negatives can occur because of inefficiencies in recovering the contaminant by sampling, extraction of the contaminant from samples, and the analytical method. However, if the concentration of contaminant is high enough, the FNR can be zero (or near zero) despite sampling-recovery inefficiencies, extraction inefficiencies, and analytical uncertainties.

\section{UNCLASSIFIED}


contaminated areas are not presented because they correspond to unrealistically large numbers of samples. Appendix A contains additional figures displaying the numbers of samples calculated. These figures display realistic numbers of samples for all combinations of contaminated areas (from 1 foot to 10 feet in diameter), FNRs ( $0 \%$ to $50 \%)$, and confidence $(50 \%, 75 \%, 90 \%$, and $95 \%)$ for a typical room and for a single floor.

Figure 4.1 summarizes the calculations for the number of probabilistic samples required to sample a typical room and detect contamination with $95 \%$ confidence when the diameter of a circular, contaminated area and the FNR are varied. This plot shows that 20 samples provide $95 \%$ confidence for detecting a circular, contaminated area of 6 feet in diameter with an FNR of 30\%. If a smaller FNR of about $15 \%$ is assumed, then 20 samples are required to achieve $95 \%$ confidence for detecting a circular, contaminated area with a 5 -foot diameter.

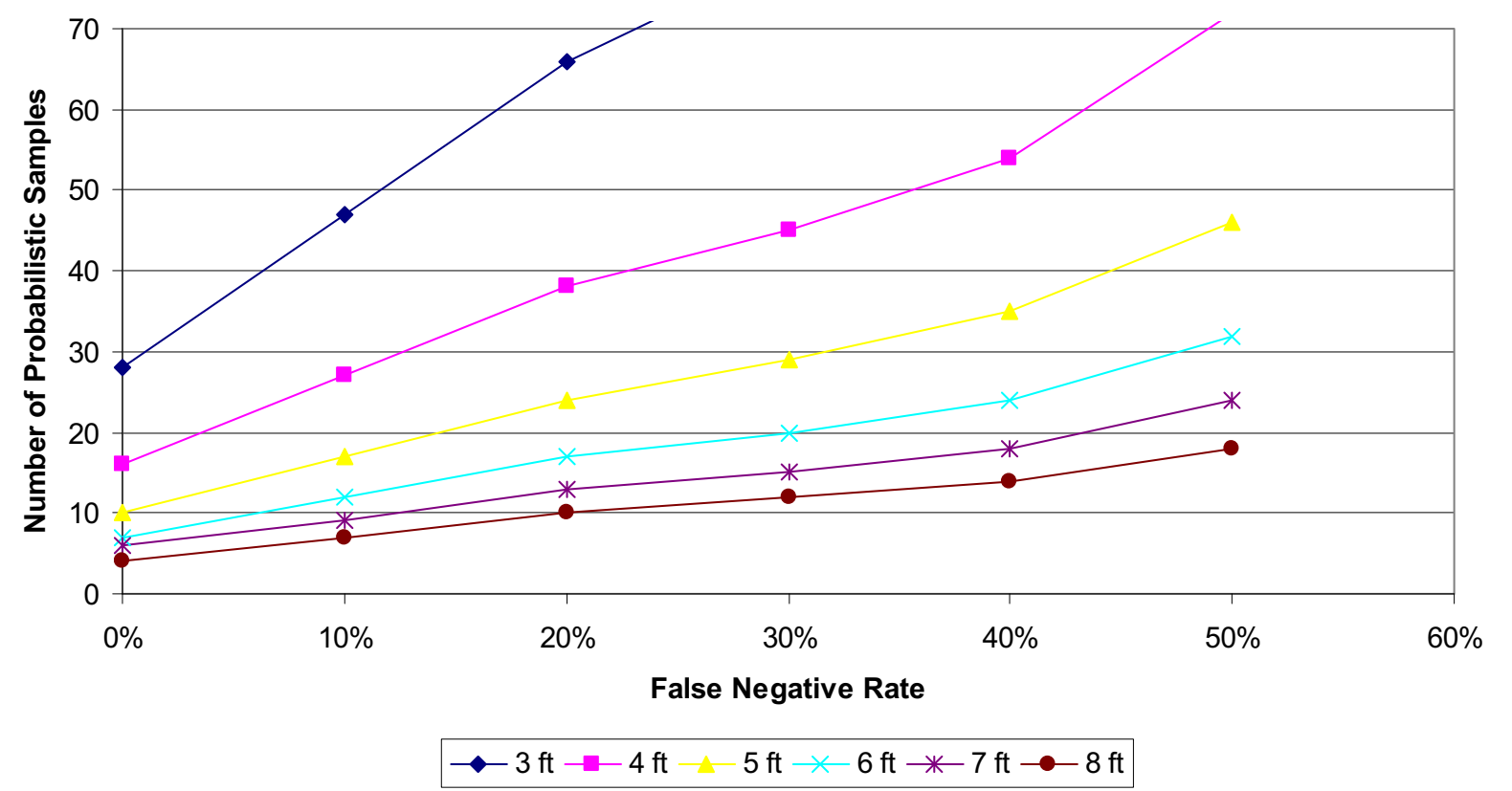

Figure 4.1. Number of Probabilistic Samples Required to Detect with $95 \%$ Confidence a Circular Contaminated Area of a Given Diameter (represented by the colored lines) within a Typical Room of the INL PBF-632 Building

Figure 4.2 summarizes these calculations for the number of samples required to sample a single floor and detect contamination with $95 \%$ confidence when the contamination diameter and the FNR are varied. This plot shows that 200 samples provide $95 \%$ confidence for detecting a 7 -foot contamination diameter with an FNR of about $23 \%$. If a smaller FNR of about $12 \%$ is assumed, then 200 samples are required to achieve $95 \%$ confidence for detecting a 6 -foot contamination diameter. 


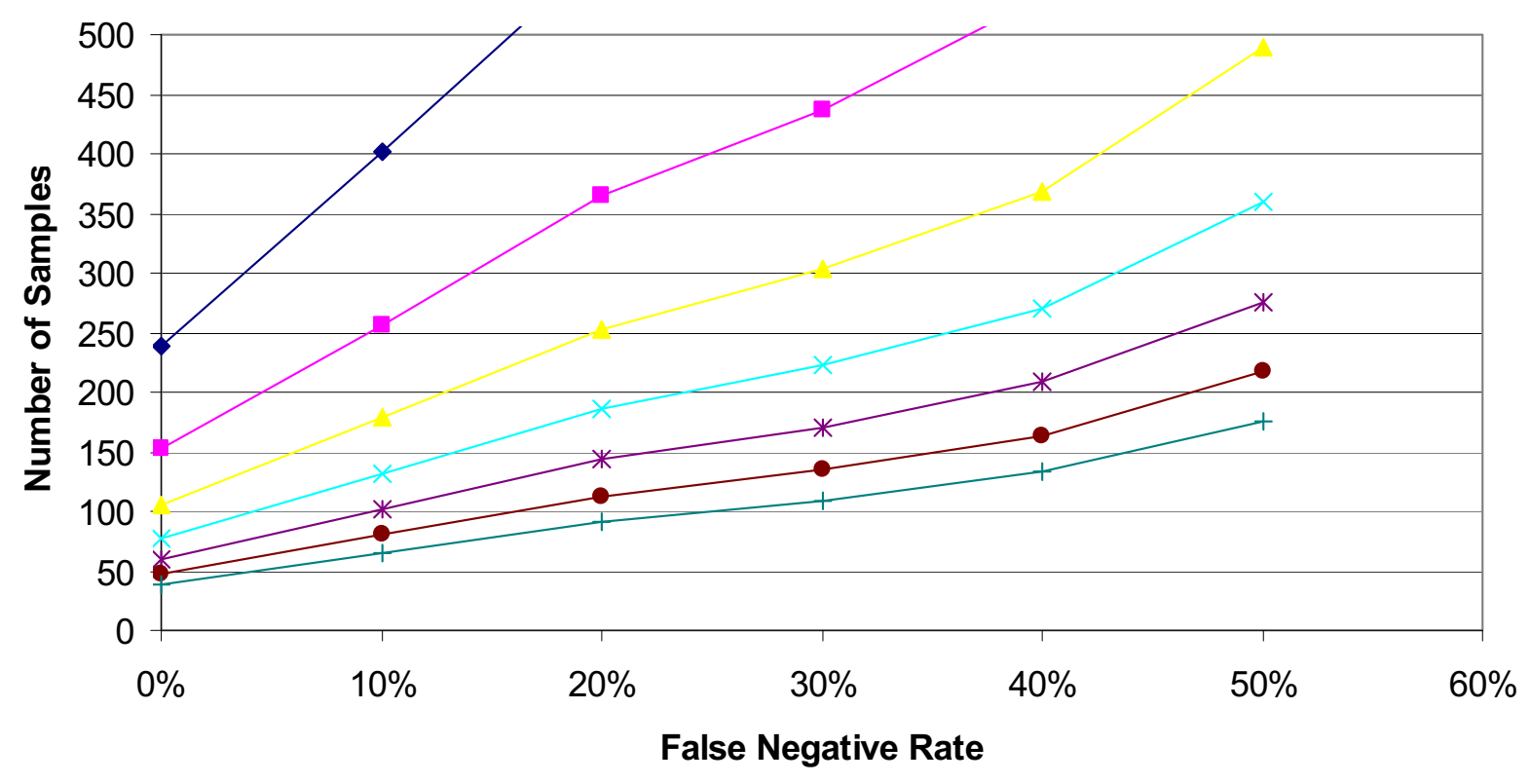

$\rightarrow-4 \mathrm{ft} \rightarrow-5 \mathrm{ft} \rightarrow 6 \mathrm{ft} \rightarrow 7 \mathrm{ft} \rightarrow-8 \mathrm{ft} \rightarrow 9 \mathrm{ft}+10 \mathrm{ft}$

Figure 4.2. Number of Probabilistic Samples Required to Detect with $95 \%$ Confidence a Circular Contaminated Area of a Given Diameter (represented by the colored lines) within a Single Floor of the INL PBF-632 Building

Table 4.1 lists implication statements ${ }^{(a)}$ given the number of probabilistic samples and holding constant two of the three variables. In each set of implication statements, $95 \%$ confidence was used. In the first column of implication statements, the FNR was set at $10 \%$, so that the size of the contaminated area could be calculated. In the second column of implication statements, the diameter of the circular, contaminated area was set at 10 feet so that the FNR could be calculated. These calculations were made to quantify what is gained by increasing the number of probabilistic samples.

There are other assumptions that are not allowed to vary because of limitations in the VSP software (Matzke et al. 2007). VSP performs probabilistic sampling using a grid approach and assumes an equal probability of contamination within each grid cell. VSP does not, at this time, allow for different areas of the sampling grid to have different probabilities of contamination. Another assumption not included in the calculations is the sample area (i.e., the physical area sampled). VSP is able to factor in the sample area when $0 \%$ FNR is assumed ( 1 value of $1 \mathrm{ft}^{2}$ was used for the work in this report, based on input from experts on the VSPWG). However, VSP does not yet have the capability to vary the sample area and FNR for a grid sampling approach. Further, the VSP capability to address the sample area assumes that the area is the same for every sample. Thus, VSP does not currently have the capability to account for the smaller area sampled by a swab versus the larger areas sampled by a wipe or vacuum. When the FNR is greater than zero, VSP assumes point sampling (i.e., samples cover a negligible area). This results in conservative estimates for the numbers of samples, meaning that the implication statements are actually

(a) An implication statement indicates the confidence, false negative rate, and size of contaminated area to be detected that are associated with a given number of samples.

\section{UNCLASSIFIED}


Table 4.1. Implications Given the Number of Probabilistic Samples Per Room and Per Floor for Characterizing the INL PGF-632 Building

\begin{tabular}{|c|c|c|}
\hline $\begin{array}{c}\# \text { of } \\
\text { Probabilistic } \\
\text { Samples }\end{array}$ & Implication $\mathbf{1}^{(a)}$ & Implication $2^{(b)}$ \\
\hline \multicolumn{3}{|c|}{ Per Room } \\
\hline 3 & $95 \%$ conf $/ 11.8 \mathrm{ft}$ diameter $/ 10 \%$ FNR & $95 \%$ conf $/ 10 \mathrm{ft}$ diameter $/ 0 \%$ FNR \\
\hline 6 & $95 \%$ conf $/ 9 \mathrm{ft}$ diameter $/ 10 \%$ FNR & $95 \%$ conf $/ 10 \mathrm{ft}$ diameter/21\% FNR \\
\hline 7 & $95 \%$ conf $/ 8 \mathrm{ft}$ diameter $/ 10 \%$ FNR & $95 \%$ conf $/ 10 \mathrm{ft}$ diameter/29\% FNR \\
\hline 9 & $95 \%$ conf $/ 7 \mathrm{ft}$ diameter $/ 10 \%$ FNR & $95 \%$ conf $/ 10 \mathrm{ft}$ diameter $/ 42 \% \mathrm{FNR}$ \\
\hline 12 & $95 \%$ conf $/ 6 \mathrm{ft}$ diameter $/ 10 \% \mathrm{FNR}$ & $95 \%$ conf $/ 10 \mathrm{ft}$ diameter/ $>50 \% \mathrm{FNR}$ \\
\hline 17 & $95 \%$ conf $/ 5 \mathrm{ft}$ diameter $/ 10 \%$ FNR & $95 \%$ conf $/ 10 \mathrm{ft}$ diameter/ $>50 \% \mathrm{FNR}$ \\
\hline \multicolumn{3}{|c|}{ Per Floor } \\
\hline 65 & $95 \%$ conf $/ 10 \mathrm{ft}$ diameter $/ 10 \%$ FNR & $95 \%$ conf $/ 10 \mathrm{ft}$ diameter $/ 10 \%$ FNR \\
\hline 82 & $95 \%$ conf $/ 9 \mathrm{ft}$ diameter $/ 10 \%$ FNR & $95 \%$ conf $/ 10 \mathrm{ft}$ diameter $/ 15 \%$ FNR \\
\hline 101 & $95 \%$ conf $/ 8 \mathrm{ft}$ diameter $/ 10 \%$ FNR & $95 \%$ conf $/ 10 \mathrm{ft}$ diameter $/ 25 \%$ FNR \\
\hline
\end{tabular}

(a) Implication 1 lists the calculated circular diameter of the contamination that can be detected, given the number of probabilistic samples, $95 \%$ confidence, and $10 \%$ FNR.

(b) Implication 2 lists the calculated FNR, given the number of probabilistic samples, $95 \%$ confidence, and detecting a 10 -foot diameter of contamination.

better than stated for point samples. On the other hand, the number of samples is conservative (i.e., larger than what would otherwise be needed) by basing calculations on point samples rather than actual areas covered by samples.

\subsection{Clearance of a Non-Contaminated or Decontaminated Area}

In a situation where decontamination has occurred, or in an area of the INL PBF-632 building expected not to have been contaminated, sampling may be performed to clear the area, (i.e., declare that there is no detectable contamination). When sampling an area for clearance, probabilistic samples are typically used because they allow making an X\%/Y\% clearance statement (see Section 1.2). A Bayesian approach that combines judgmental and probabilistic samples (Sego et al. 2007) also provides for making an $\mathrm{X} \% / \mathrm{Y} \%$ clearance statement. The Bayesian approach is implemented in the VSP Version 5 software (Matzke et al. 2007). Both options (probabilistic samples only and the Bayesian approach) will be examined in this study. It is recommended that actual samples be placed using an adaptive fill algorithm to spread out the probabilistic samples.

There are many parameters that affect the number of probabilistic samples taken using the Bayesian approach for a room or a floor of the INL PBF-632 building to clear an area that has been decontaminated or is not expected to be contaminated. These parameters include 1) the percent confidence (X\%) desired, 2 ) the minimum percent ( $\mathrm{Y} \%$ ) of the room or floor that can be stated to not contain detectable contamination, ${ }^{(a)} 3$ ) the number of judgmental samples taken, 4) how much more likely it is that a

(a) It would require $100 \%$ sampling of an area and zero false-negative rate to state with $100 \%$ confidence that $100 \%$ of the area is not contaminated. With less than $100 \%$ sampling and possibly a false-negative rate higher than zero, then an $\mathrm{X} \% / \mathrm{Y} \%$ clearance statement must have $\mathrm{X}<100$ and $\mathrm{Y}<100$.

\section{UNCLASSIFIED}


judgmental sample location contains detectable contamination than a probabilistic sample location, and 5) the a priori probability that the area contains detectable contamination. The clearance statement only holds true if none of the samples (judgmental or probabilistic) indicate the presence of contamination. More probabilistic samples are necessary to have higher values of $\mathrm{X}$ and/or Y. Fewer probabilistic samples are necessary when more judgmental samples are taken and/or when locations with judgmental samples are more likely to contain detectable contamination. Fewer probabilistic samples are also necessary as the a priori probability of the area containing detectable contamination decreases. FNRs have not yet been implemented into the Bayesian approach of the VSP software, so they were not considered for these calculations. For this reason, the $\mathrm{X} \% / \mathrm{Y} \%$ clearance statement that can be made using the Bayesian approach in VSP is defined as " $\mathrm{X} \%$ confidence that at least $\mathrm{Y} \%$ of the area does not contain detectable contamination."

Figure 4.3 summarizes the number of probabilistic samples required to sample an area consisting of two typical rooms in the INL PBF-632 building using the Bayesian method. This figure assumes a $95 \%$ confidence level and the likelihood that a judgmental sample location is three times more likely to contain detectable contamination than a probabilistic sample location. The number of judgmental samples, the percentage of the two rooms that does not contain detectable contamination, and the a priori probability of the rooms containing detectable contamination (very low or low ${ }^{(a)}$ ) were allowed to vary. Figure 4.3 shows that given 12 negative judgmental samples (i.e., ones that do not detect contamination),

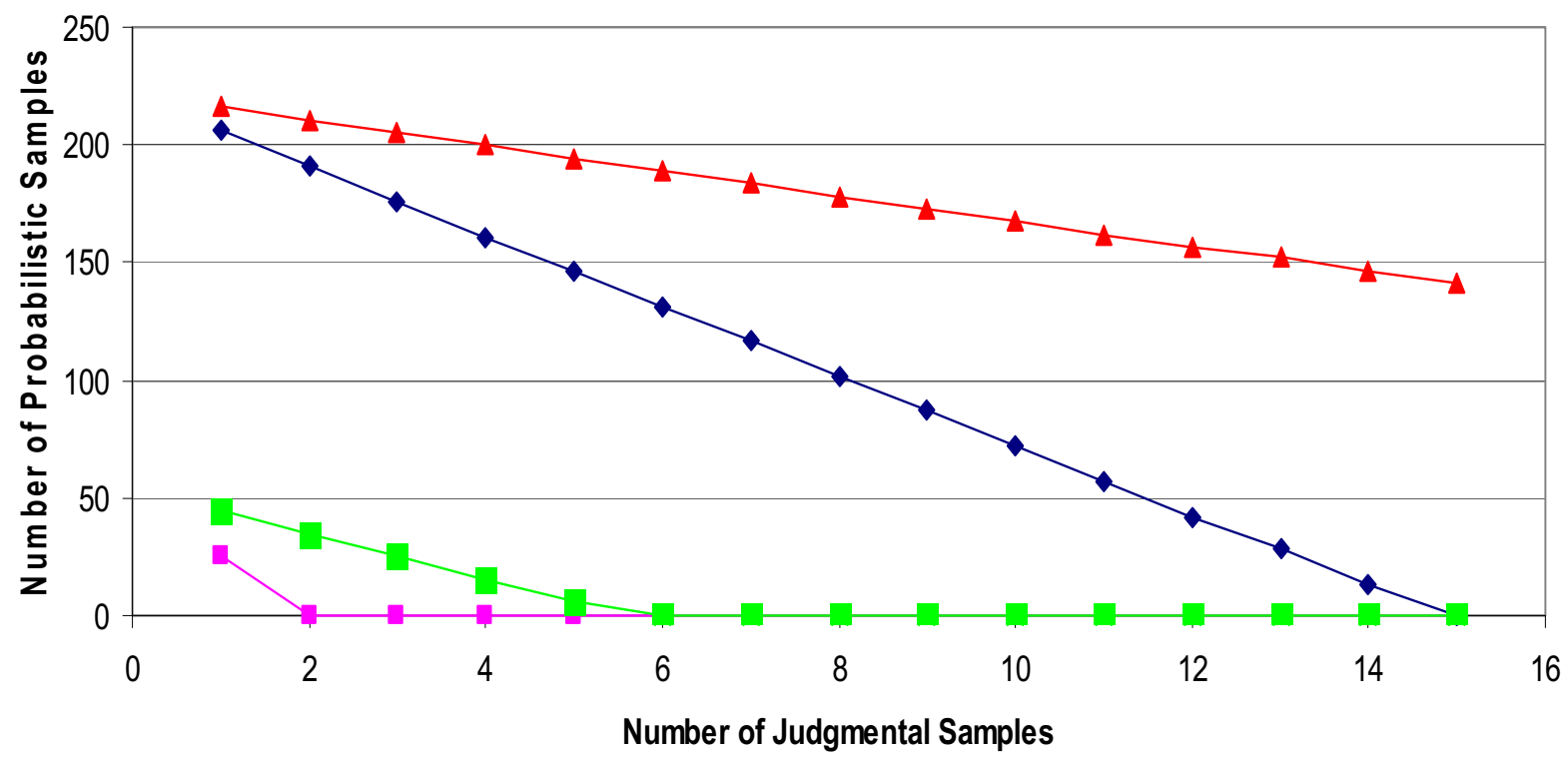

$\neg-99 \%$ clean / very low $\rightarrow-95 \%$ clean / very low $\neg-99 \%$ clean / low $-\square-95 \%$ clean / low

Figure 4.3. Number of Negative Probabilistic Samples Required to be $95 \%$ Confident that Two Rooms in the INL PBF-632 Building Do Not Contain Detectable Contamination Given Various Numbers of Negative Judgmental Samples. Colored lines represent the percentage of the area not containing detectable contamination for the two rooms (considered together as a "zone") and the a priori probabilities that the area contains detectable contamination.

(a) VSP defines low as a $30 \%$ chance, and very low as a $10 \%$ chance. 
42 negative probabilistic samples would be necessary to have $95 \%$ confidence that at least $99 \%$ of the area in the two rooms does not contain detectable contamination. This result is obtained when there is a very low a priori probability that an area contains detectable contamination.

Figure 4.4 summarizes the number of probabilistic samples necessary to make an $\mathrm{X} \% / \mathrm{Y} \%$ clearance statement about a single floor in the INL PBF-632 building when using the Bayesian method. Three parameters were allowed to vary: 1) the number of judgmental samples, 2) the a priori probability of the floor containing detectable contamination (very low or low), and 3) the likelihood that a judgmental sample location contains detectable contamination as compared to a probabilistic sample location $(1 \times=$ judgmental location just as likely as probabilistic or $3 \times=$ judgmental location is three times as likely as probabilistic location, etc.). Figure 4.4 shows that with 19 negative judgmental samples, 100 negative probabilistic samples would be required to have $95 \%$ confidence that $99 \%$ of the floor does not contain detectable contamination. This result is obtained when either 1) there is a very low a priori probability that an area contains detectable contamination and a judgmental sample location is just as likely to contain detectable contamination as a probabilistic sample location, or 2) there is a low a priori probability that an area contains detectable contamination and a judgmental sample location is twice as likely to contain detectable contamination as a probabilistic sample location.

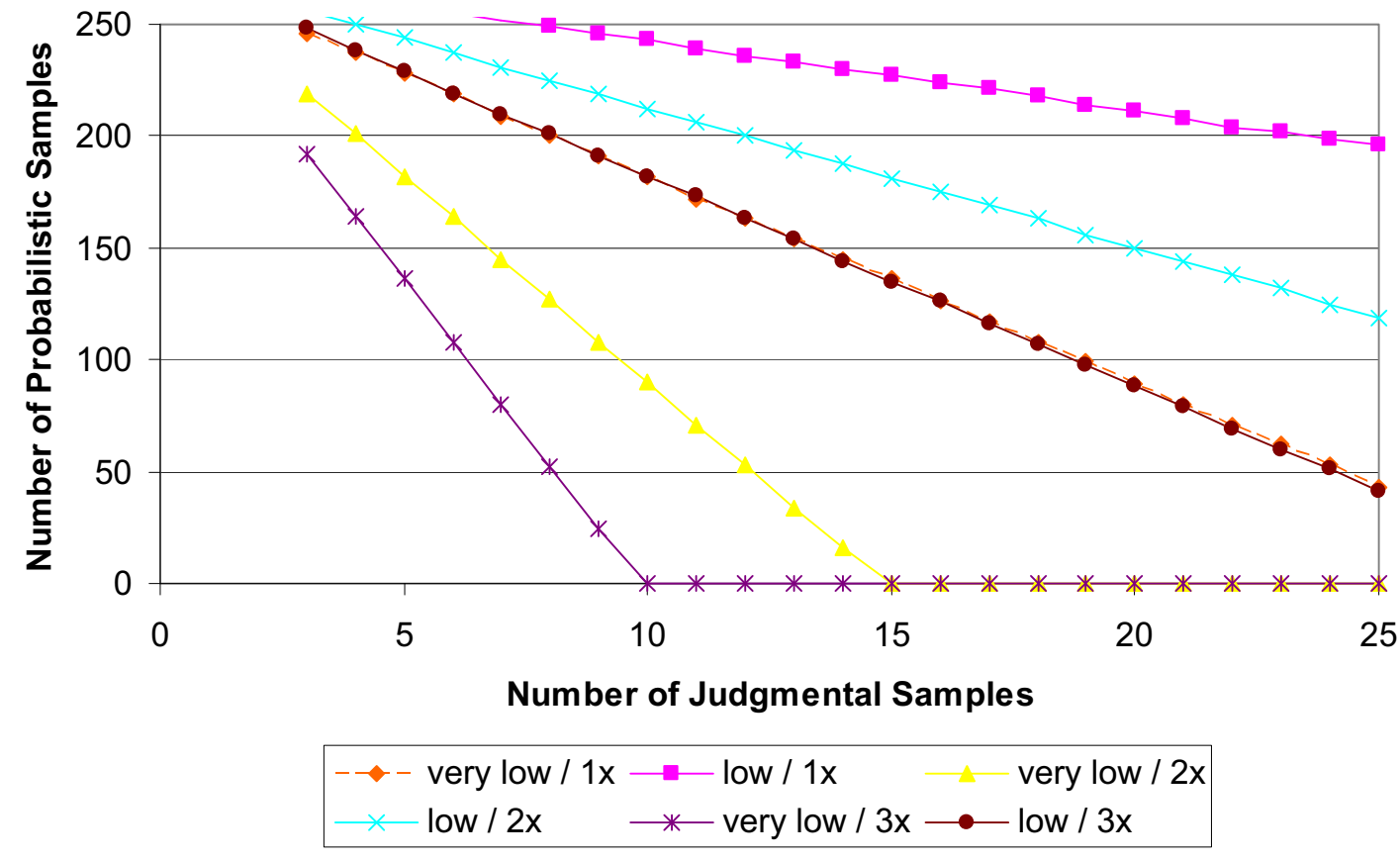

Figure 4.4. Number of Negative Probabilistic Samples Required to be $95 \%$ Confident that at Least $99 \%$ of a Typical Floor in the INL PBF-632 Building Does Not Contain Detectable Contamination Given Various Numbers of Negative Judgmental Samples. Colored lines represent a priori probabilities of detectable contamination existing and the likelihood of a judgmental sample location containing detectable contamination relative to a probabilistic sample location. Note that the "very low/1×" and "low/3×" lines are nearly identical. 
Figure 4.5 summarizes the number of negative probabilistic samples required to make an $\mathrm{X} \% / \mathrm{Y} \%$ clearance statement about two typical rooms (considered together as a "zone") in the INL PBF-632 building using only probabilistic samples. The percent confidence $(\mathrm{X} \%)$ and the minimum percent of the room not containing detectable contamination (Y\%) were allowed to vary. If 42 probabilistic samples all came back negative (the same number in the example above for Figure 4.2), then there would 95\% confidence that at least 93\% (approximately) of the room does not contain detectable contamination. Thus, the 12 judgmental samples in the example associated with Figure 4.3, combined with the 42 probabilistic samples, increased the percentage of the room that can be declared not to contain detectable contamination from $93 \%$ to $99 \%$. Although not illustrated in this report, it is also possible to calculate the reduction in percentage confidence $(\mathrm{X} \%$ ) associated with $\mathrm{Y}=99 \%$ by only using probabilistic samples instead of the Bayesian combination of judgmental and probabilistic samples.

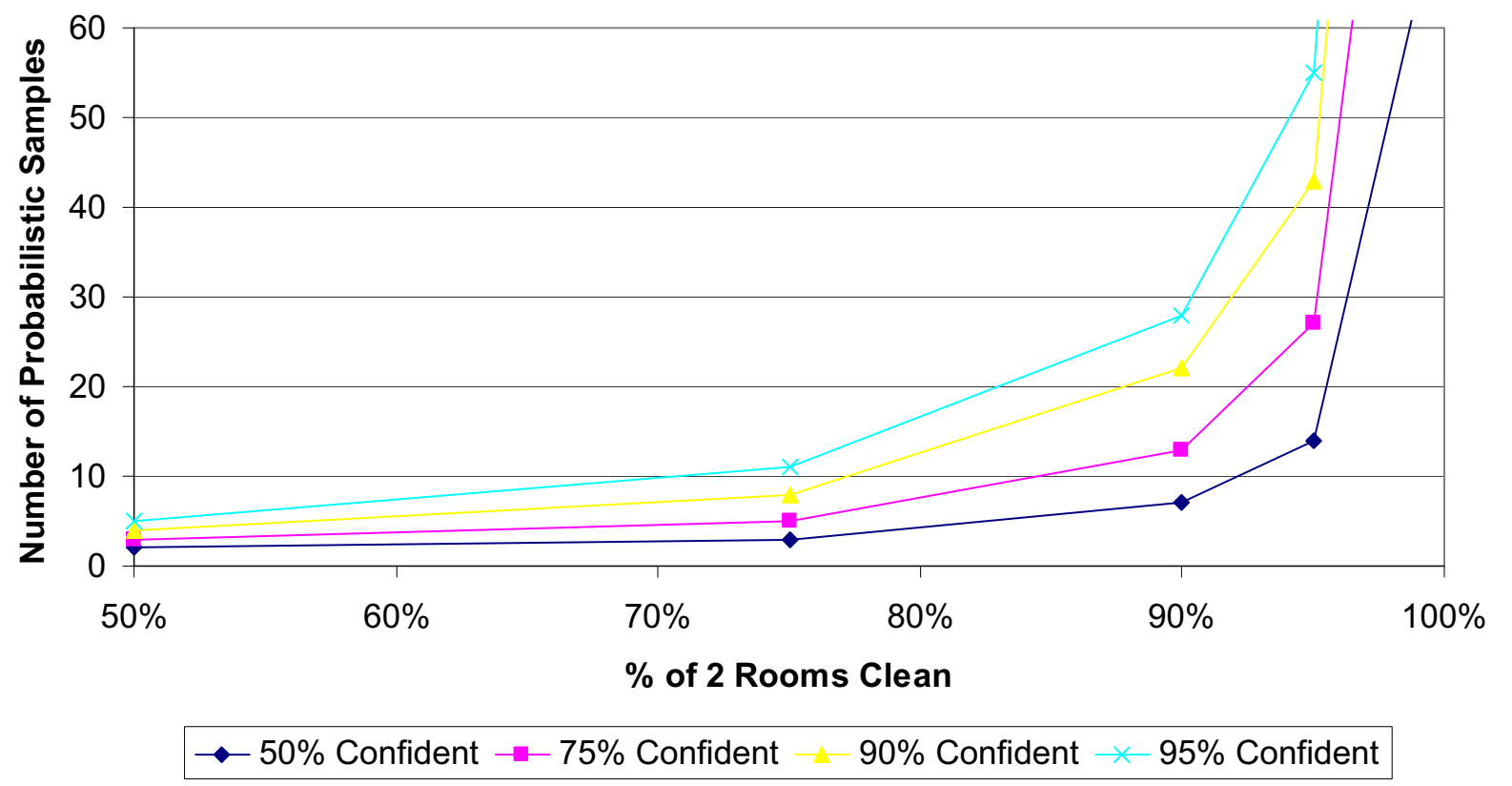

Figure 4.5. Number of Probabilistic Samples Required to Determine if a Given Percent of Two Typical Rooms in the INL PBF-632 Building Does Not Contain Detectable Contamination (x-axis) with a Given Level of Confidence (color lines).

Figure 4.6 summarizes the number of probabilistic samples required to make an $\mathrm{X} \% / \mathrm{Y} \%$ clearance statement about a single floor in the INL PBF-632 building using the only probabilistic samples. The percent confidence $(\mathrm{X} \%)$ and the percent of the room that does not contain detectable contamination (Y\%) were allowed to vary. This plot shows that if 119 probabilistic samples were taken and found to be negative (the same number as in the example above for Figure 4.4), then there would be $95 \%$ confidence that at least $96 \%$ of the floor does not contain detectable contamination. Although not illustrated, it is also possible to calculate the $\mathrm{X} \%$ confidence associated with $\mathrm{Y}=99 \%$ for a given number of probabilistic samples compared to also having a given number of judgmental samples in the Bayesian approach. 


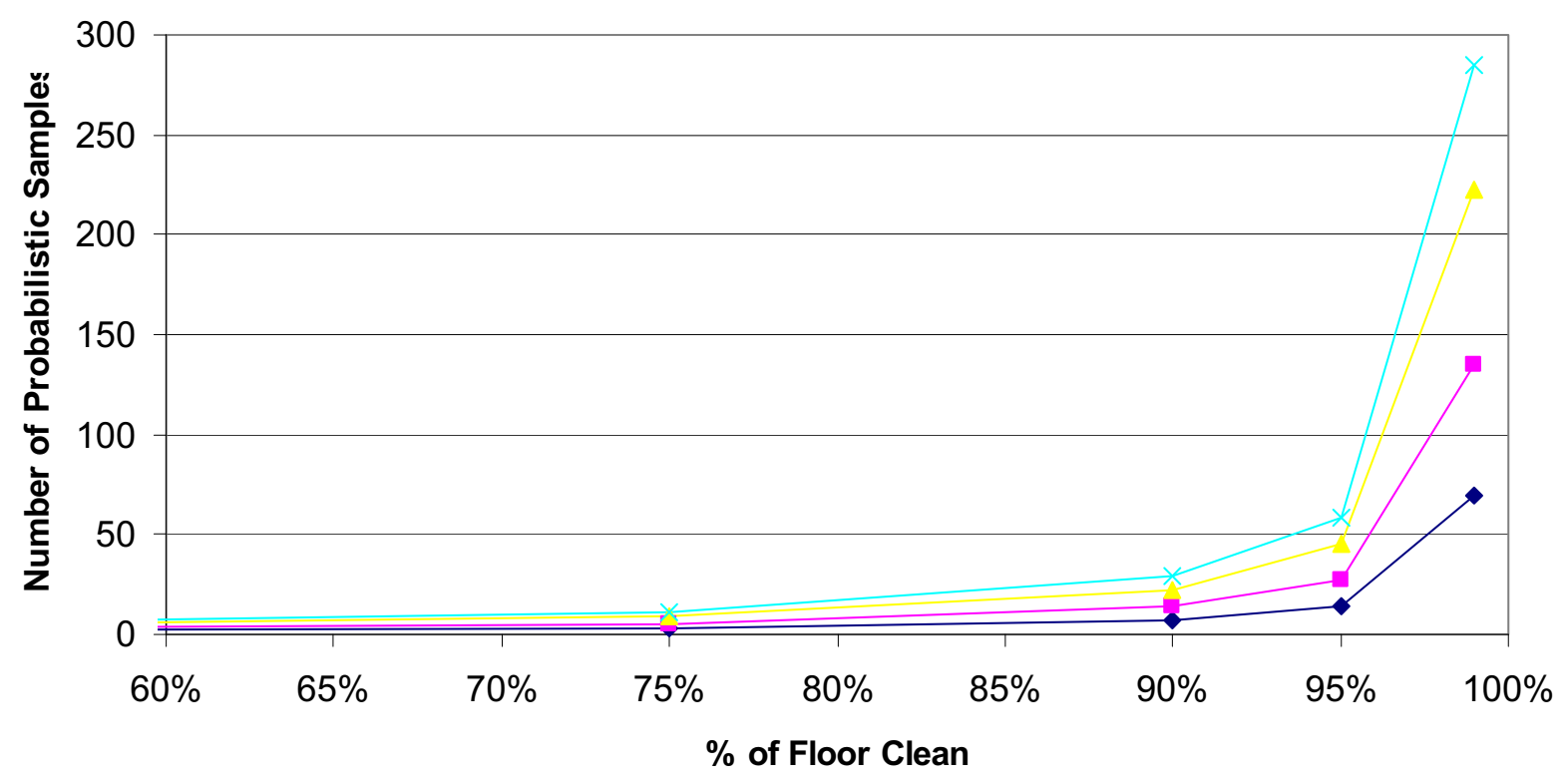

$-50 \%$ Confident $\rightarrow-75 \%$ Confident

90\% Confident

95\% Confident

Figure 4.6. Number of Probabilistic Samples Required to Determine if a Given Percent of a Typical Floor in the INL PBF-632 Building Does Not Contain Detectable Contamination (x-axis) with a Given Level of Confidence (color lines).

Figure 4.3 through Figure 4.6 were used to determine numbers of judgmental and probabilistic samples for determining clearance of a floor or a zone of two rooms in the INL Sample Collection Operational Test. Table 4.2 lists implication statements for the Bayesian approach given these numbers of judgmental and probabilistic samples and assuming that two of the three other variables are held constant. In each set of implication statements, 95\% confidence was used, as well as a sample area of 1 $\mathrm{ft}^{2}$. In the first column of implication statements, the likelihood that a judgmental sample location contains detectable contamination relative to a probabilistic sample location was set to three times, and the a priori probability that detectable contamination exists was set to "low", so that the percent of the room not containing detectable contamination could be calculated. In the second column of implication statements, the likelihood that a judgmental sample location contains detectable contamination relative to a probabilistic sample location was set to be equivalent $(1 \times)$, and the a priori probability that detectable contamination exists was set to "low," so that the percent of the rooms/floor not containing detectable contamination could be calculated. The third column did not use the Bayesian approach, but instead relied on a compliance sampling methodology that uses probabilistic sampling only (Bowen and Bennett 1998). It did not rely on assumptions about the a priori probability that detectable contamination exists nor the relationship between the likelihood of detectable contamination existing in the judgmental and probabilistic sample locations. The implication statement lists the percent of the rooms/floor that does not contain detectable contamination, given the number of negative probabilistic samples and desired $95 \%$ confidence. 
Table 4.2. Implications Given the Number of Probabilistic and Judgmental Samples for Clearance of a Decontaminated or Non-Contaminated Area in the INL PBF-632 Building

\begin{tabular}{|c|c|c|c|c|}
\hline 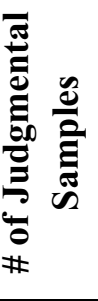 & 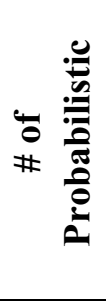 & Implication $1^{(a)}$ & Implication $\mathbf{2}^{(\mathbf{b})}$ & Implication $3^{(\mathrm{c})}$ \\
\hline \multicolumn{5}{|c|}{ per 2 Rooms } \\
\hline 8 & 26 & $95 \% / 97 \% / 3 \times /$ low & $95 \% / 94 \% / 1 \times /$ low & $95 \% / 91 \%$ \\
\hline \multicolumn{5}{|c|}{ per Floor } \\
\hline 15 & 60 & $95 \% / 98 \% / 3 \times /$ low & $95 \% / 97 \% / 1 \times /$ low & $95 \% / 96 \%$ \\
\hline 20 & 88 & $95 \% / 99 \% / 3 \times /$ low & $95 \% / 98 \% / 1 \times /$ low & $95 \% / 97 \%$ \\
\hline
\end{tabular}

(a) Implication 1 is listed as the percent confidence/percent of room that does not contain detectable contaminated/multiplier that indicates a judgmental sample location is three times $(3 \times)$ more likely to contain detectable contamination than a probabilistic sample location/low a priori probability that the area contains detectable contamination.

(b) Implication 2 is listed as the percent confidence/percent of room that does not contain detectable contamination/multiplier that indicates a judgmental sample location is equally $(1 \times)$ likely to contain detectable contamination than a probabilistic sample location/low a priori probability that the area contains detectable contamination.

(c) Implication 3 is listed as the percent confidence/percent of room that does not contain detectable contamination using only probabilistic sampling.

There are other assumptions that are not allowed to vary when sampling for clearance because of limitations in the VSP software (Matzke et al. 2007). At this time, VSP does not allow for different areas of the sampling grid to have different a priori probabilities of detectable contamination. VSP also does not yet account for the FNR in a grid sampling approach. 


\subsection{Experimental Design}

The experimental design for the INL building exercise is described in this section. The rationale concerning the characterization sampling is explained in Section 5.1. The rationale concerning the clearance sampling is explained in Section 5.2. The ORI (Test Event 1) is described in Section 5.3, while Test Events 2, 3, 4, and 5 are, respectively, described in Sections 5.4 to 5.7. Table 2.1 in Section 2 lists the characteristics for the five test events. Two plans for the numbers of samples are presented for each test event. The preferred plan lists the recommend numbers of samples, while the minimal plan lists the acceptable numbers of samples if the preferred plan cannot be carried out. The total numbers of samples are summarized in Section 5.8, and additional details about the experimental design are discussed in Section 5.9.

\subsection{Characterization Sampling Rationale}

For sampling with the goal of characterization, the resulting numbers of samples are based on three quantities: 1) percent confidence, 2) size of the contaminated area (assumed to be circular and quantified by the diameter, in feet) one wishes to be able to detect with high confidence, and 3) FNR. For this experimental design, the percent confidence was consistently set at $95 \%$. Specifying values for any two of 1) contamination size, 2) FNR, and 3) number of samples permits calculating the third quantity. In each sampling case, two implication statements were made. The first statement involved specifying the size (diameter) of a circular contaminated area with $\mathrm{FNR}=10 \%$ and then calculating the required number of samples. The second statement involved choosing a consistent contaminated area size (10-ft diameter) and calculating the FNR for the number of samples calculated corresponding to the first implication statement. Only one implication statement was made for overt events when sampling the area (room) in which the contaminant will be released. In this case, a $0 \%$ FNR was assumed. Also, one implication statement was made when the number of samples corresponded to a 10 -ft-diameter circular contaminated area and a $10 \%$ FNR.

Each of these implication statements allows the opportunity to see what advantage is gained when increasing the numbers of samples. The advantages include the ability to detect a smaller contaminated area and/or being able to detect contamination when the FNR is higher. Because it is not known at this time 1) how much of each room in the INL PBF-632 building will be contaminated after BG contaminant dissemination, and 2) how the FNR will vary with contamination level, it is informative to consider what each number of samples implies in this case.

The numbers of samples taken after contamination are presented in Sections 5.3 to 5.7 and are summarized in Section 5.8. The following guidelines were used to help determine the recommended numbers of samples after contamination:

- There will be four sampling teams working simultaneously.

- Sampling will be done over a 6-hour period. This period needs to include a break after 3 hours and time to get into and out of protective gear.

- Three to five referee samples will be taken in each room where sampling will take place.

\section{UNCLASSIFIED}




\section{UNCLASSIFIED}

- It takes an average of 6 minutes per sample per sampling team. Referee samples will take less time, vacuum samples more time.

- It is recommended that a single sampling team works in an individual room without being interrupted by taking a break. By following this recommendation, an individual room should not have more than 30 total samples taken.

- Given this guidance, it has been determined that a maximum of 200 "after contamination" samples should be planned for each event.

The numbers of characterization samples proposed in Sections 5.3 to 5.7 allow making 95\% confidence statements about detecting contamination in circular areas ranging from $5 \mathrm{ft}$ to $10 \mathrm{ft}$ in diameter for a room or one complete floor of the INL PBF- 632 building and have FNRs ranging from $0 \%$ to over $50 \%$.

It is important to note that the sample area is expected to be the same size whether the sample is probabilistic or judgmental. For this reason, judgmental composite sampling will not be allowed. Multiple judgmental samples will be necessary to sample a larger area if so desired. There should be enough planned numbers of judgmental samples to allow for multiple samples when needed.

\subsection{Clearance Sampling Rationale}

For sampling with the goal of clearance, the resulting numbers of samples are based on four quantities: 1) percent confidence, 2) percent of a room or floor of the INL PBF-632 building that does not contain detectable contamination, 3) a priori probability of detectable contamination, and 4) likelihood that a judgmental sample location contains detectable contamination relative to a probabilistic sample location. For this experimental design, percent confidence was consistently set at $95 \%$, and the a priori probability of detectable contamination was set to low $(<30 \%)$. Specifying values for any two of 1$)$ percent of area containing detectable contamination, 2) likelihood that a judgmental sample location contains detectable contamination relative to a probabilistic sample location, and 3) number of samples (judgmental and probabilistic) permits calculating the third quantity. In each sampling case, two implication statements were made. Each statement listed the percentage of the room or floor not containing detectable contamination, given that a judgmental sample location was either three times $(3 \times)$ more likely to contain detectable contamination, or just as likely $(1 \times)$ to contain detectable contamination as a probabilistic sample location.

The numbers of clearance samples proposed in the following sections allow making clearance statements of the form " $\mathrm{X} \%$ confidence that at least $\mathrm{Y} \%$ of an area does not contain detectable contamination" with $\mathrm{X}=95 \%$ and $\mathrm{Y}$ values between $94 \%$ and $99 \%$. The tables also show that increasing the likelihood that a judgmental sample location contains detectable contamination from $1 \times$ to $3 \times$ relative to a probabilistic sample location will increase $\mathrm{Y}$ by $1 \%$ to $3 \%$. To appreciate these increases, it may be more appropriate to consider them in terms of the percentage of the area containing detectable contamination (i.e., $100 \%-\mathrm{Y} \%$ ). If the percentage not containing detectable contamination increases from $98 \%$ to $99 \%$, then this is actually a $50 \%$ decrease in the percentage containing detectable contamination (from $2 \%$ to $1 \%$ ). The change is a more dramatic when expressed in terms of the percentage of room or floor containing detectable contamination.

\section{UNCLASSIFIED}


The numbers of samples to be taken after decontamination are presented in Sections 5.3 to 5.7 and are summarized in Section 5.8. The following guidelines were used to help determine the recommended numbers of samples after decontamination:

- There will be four sampling teams working simultaneously.

- Sampling will be done over a 4-hour period. This period needs to include a break after 2 hours and time to get into and out of protective gear.

- No referee samples will be taken.

- It takes an average of 6 minutes per sample per sampling team.

- It is recommended that a single sampling team works in an individual room without being interrupted by taking a break. By following this recommendation, an individual room should not have more than 30 total samples taken.

- Given this guidance, it has been determined that a maximum of 120 samples should be planned after decontamination for each event.

Because the decontamination is expected to be thorough and similar after each test event, the same numbers of post-decontamination samples are recommended at the end of each test event.

\subsection{Operational Readiness Inspection (Test Event 1)}

Table 5.1 summarizes the numbers of samples to be taken after contamination and after decontamination, the types of samples that will be taken (judgmental, probabilistic, and referee), and in which rooms (or floor) the samples will be taken during the ORI (Test Event 1). The ORI consists of an overt dissemination in the lobby of the first floor of the INL PBF-632 building with subsequent sampling occurring in selected rooms on the first floor. The numbers of samples in the preferred plan are recommended, assuming that the sampling guidelines (as listed in Sections 5.1 and 5.2) can be met. If it is determined that the guidelines cannot be achieved and fewer samples are necessary, then the numbers of samples in the minimal plan can be implemented, either as a whole, or individually for specific rooms. Figure 5.1 gives a visual display of the numbers of samples after contamination using the preferred plan for the ORI.

The numbers of samples for the ORI were based on the following information:

- The room of dissemination (first floor lobby) was assigned 3 judgmental and 3 probabilistic samples because it was assumed that contamination will be easily detected there with a $0 \% \mathrm{FNR}$.

- Rooms 101 and 102 near and "downwind" of the contaminant release location (the lobby) had 4 judgmental samples allocated and 9 probabilistic samples ( 6 for the minimal plan) with the ability to detect a 7-foot (9-foot for the minimal plan) diameter circular contaminated area with $95 \%$ confidence and assuming an FNR of $10 \%$.

- Rooms further from the contaminant release location, but still expected to be contaminated (Rooms 105, 106), had 6 judgmental samples allocated (5 for the minimal plan) and 17 probabilistic samples ( 9 for the minimal plan) to detect a 5-foot (7-foot for the minimal plan) diameter circular contaminated area with $95 \%$ confidence and assuming an FNR of $10 \%$.

\section{UNCLASSIFIED}


Table 5.1. Numbers of Samples for the Operational Readiness Inspection (Test Event 1) on the First Floor of the INL PBF-632 Building

\begin{tabular}{|c|c|c|c|c|c|c|c|c|c|}
\hline \multirow[b]{2}{*}{ Run Information } & \multirow[b]{2}{*}{ 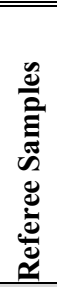 } & \multicolumn{4}{|c|}{ Minimal Plan } & \multicolumn{4}{|c|}{ Preferred Plan } \\
\hline & & 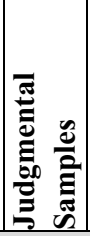 & 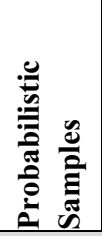 & 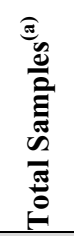 & Implication $^{(\mathbf{b})}$ & 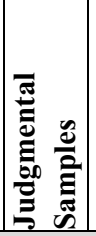 & 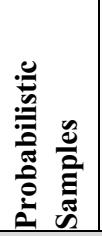 & 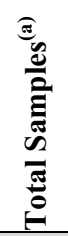 & Implication $^{(\mathbf{b})}$ \\
\hline \multicolumn{10}{|c|}{ Contamination } \\
\hline Lobby (Dissemination) $^{(\mathrm{c})}$ & 5 & 3 & 3 & 11 & $95 \% / 10 \mathrm{ft} / 0 \% \mathrm{FNR}^{(\mathrm{d})}$ & 3 & 3 & 11 & $95 \% / 10 \mathrm{ft} / 0 \% \mathrm{FNR}$ \\
\hline Office $101^{(\mathrm{c})}$ & 5 & 4 & 6 & 15 & $\begin{array}{l}95 \% / 9 \mathrm{ft} / 10 \% \text { FNR } \\
95 \% / 10 \mathrm{ft} / 21 \% \mathrm{FNR}^{(\mathrm{e})}\end{array}$ & 4 & 9 & 18 & $\begin{array}{l}95 \% / 7 \mathrm{ft} / 10 \% \text { FNR } \\
95 \% / 10 \mathrm{ft} / 42 \% \text { FNR }\end{array}$ \\
\hline Office $102^{(\mathrm{c})}$ & 5 & 4 & 6 & 15 & $\begin{array}{l}95 \% / 9 \mathrm{ft} / 10 \% \text { FNR } \\
95 \% / 10 \mathrm{ft} / 21 \% \text { FNR }\end{array}$ & 4 & 9 & 18 & $\begin{array}{l}95 \% / 7 \mathrm{ft} / 10 \% \text { FNR } \\
95 \% / 10 \mathrm{ft} / 42 \% \text { FNR }\end{array}$ \\
\hline Office $105^{(\mathrm{c})}$ & 5 & 5 & 9 & 19 & $\begin{array}{l}95 \% / 7 \mathrm{ft} / 10 \% \text { FNR } \\
95 \% / 10 \mathrm{ft} / 42 \% \text { FNR }\end{array}$ & 6 & 17 & 28 & $\begin{array}{l}95 \% / 5 \mathrm{ft} / 10 \% \mathrm{FNR} \\
95 \% / 10 \mathrm{ft} />50 \% \mathrm{FNR}\end{array}$ \\
\hline Office $106^{(\mathrm{c})}$ & 5 & 5 & 9 & 19 & $\begin{array}{l}95 \% / 7 \mathrm{ft} / 10 \% \text { FNR } \\
95 \% / 10 \mathrm{ft} / 42 \% \text { FNR }\end{array}$ & 6 & 17 & 28 & $\begin{array}{l}95 \% / 5 \mathrm{ft} / 10 \% \mathrm{FNR} \\
95 \% / 10 \mathrm{ft} />50 \% \mathrm{FNR}\end{array}$ \\
\hline Offices $109 \& 110^{(\mathrm{f})}$ & 10 & 8 & 26 & 44 & $\begin{array}{l}95 \% / 97 \% / 3 \times \\
95 \% / 94 \% / 1 \times^{(\mathrm{g})}\end{array}$ & 8 & 26 & 44 & $\begin{array}{l}95 \% / 97 \% / 3 \times \\
95 \% / 94 \% / 1 \times\end{array}$ \\
\hline \# Contamination Samples & 35 & 29 & 59 & 123 & & 31 & 81 & 147 & \\
\hline \multicolumn{10}{|c|}{ Decontamination } \\
\hline First floor $^{(\mathrm{f})}$ & 0 & 15 & 60 & 75 & $\begin{array}{l}95 \% / 98 \% / 3 \times \\
95 \% / 97 \% / 1 \times \\
\end{array}$ & 20 & 88 & 108 & $\begin{array}{l}95 \% / 99 \% / 3 \times \\
95 \% / 98 \% / 1 \times \\
\end{array}$ \\
\hline Total Samples & 35 & 44 & 119 & 198 & & 51 & 169 & 255 & \\
\hline
\end{tabular}

(a) "Total Samples" is the sum of referee samples, judgmental samples, and probabilistic samples.

(b) These statements are listed for characterization as percent confidence/diameter of circular contaminated area in feet/FNR. For clearance, they are listed as percent confidence/percent of room that does not contain detectable contamination/multiplier that indicates a judgmental sample location is three times $(3 \times)$ more likely or equally $(1 \times)$ likely to contain detectable contamination relative to a probabilistic sample location.

(c) Room is being sampled with a characterization goal.

(d) Characterization implication: 95\% confidence of detecting a single circular contaminated area of diameter $10 \mathrm{ft}$ with an FNR of $0 \%$.

(e) The 6 probabilistic samples provide $95 \%$ confidence for either detecting a single circular contaminated area of diameter $9 \mathrm{ft}$ with an FNR of $10 \%$ or detecting a single contaminated area of diameter $10 \mathrm{ft}$ with an FNR of $21 \%$.

(f) Area (rooms or floor) is being sampled with a clearance goal.

(g) Bayesian-based clearance implication: $95 \%$ confidence that either $97 \%$ of the room does not contain detectable contamination with a judgmental sample location being three times $(3 \times)$ more likely to contain detectable contamination relative to a probabilistic sample location, or $94 \%$ of the room does not contain detectable contamination with a judgmental sample location equally likely $(1 \times)$ to contain detectable contamination as a probabilistic sample location. All clearance numbers of samples assume that the a priori probability of contamination is low (30\%). 


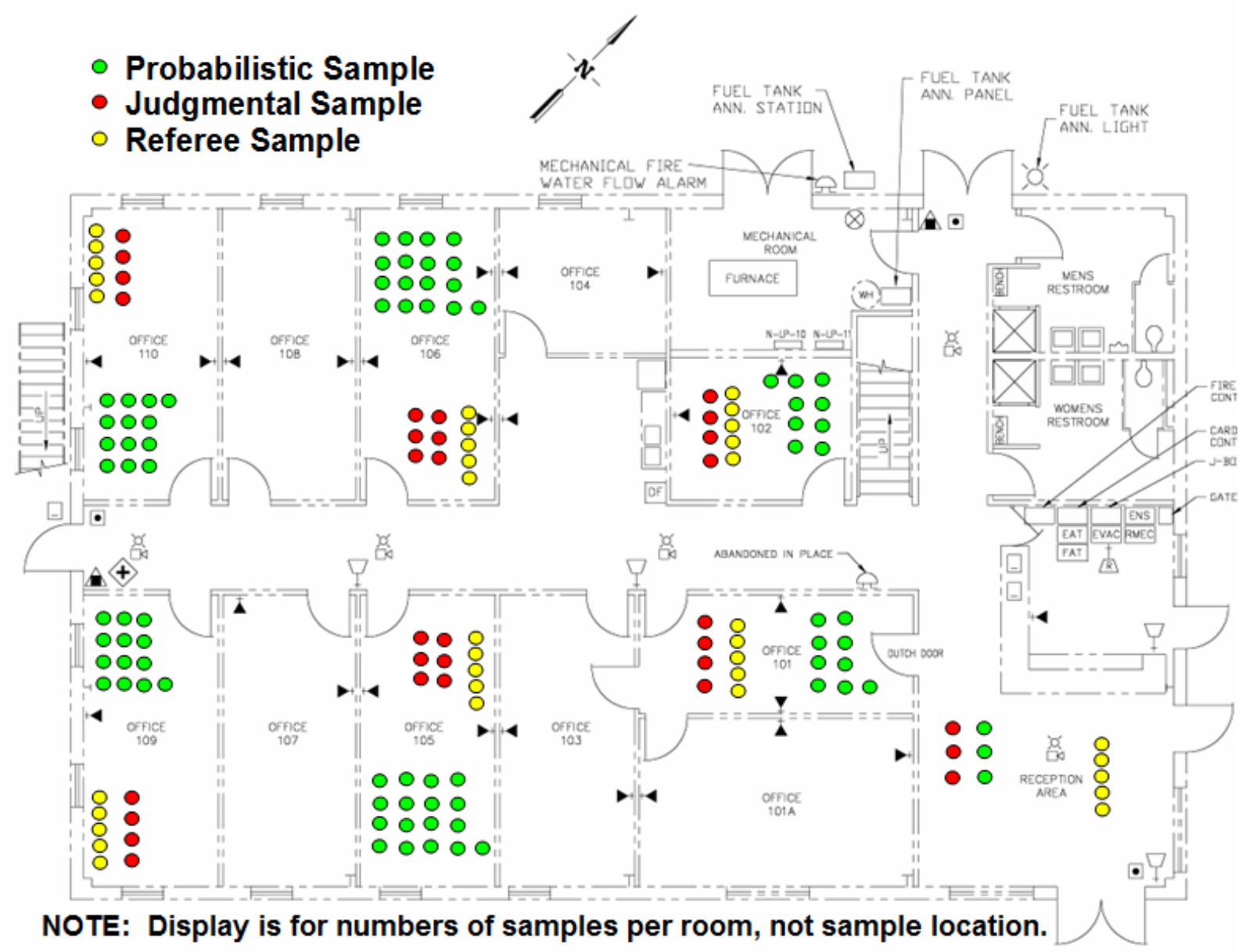

Figure 5.1. Numbers of Samples in the Preferred Plan to be Taken After Contamination During the Operational Readiness Inspection (Test Event 1) on the First Floor of the INL PBF-632 Building

- Rooms farthest from the contaminant release location that may not be contaminated (Rooms 109 and 110) were selected for clearance sampling using the Bayesian approach. This requires 8 negative judgmental samples (i.e., no detectable contamination) and 26 negative probabilistic samples to obtain $95 \%$ confidence that $97 \%$ of the area in the rooms does not contain detectable contamination, assuming that a judgmental sample location is three times more likely to contain detectable contamination than a probabilistic sample location. There is no difference in the numbers of samples between the minimal and preferred plans.

- The difference between the minimum and the preferred plan involves reducing the diameter of the contaminated area by 1 to 2 feet or looking at the increase in the allowable FNR with a constant area of contamination (10-ft diameter).

- It was decided that 5 referee samples would be taken in each sampled room. This resulted in 35 total referee samples. 
The purpose of the ORI is to provide an opportunity for any issues that might arise (e.g., concerning the dissemination, contamination gradient, sampling, and decontamination) to be addressed before the remaining test events. For this purpose, the numbers of samples were limited to 123 (minimal plan) or 147 (preferred plan) of the possible 200 "after contamination" samples. Following the ORI, adjustments should be made to the process so that the subsequent test events have the greatest probability of success. If the data from the ORI are deemed useful, then they may be included in the data analyses.

\subsection{Test Event 2}

Table 5.2 summarizes the numbers of samples to be taken after contamination and after decontamination, the types of samples that will be taken (judgmental, probabilistic, and referee), and in which rooms (or floor) the samples will be taken during the second test event. This event consists of an overt dissemination in the lobby of the first floor of the INL PBF-632 building with subsequent sampling occurring in selected rooms on the first floor. The numbers of samples in the preferred plan are recommended, assuming that the sampling guidelines (as listed in Sections 5.1 and 5.2) can be met. If it is determined that the guidelines cannot be achieved and fewer samples are necessary, then the numbers of samples in the minimal plan can be implemented, either as a whole, or individually for specific rooms. Figure 5.2 gives a visual display of the numbers of samples after contamination using the preferred plan for the second test event.

The numbers of samples for the second test event were based on the following information:

- The room of dissemination (first floor lobby) was assigned 3 judgmental and 3 probabilistic samples because it was assumed that contamination will be easily detected there with a $0 \% \mathrm{FNR}$.

- Rooms 101 and 102 near and "downwind" of the contaminant release location (the lobby) had 4 judgmental samples allocated and 9 probabilistic samples (6 for the minimal plan) with the ability to detect a 7-foot (9-foot for the minimal plan) diameter circular contaminated area with $95 \%$ confidence and assuming an FNR of $10 \%$.

- Rooms further from the contaminant release location, but still expected to be contaminated (Rooms 105, 106, 107, 108) had 5 or 6 judgmental samples allocated ( 4 or 5 for the minimal plan) and 12 or 17 probabilistic samples ( 7 or 9 for the minimal plan) to detect a 5-foot or 6-foot (7-foot or 8-foot for the minimal plan) diameter circular contaminated area with $95 \%$ confidence and assuming an FNR of $10 \%$.

- Rooms farthest from the contaminant release location that may not be contaminated (Rooms 109 and 110) were selected for clearance sampling using the Bayesian approach. This requires 8 negative judgmental samples (i.e., no detectable contamination) and 26 negative probabilistic samples to obtain $95 \%$ confidence that $97 \%$ of the area in the rooms does not contain detectable contamination, assuming that a judgmental sample location is three times more likely to contain detectable contamination than a probabilistic sample location. There is no difference in the numbers of samples between the minimal and preferred plans. 
UNCLASSIFIED

Table 5.2. Numbers of Samples for Test Event 2 on the First Floor of the INL PBF-632 Building

\begin{tabular}{|c|c|c|c|c|c|c|c|c|c|}
\hline \multirow[b]{2}{*}{ Run Information } & \multirow[b]{2}{*}{ 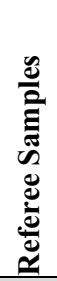 } & \multicolumn{4}{|c|}{ Minimal Plan } & \multicolumn{4}{|c|}{ Preferred Plan } \\
\hline & & 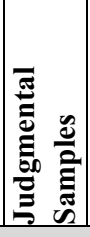 & 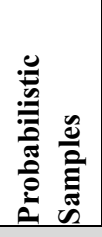 & 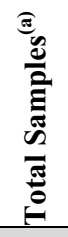 & Implication $^{(\mathbf{b})}$ & 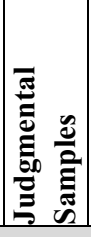 & 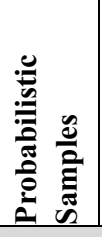 & 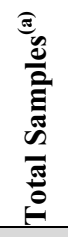 & Implication $^{(\mathbf{b})}$ \\
\hline \multicolumn{10}{|c|}{ Contamination } \\
\hline Lobby (Dissemination) $^{(\mathrm{c})}$ & 5 & 3 & 3 & 11 & $95 \% / 10 \mathrm{ft} / 0 \% \mathrm{FNR}^{(\mathrm{d})}$ & 3 & 3 & 11 & $95 \% / 10 \mathrm{ft} / 0 \% \mathrm{FNR}$ \\
\hline Office $101^{(\mathrm{c})}$ & 5 & 4 & 6 & 15 & $\begin{array}{l}95 \% / 9 \mathrm{ft} / 10 \% \mathrm{FNR} \\
95 \% / 10 \mathrm{ft} / 21 \% \mathrm{FNR}^{(\mathrm{e})}\end{array}$ & 4 & 7 & 16 & $\begin{array}{l}95 \% / 8 \mathrm{ft} / 10 \% \mathrm{FNR} \\
95 \% / 10 \mathrm{ft} / 29 \% \mathrm{FNR}\end{array}$ \\
\hline Office $102^{(\mathrm{c})}$ & 5 & 4 & 6 & 15 & $\begin{array}{l}95 \% / 9 \mathrm{ft} / 10 \% \text { FNR } \\
95 \% / 10 \mathrm{ft} / 21 \% \text { FNR }\end{array}$ & 4 & 7 & 16 & $\begin{array}{l}95 \% / 8 \mathrm{ft} / 10 \% \text { FNR } \\
95 \% / 10 \mathrm{ft} / 29 \% \text { FNR }\end{array}$ \\
\hline Office $105^{(\mathrm{c})}$ & 5 & 4 & 7 & 16 & $\begin{array}{l}95 \% / 8 \mathrm{ft} / 10 \% \mathrm{FNR} \\
95 \% / 10 \mathrm{ft} / 29 \% \mathrm{FNR}\end{array}$ & 5 & 12 & 22 & $\begin{array}{l}95 \% / 6 \mathrm{ft} / 10 \% \mathrm{FNR} \\
95 \% / 10 \mathrm{ft} />50 \% \mathrm{FNR}\end{array}$ \\
\hline Office $106^{(\mathrm{c})}$ & 5 & 4 & 7 & 16 & $\begin{array}{l}95 \% / 8 \mathrm{ft} / 10 \% \mathrm{FNR} \\
95 \% / 10 \mathrm{ft} / 29 \% \text { FNR }\end{array}$ & 5 & 12 & 22 & $\begin{array}{l}95 \% / 6 \mathrm{ft} / 10 \% \mathrm{FNR} \\
95 \% / 10 \mathrm{ft} />50 \% \mathrm{FNR}\end{array}$ \\
\hline Office $107^{(\mathrm{c})}$ & 5 & 5 & 9 & 19 & $\begin{array}{l}95 \% / 7 \mathrm{ft} / 10 \% \text { FNR } \\
95 \% / 10 \mathrm{ft} / 42 \% \text { FNR }\end{array}$ & 6 & 17 & 28 & $\begin{array}{l}95 \% / 5 \mathrm{ft} / 10 \% \text { FNR } \\
95 \% / 10 \mathrm{ft} />50 \% \text { FNR }\end{array}$ \\
\hline Office $108^{(\mathrm{c})}$ & 5 & 5 & 9 & 19 & $\begin{array}{l}95 \% / 7 \mathrm{ft} / 10 \% \mathrm{FNR} \\
95 \% / 10 \mathrm{ft} / 42 \% \text { FNR }\end{array}$ & 6 & 17 & 28 & $\begin{array}{l}95 \% / 5 \mathrm{ft} / 10 \% \mathrm{FNR} \\
95 \% / 10 \mathrm{ft} />50 \% \mathrm{FNR}\end{array}$ \\
\hline Offices $109 \& 110^{(\mathrm{f})}$ & 10 & 8 & 26 & 44 & $\begin{array}{l}95 \% / 97 \% / 3 \times \\
95 \% / 94 \% / 1 \times^{(\mathrm{g})}\end{array}$ & 8 & 26 & 44 & $\begin{array}{l}95 \% / 97 \% / 3 \times \\
95 \% / 94 \% / 1 \times\end{array}$ \\
\hline \# Contamination Samples & 45 & 37 & 73 & 155 & & 41 & 101 & 187 & \\
\hline \multicolumn{10}{|c|}{ Decontamination } \\
\hline First floor $^{(\mathrm{f})}$ & 0 & 15 & 60 & 75 & $\begin{array}{l}95 \% / 98 \% / 3 \times \\
95 \% / 97 \% / 1 \times\end{array}$ & 20 & 88 & 108 & $\begin{array}{l}95 \% / 99 \% / 3 \times \\
95 \% / 98 \% / 1 \times\end{array}$ \\
\hline Total Samples & 45 & 52 & 133 & 230 & & 61 & 189 & 295 & \\
\hline
\end{tabular}

(a) "Total Samples" is the sum of referee samples, judgmental samples, and probabilistic samples.

(b) These statements are listed for characterization as percent confidence/diameter of circular contaminated area in feet/FNR. For clearance, they are listed as percent confidence/percent of room that does not contain detectable contamination/multiplier that indicates a judgmental sample location is three times $(3 \times)$ more likely or equally $(1 \times)$ likely to contain detectable contamination relative to a probabilistic sample location.

(c) Room is being sampled with a characterization goal.

(d) Characterization implication: 95\% confidence of detecting a single circular contaminated area of diameter $10 \mathrm{ft}$ with an FNR of $0 \%$.

(e) The 6 probabilistic samples provide $95 \%$ confidence for either detecting a single circular contaminated area of diameter $9 \mathrm{ft}$ with an FNR of $10 \%$ or detecting a single circular contaminated area of diameter $10 \mathrm{ft}$ with an FNR of $21 \%$.

(f) Area (rooms or floor) is being sampled with a clearance goal.

(g) Bayesian-based clearance implication: $95 \%$ confidence that either $97 \%$ of the room does not contain detectable contamination with a judgmental sample location being three times $(3 \times)$ more likely to contain detectable contamination relative to a probabilistic sample location, or $94 \%$ of the room does not contain detectable contamination with a judgmental sample location equally likely $(1 \times)$ to contain detectable contamination as a probabilistic sample location. All clearance numbers of samples assume that the a priori probability of contamination is low (30\%).

\section{UNCLASSIFIED}




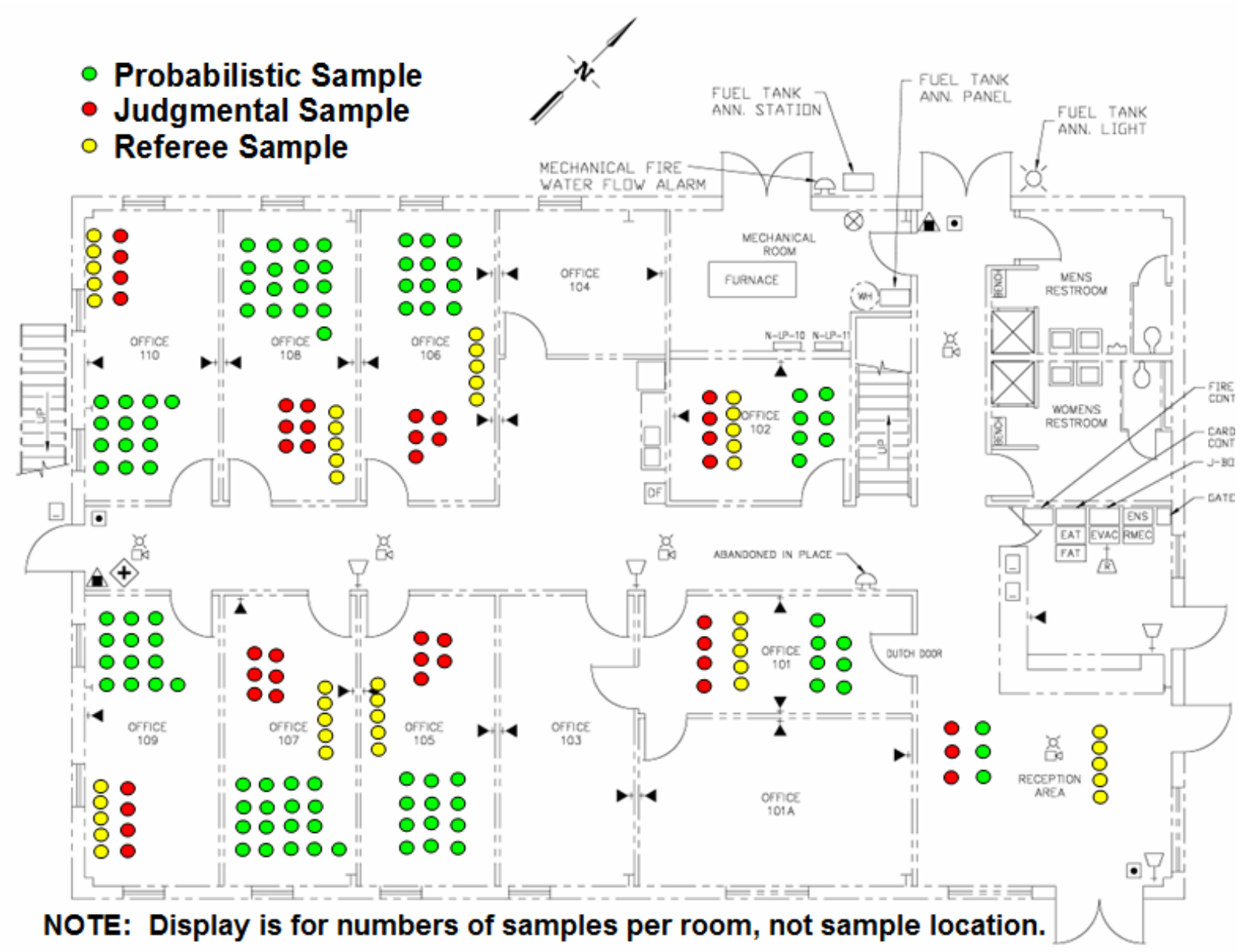

Figure 5.2. Numbers of Samples in the Preferred Plan to be Taken After Contamination During Test Event 2 on the First Floor of the INL PBF-632 Building

- The difference between the minimum and the preferred plans involves reducing the diameter of the contaminated area by 1 to 2 feet or looking at the increase in the allowable FNR with a constant area of contamination (10-ft diameter).

- It was decided that 5 referee samples would be taken in each sampled room. This resulted in 45 total referee samples.

The numbers of samples in Figure 5.2 reflect the above information.

\subsection{Test Event 3}

Table 5.3 summarizes the numbers of samples to be taken after contamination and after decontamination, the types of samples that will be taken (judgmental, probabilistic, and referee), and in which rooms (or floor) the samples will be taken during the third test event. This event consists of an overt dissemination in Room 201 on the second floor of the INL PBF-632 building, with subsequent sampling occurring in selected rooms on the second floor. The numbers of samples in the preferred plan. 
UNCLASSIFIED

Table 5.3. Numbers of Samples for Test Event 3 on the Second Floor of the INL PBF-632 Building

\begin{tabular}{|c|c|c|c|c|c|c|c|c|c|}
\hline \multirow[b]{2}{*}{ Run Information } & \multirow[b]{2}{*}{ 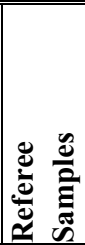 } & \multicolumn{4}{|c|}{ "Minimal Plan } & \multicolumn{4}{|c|}{ Preferred Plan } \\
\hline & & 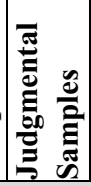 & 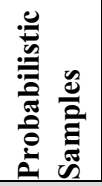 & 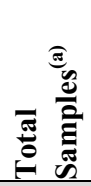 & Implication $^{(\mathbf{b})}$ & 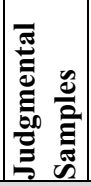 & 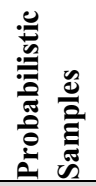 & 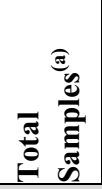 & Implication $^{(b)}$ \\
\hline \multicolumn{10}{|c|}{ Contamination } \\
\hline $\begin{array}{l}\text { Office } 201 \\
\text { (Dissemination) }^{(\mathrm{c})}\end{array}$ & 5 & 3 & 3 & 11 & $95 \% / 10 \mathrm{ft} / 0 \% \mathrm{FNR}^{(\mathrm{d})}$ & 3 & 3 & 11 & $95 \% / 10 \mathrm{ft} / 0 \% \mathrm{FNR}$ \\
\hline Office $202^{(\mathrm{c})}$ & 5 & 4 & 6 & 15 & $\begin{array}{l}95 \% / 9 \mathrm{ft} / 10 \% \text { FNR } \\
95 \% / 10 \mathrm{ft} / 21 \% \mathrm{FNR}^{(\mathrm{e})}\end{array}$ & 4 & 7 & 16 & $\begin{array}{l}95 \% / 8 \mathrm{ft} / 10 \% \mathrm{FNR} \\
95 \% / 10 \mathrm{ft} / 29 \% \mathrm{FNR}\end{array}$ \\
\hline Office $203^{(c)}$ & 5 & 4 & 6 & 15 & $\begin{array}{l}95 \% / 9 \mathrm{ft} / 10 \% \mathrm{FNR} \\
95 \% / 10 \mathrm{ft} / 21 \% \mathrm{FNR}\end{array}$ & 4 & 7 & 16 & $\begin{array}{l}95 \% / 8 \mathrm{ft} / 10 \% \text { FNR } \\
95 \% / 10 \mathrm{ft} / 29 \% \text { FNR }\end{array}$ \\
\hline Office $206^{(c)}$ & 5 & 4 & 7 & 16 & $\begin{array}{l}95 \% / 8 \mathrm{ft} / 10 \% \mathrm{FNR} \\
95 \% / 10 \mathrm{ft} / 29 \% \mathrm{FNR}\end{array}$ & 5 & 12 & 22 & $\begin{array}{l}95 \% / 6 \mathrm{ft} / 10 \% \mathrm{FNR} \\
95 \% / 10 \mathrm{ft} />50 \% \mathrm{FNR}\end{array}$ \\
\hline Office $207^{(\mathrm{c})}$ & 5 & 4 & 7 & 16 & $\begin{array}{l}95 \% / 8 \mathrm{ft} / 10 \% \mathrm{FNR} \\
95 \% / 10 \mathrm{ft} / 29 \% \mathrm{FNR}\end{array}$ & 5 & 12 & 22 & $\begin{array}{l}95 \% / 6 \mathrm{ft} / 10 \% \mathrm{FNR} \\
95 \% / 10 \mathrm{ft} />50 \% \mathrm{FNR}\end{array}$ \\
\hline Office $210^{(\mathrm{c})}$ & 5 & 5 & 9 & 19 & $\begin{array}{l}95 \% / 7 \mathrm{ft} / 10 \% \mathrm{FNR} \\
95 \% / 10 \mathrm{ft} / 42 \% \mathrm{FNR}\end{array}$ & 6 & 17 & 28 & $\begin{array}{l}95 \% / 5 \mathrm{ft} / 10 \% \mathrm{FNR} \\
95 \% / 10 \mathrm{ft} />50 \% \text { FNR }\end{array}$ \\
\hline Office $211^{(\mathrm{c})}$ & 5 & 5 & 9 & 19 & $\begin{array}{l}95 \% / 7 \mathrm{ft} / 10 \% \text { FNR } \\
95 \% / 10 \mathrm{ft} / 42 \% \text { FNR }\end{array}$ & 6 & 17 & 28 & $\begin{array}{l}95 \% / 5 \mathrm{ft} / 10 \% \text { FNR } \\
95 \% / 10 \mathrm{ft} />50 \% \text { FNR }\end{array}$ \\
\hline Offices $212 \& 213^{(\mathrm{f})}$ & 10 & 8 & 26 & 44 & $\begin{array}{l}95 \% / 97 \% / \text { low/3× } \\
95 \% / 94 \% / \text { low } / 1 \times^{(\mathrm{g})}\end{array}$ & 8 & 26 & 44 & $\begin{array}{l}95 \% / 97 \% / \text { low } / 3 \times \\
95 \% / 94 \% / \text { low } / 1 \times\end{array}$ \\
\hline \# Contamination Samples & 45 & 37 & 73 & 155 & & 41 & 101 & 187 & \\
\hline \multicolumn{10}{|c|}{ Decontamination } \\
\hline Second floor ${ }^{(\mathrm{f})}$ & 0 & 15 & 60 & 75 & $\begin{array}{l}95 \% / 98 \% / \text { low } / 3 \times \\
95 \% / 97 \% / \text { low } / 1 \times\end{array}$ & 20 & 88 & 108 & $\begin{array}{l}95 \% / 99 \% / \text { low } / 3 \times \\
95 \% / 98 \% / \text { low } / 1 \times\end{array}$ \\
\hline Total Samples & 45 & 52 & 133 & 230 & & 61 & 189 & 295 & \\
\hline
\end{tabular}

(a) "Total samples" is the sum of referee samples, judgmental samples, and probabilistic samples.

(b) These statements are listed for characterization as percent confidence/diameter of circular contaminated area in feet/FNR. For clearance, they are listed as percent confidence/percent of room that does not contain detectable contamination/multiplier that indicates a judgmental sample location is three times $(3 \times)$ more likely or equally $(1 \times)$ likely to contain detectable contamination relative to a probabilistic sample location.

(c) Room is being sampled with a characterization goal.

(d) Characterization implication: 95\% confidence of detecting a single circular contaminated area of diameter $10 \mathrm{ft}$ with an FNR of $0 \%$.

(e) The 6 probabilistic samples provide $95 \%$ confidence for either detecting a single circular contaminated area of diameter $9 \mathrm{ft}$ with an FNR of $10 \%$ or detecting a single circular contaminated area of diameter $10 \mathrm{ft}$ with an FNR of $21 \%$.

(f) Area (rooms or floor) is being sampled with a clearance goal.

(g) Bayesian-based clearance implication: $95 \%$ confidence that either $97 \%$ of the room does not contain detectable contamination with a judgmental sample location being three times $(3 \times)$ more likely to contain detectable contamination relative to a probabilistic sample location, or $94 \%$ of the room does not contain detectable contamination with a judgmental sample location equally likely $(1 \times)$ to contain detectable contamination as a probabilistic sample location. All clearance numbers of samples assume that the a priori probability of contamination is low (30\%) clearance implication: $95 \%$ confidence that either $97 \%$ of the room does not contain detectable contamination with a judgmental sample location being three times $(3 \times)$ more likely to contain detectable contamination relative to a probabilistic sample location, or $94 \%$ of the room does not contain detectable contamination with a judgmental sample location equally likely $(1 \times)$ to contain detectable contamination as a probabilistic sample location. All clearance numbers of samples assume that the a priori probability of contamination is low $(30 \%)$. 
are recommended, assuming that the sampling guidelines (as listed in Sections 5.1 and 5.2) can be met. If it is determined that the guidelines cannot be achieved and fewer samples are necessary, then the numbers of samples in the minimal plan can be implemented, either as a whole, or individually for specific rooms. Figure 5.3 gives a visual display of the numbers of samples after contamination using the preferred plan for the third test event.

The numbers of samples for the third test event were based on the following information:

- The room of dissemination (Room 201 on the second floor) was assigned 3 judgmental and 3 probabilistic samples because it was assumed that contamination will be easily detected there with a $0 \%$ FNR.

- Rooms 202 and 203 near and "downwind" of the contaminant release location (Room 201) had 4 judgmental samples allocated and 9 probabilistic samples ( 6 for the minimal plan) with the ability to detect a 7-foot (9-foot for the minimal plan) diameter circular contaminated area with 95\% confidence and assuming an FNR of $10 \%$.

- Rooms further from the contaminant release location, but still expected to be contaminated (Rooms 206, 207, 210, 211), had 5 or 6 judgmental samples allocated (4 or 5 for the minimal plan) and 12 or 17 probabilistic samples (7 or 9 for the minimal plan) to detect a 5-foot or 6 -foot (7-foot or 8-foot for the minimal plan) diameter circular contaminated area with $95 \%$ confidence and assuming an FNR of $10 \%$.

- Rooms farthest from the contaminant release location that may not be contaminated (Rooms 212 and 213) were selected for clearance sampling using the Bayesian approach. This requires 8 negative judgmental samples (i.e., no detectable contamination) and 26 negative probabilistic samples to obtain $95 \%$ confidence that $97 \%$ of the area in the rooms does not contain detectable contamination, assuming that a judgmental sample location is three times more likely to contain detectable contamination than a probabilistic sample location. There is no difference in the numbers of samples between the minimal and preferred plan.

- The difference between the minimum and the preferred plans involved reducing the diameter of the contaminated area by 1 to 2 feet or looking at the increase in the allowable FNR with a constant area of contamination (10-ft diameter).

- It was decided that 5 referee samples would be taken in each sampled room. This resulted in 45 total referee samples.

The numbers of samples in Table 5.3 reflect the above information. 


\section{- Probabilistic Sample \\ - Judgmental Sample \\ - Referee Sample}

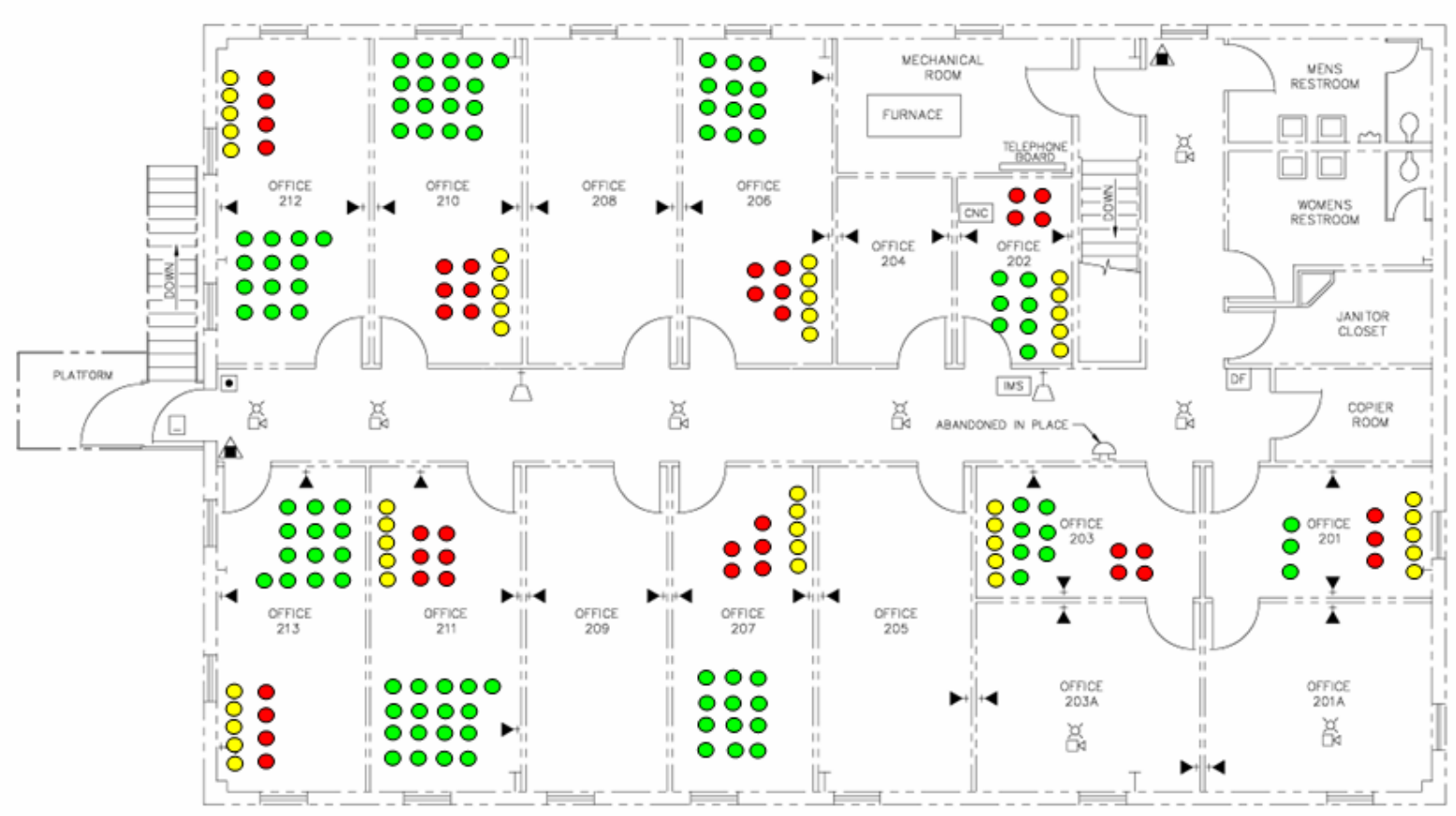

NOTE: Display is for numbers of samples per room, not sample location.

Figure 5.3. Numbers of Samples in the Preferred Plan to be Taken After Contamination During Test Event 3 on the Second Floor of the INL PBF-632 Building

\subsection{Test Event 4}

Table 5.4 summarizes the numbers of samples to be taken after contamination and after decontamination and the types of samples that will be taken (judgmental, probabilistic, and referee) during the fourth test event. This event consists of a covert dissemination in the lobby of the first floor of the INL PBF-632 building with subsequent sampling occurring on the first floor. The location of the BG contaminant release was not disclosed to the individuals who were to select the locations of the judgmental and probabilistic samples, nor was it disclosed to the sampling teams. The contaminant concentration will ideally create a gradient of contamination along much of the first floor and may be adjusted according to the results from the previous test events. The numbers of samples in the preferred plan are recommended, assuming that the sampling guidelines (as listed in Sections 5.1 and 5.2) can be met. If it is determined that the guidelines cannot be achieved and fewer samples are necessary, then the numbers of samples in the minimal plan can be implemented, either as a whole, or individually for contamination or decontamination. Figure 5.4 gives a visual display of the numbers of samples after contamination using the preferred plan for the fourth test event. It is important to note that this figure is based on the assumption that the judgmental samples will be distributed equally among the rooms. However, the location of the judgmental samples will be decided by the people tasked with determining

\section{UNCLASSIFIED}


UNCLASSIFIED

Table 5.4. Numbers of Samples for Test Event 4 on the First Floor of the INL PBF-632 Building

\begin{tabular}{|c|c|c|c|c|c|c|c|c|c|}
\hline \multirow[b]{2}{*}{ Run Information } & \multirow[b]{2}{*}{ 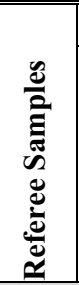 } & \multicolumn{4}{|c|}{ Minimal Plan } & \multicolumn{4}{|c|}{ Preferred Plan } \\
\hline & & 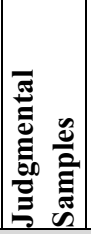 & 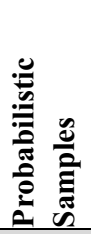 & 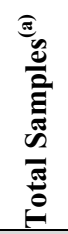 & Implication $^{(\mathbf{b})}$ & 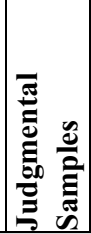 & 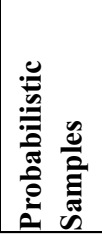 & 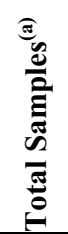 & Implication $^{(b)}$ \\
\hline \multicolumn{10}{|c|}{ Contamination } \\
\hline First floor ${ }^{(c)}$ & $36^{(\mathrm{d})}$ & 48 & 65 & 149 & $95 \% / 10 \mathrm{ft} / 10 \% \mathrm{FNR}^{(\mathrm{e})}$ & 60 & 101 & 197 & $\begin{array}{l}95 \% / 8 \mathrm{ft} / 10 \% \mathrm{FNR} \\
95 \% / 10 \mathrm{ft} / 25 \% \mathrm{FNR}^{(\mathrm{f})}\end{array}$ \\
\hline \multicolumn{10}{|c|}{ Decontamination } \\
\hline First floor ${ }^{(\mathrm{g})}$ & 0 & 15 & 60 & 75 & $\begin{array}{l}95 \% / 98 \% / 3 \times \\
95 \% / 97 \% / 1 \times^{(\mathrm{h})}\end{array}$ & 20 & 88 & 108 & $\begin{array}{l}95 \% / 99 \% / 3 \times \\
95 \% / 98 \% / 1 \times\end{array}$ \\
\hline Total Samples & 36 & 63 & 125 & 224 & & 80 & 189 & 305 & \\
\hline
\end{tabular}

(a) "Total samples" is the sum of referee samples, judgmental samples, and probabilistic samples.

(b) These statements are listed for characterization as percent confidence/diameter of contaminated area in feet/FNR. For clearance, they are listed as percent confidence/percent of room that does not contain detectable contamination/multiplier that indicates a judgmental sample location is three times $(3 \times)$ more likely or equally $(1 \times)$ likely to contain detectable contamination relative to a probabilistic sample location.

(c) Floor is being sampled with a characterization goal.

(d) The 36 referee samples correspond to 3 referee samples in each of the 12 offices.

(e) Characterization implication: $95 \%$ confidence of detecting a single contaminated area of diameter $10 \mathrm{ft}$ with an FNR of $10 \%$.

(f) The 101 probabilistic samples over the first floor provide $95 \%$ confidence for either detecting a single circular contaminated area of diameter $8 \mathrm{ft}$ with an FNR of $10 \%$ or detecting a single circular contaminated area of diameter $10 \mathrm{ft}$ with an FNR of $25 \%$.

(g) Floor is being sampled with a clearance goal.

(h) Bayesian-based clearance implication: $95 \%$ confidence that either $98 \%$ of the room does not contain detectable contamination with a judgmental sample location being three times $(3 \times)$ more likely to contain detectable contamination relative to a probabilistic sample location, or $97 \%$ of the room does not contain contamination with a judgmental sample location just as likely $(1 \times)$ to contain detectable contamination as a probabilistic sample location. All numbers of samples for clearance assume that the a priori probability of contamination is low (30\%).

these locations, and they have the freedom to distribute these across the floor as they see fit. However, it is assumed that the judgmental sample locations will be selected and entered into a specific test matrix (see Appendix B) for each room that the sampling team will use to collect all samples in the determined order (see the last paragraph of Section 3.1).

The following information was used to determine the numbers of samples for the fourth test event. Because the fourth test event involves a covert release, sampling numbers were determined for the whole first floor and not by room. This was done to reflect that in reality, it would not be possible to classify rooms by their likelihood of contamination (see Section 4.0), and thus to assign numbers of judgmental and probabilistic samples on that basis, if the contaminant release location is not known.

- For the preferred plan, it was decided to allow for 60 judgmental samples to be taken, resulting in an average of 5 per room. For the minimal plan, this was decreased to 48 judgmental samples, an

\section{UNCLASSIFIED}


average of 4 per room. However, the experts will select the locations of the judgmental samples over the first floor of the INL PBF-632 building.

- The increase in the numbers of samples for the preferred plan from the minimal plan allows for an increase of $15 \%$ in the FNR or a decrease in the diameter of the contaminated area of 2 feet (from 10 feet to 8 feet).

- Because sampling will occur in each room, the referee samples must cover the complete floor. It was decided to allow for 3 referee samples per room, resulting in 36 total referee samples.

The numbers of samples in Table 5.4 reflect the above information.

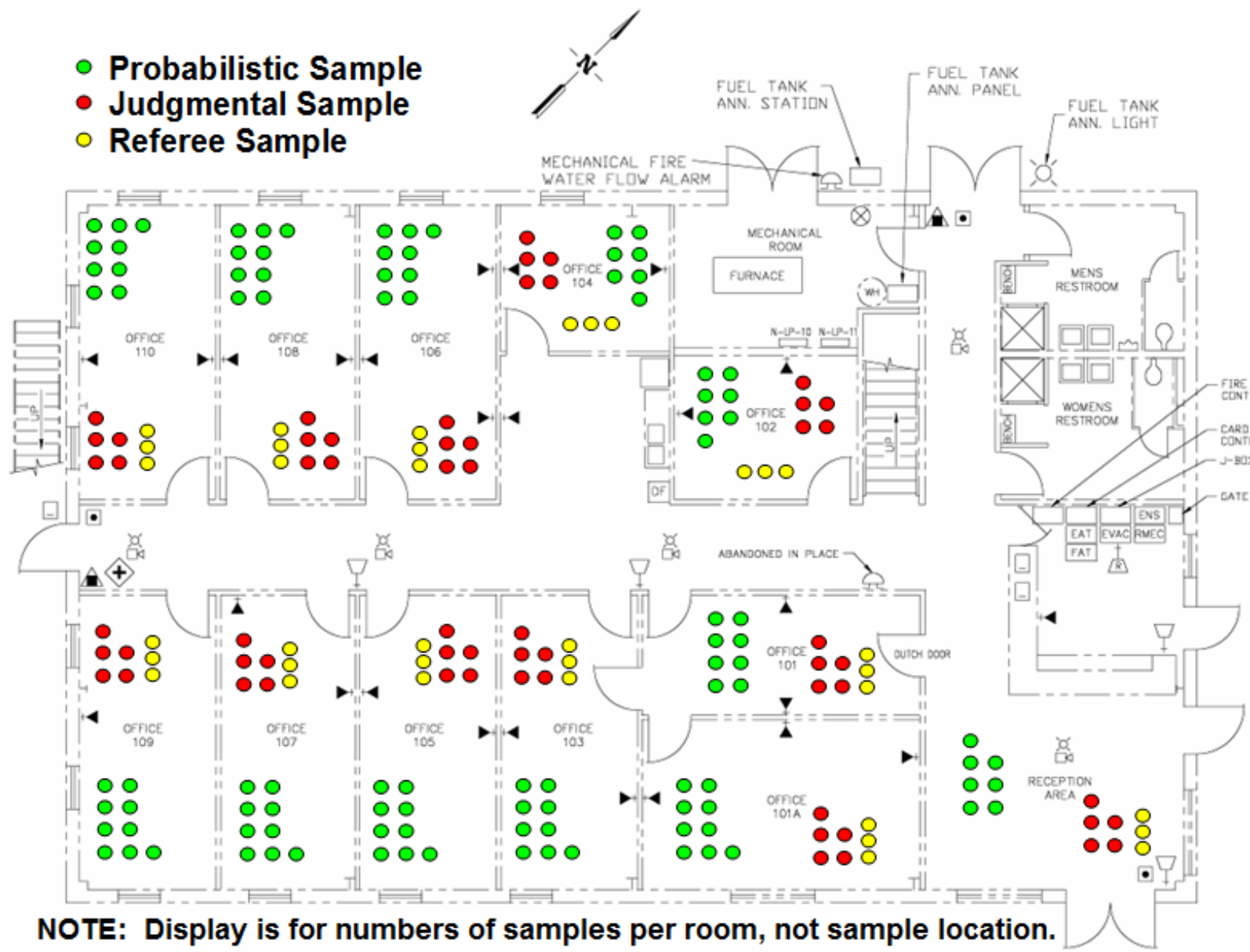

Figure 5.4. Numbers of Samples in the Preferred Plan to be Taken After Contamination During Test Event 4 on the First Floor of the INL PBF-632 Building. 


\subsection{Test Event 5}

Table 5.5 summarizes the numbers of samples to be taken after contamination and after decontamination and the types of samples that will be taken (judgmental, probabilistic, and referee) during the fifth test event. This event consists of a covert dissemination in Room 201 of the second floor of the INL PBF-632 with subsequent sampling occurring on the second floor. The location of the BG contaminant release was not disclosed to the individuals who were to select the locations of the judgmental and probabilistic samples, nor was it disclosed to the sampling teams. The contaminant concentration will be ideal to create a gradient of contamination along much of the second floor and may be adjusted according to the results from the previous test events. The numbers of samples in the preferred plan are recommended, assuming that the sampling guidelines (as listed in Sections 5.1 and 5.2)

Table 5.5. Numbers of Samples for Test Event 5 on the Second Floor of the INL PBF-632 Building

\begin{tabular}{|c|c|c|c|c|c|c|c|c|c|}
\hline \multirow[b]{2}{*}{ Run Information } & \multirow[b]{2}{*}{ 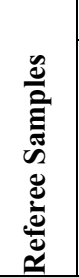 } & \multicolumn{4}{|c|}{ Minimal Plan } & \multicolumn{4}{|c|}{ Preferred Plan } \\
\hline & & 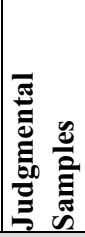 & 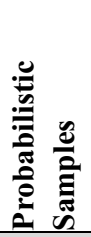 & 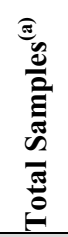 & Implication $^{(\mathbf{b})}$ & 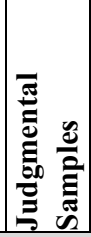 & 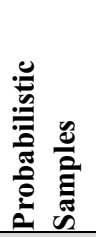 & 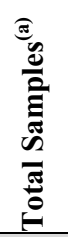 & Implication $^{(\mathbf{b})}$ \\
\hline \multicolumn{10}{|c|}{ Contamination } \\
\hline Second floor ${ }^{(c)}$ & $45^{(\mathrm{d})}$ & 52 & 65 & 162 & $95 \% / 10 \mathrm{ft} / 10 \% \mathrm{FNR}^{(\mathrm{e})}$ & 67 & 82 & 194 & $\begin{array}{l}95 \% / 9 \mathrm{ft} / 10 \% \mathrm{FNR} \\
95 \% / 10 \mathrm{ft} / 15 \% \mathrm{FNR}^{(\mathrm{f})}\end{array}$ \\
\hline \multicolumn{10}{|c|}{ Decontamination } \\
\hline Second floor ${ }^{(g)}$ & 0 & 15 & 60 & 75 & $\begin{array}{l}95 \% / 98 \% / 3 \times \\
95 \% / 97 \% / 1 \times^{(h)}\end{array}$ & 20 & 88 & 108 & $\begin{array}{l}95 \% / 99 \% / 3 \times \\
95 \% / 98 \% / 1 \times\end{array}$ \\
\hline Total Samples & 45 & 67 & 125 & 237 & & 87 & 170 & 302 & \\
\hline
\end{tabular}

(a) "Total samples" is the sum of referee samples, judgmental samples, and probabilistic samples.

(b) statements are listed for characterization as percent confidence/diameter of contaminated area in feet/FNR. For clearance, they are listed as percent confidence/percent of room that does not contain detectable contamination/multiplier that indicates a judgmental sample location is three times $(3 \times)$ more likely or equally $(1 \times)$ likely to contain detectable contamination relative to a probabilistic sample location.

(c) Floor is being sampled with a characterization goal.

(d) The 45 referee samples correspond to 3 referee samples in each of the 15 offices.

(e) Characterization implication: 95\% confidence of detecting a single circular contaminated area of diameter $10 \mathrm{ft}$ with an FNR of $10 \%$.

(f) The 82 probabilistic samples over the second floor provide $95 \%$ confidence for either detecting a single circular contaminated area of diameter $9 \mathrm{ft}$ with an FNR of $10 \%$ or detecting a single circular contaminated area of diameter $10 \mathrm{ft}$ with an FNR of $15 \%$.

(g) Floor is being sampled with a clearance goal.

(h) Bayesian-based clearance implication: $95 \%$ confidence that either $98 \%$ of the room does not contain detectable contamination with a judgmental sample location being three times $(3 \times)$ more likely to contain detectable contamination relative to a probabilistic sample location, or $97 \%$ of the room does not contain contamination with a judgmental sample location just as likely $(1 \times)$ to contain detectable contamination as a probabilistic sample location. All numbers of samples for clearance assume that the a priori probability of contamination is low $(30 \%)$. 
can be met. If it is determined that the guidelines cannot be achieved and fewer samples are necessary, then the numbers of samples in the minimal plan can be implemented, either as a whole, or individually for contamination or decontamination. Figure 5.5 gives a visual display of the numbers of samples after contamination using the preferred plan for the fifth test event. It is important to note that this figure is based on the assumption that the judgmental samples will be distributed equally among the rooms. However, the location of the judgmental samples will be decided by the people tasked with determining these locations, and they have the freedom to distribute these across the floor as they see fit. However, it is assumed that the judgmental sample locations will be selected and entered into a specific test matrix (see Appendix B) for each room that the sampling team will use to collect all samples in the determined order (see the last paragraph of Section 3.1).
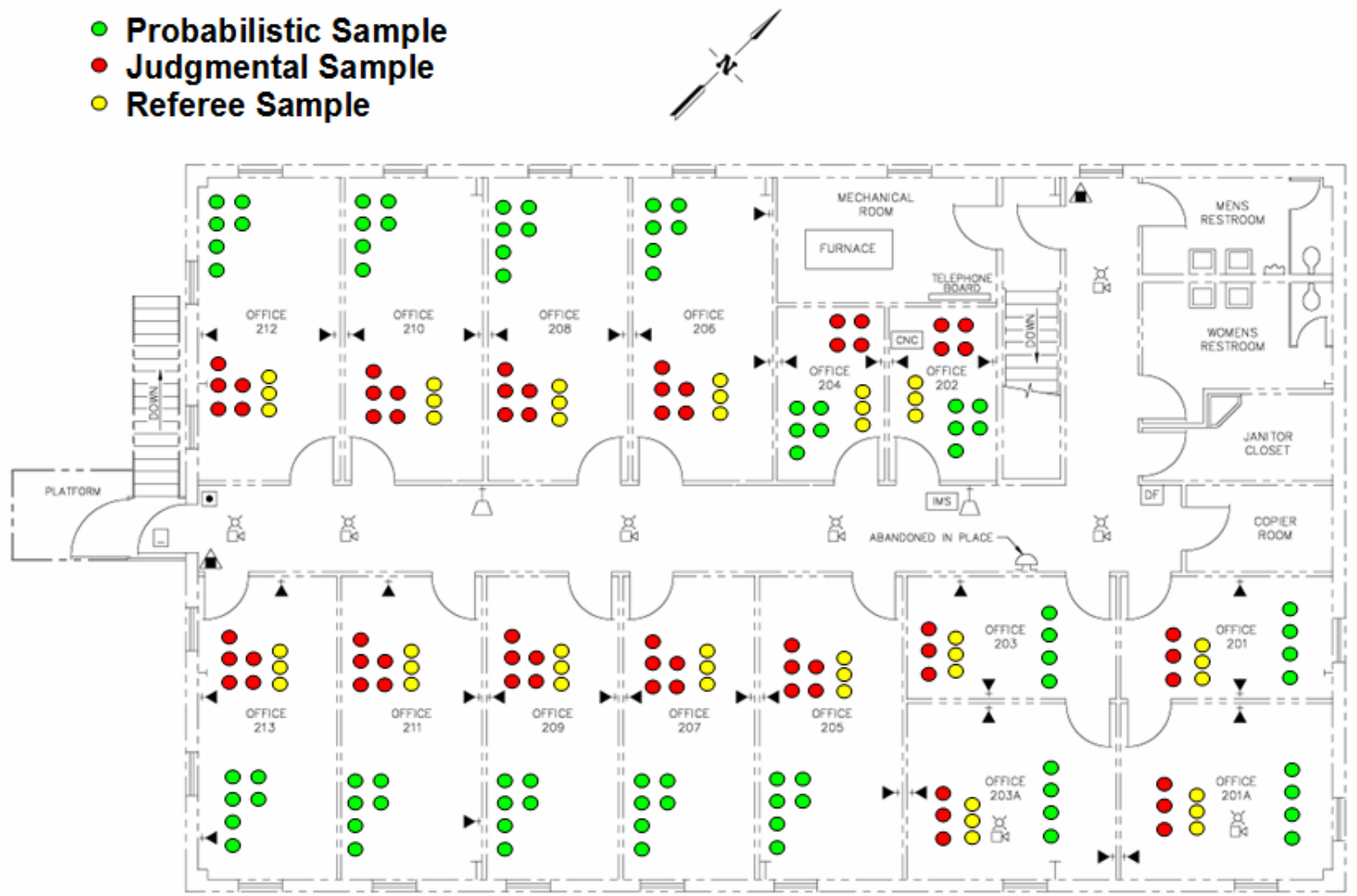

NOTE: Display is for numbers of samples per room, not sample location.

Figure 5.5. Numbers of Samples in the Preferred Plan to be Taken After Contamination During Test Event 5 on the Second Floor of the INL PBF-632 Building.

The following information was used to determine the numbers of samples for the fifth test event. Because the fifth test event involves a covert release, sampling numbers were determined for the whole second floor and not by room. This was done to reflect that in reality, it would not be possible to classify rooms by their likelihood of contamination (see Section 4.0), and thus to assign numbers of judgmental and probabilistic samples on that basis, if the contaminant release location is not known.

- For the preferred plan, it was decided to allow for 67 judgmental samples to be taken. This amounts to 5 samples in each of the nine normal sized offices $(205,206,207,208,209,210,211$, 
212, 213), 4 samples each in the smaller offices (202 and 204), and 6 samples each in the combined offices of 201/201A and 203/203A. However, the experts will select the locations of the judgmental samples over the floor.

- For the minimal plan, this was decreased to 52 judgmental samples. This amounts to 4 samples in the nine normal sized offices, 3 samples each in the smaller offices (202 and 204), and 5 samples each in the combined offices of 201/201A and 203/203A. However, the experts will select the locations of the judgmental samples over the floor.

- The increase in the numbers of samples for the preferred plan from the minimal plan allows for an increase of $5 \%$ in the FNR or a decrease in the diameter of the contaminated area of 1 foot (from 10 feet to 9 feet).

- Because sampling will occur in each room, the referee samples must cover the complete floor. It was decided to allow for 3 referee samples per room, resulting in 45 total referee samples.

The numbers of samples in Table 5.5 reflect the above information.

\subsection{Total Number of Samples}

Table 5.6 summarizes the total numbers of samples across all five test events (the ORI and the subsequent four test events). The "minimal plan" involves a total of 1119 samples, 744 samples after contamination ( $66 \%$ of the total number) and 375 samples after decontamination ( $34 \%$ of the total). The "preferred plan" involves a total of 1452 samples, 912 samples after contamination (63\% of the total) and 540 samples after decontamination (37\% of the total). There are 206 referee samples planned, which is $23 \%$ of the total number of samples after contamination for the preferred plan.

Table 5.6. Summary of the Numbers of Samples Needed for All Test Events in the INL PBF-632 Building

\begin{tabular}{|c|c|c|c|c|c|c|c|c|c|c|c|c|c|}
\hline \multirow[b]{3}{*}{ 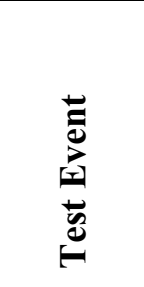 } & \multicolumn{7}{|c|}{ After Contamination } & \multicolumn{6}{|c|}{ After Decontamination } \\
\hline & \multirow[b]{2}{*}{ 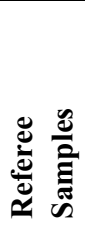 } & \multicolumn{3}{|c|}{ Minimal Plan } & \multicolumn{3}{|c|}{ Preferred Plan } & \multicolumn{3}{|c|}{ Minimal Plan } & \multicolumn{3}{|c|}{ Preferred Plan } \\
\hline & & 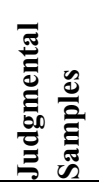 & 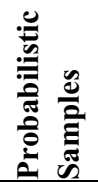 & 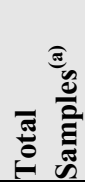 & 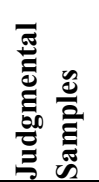 & 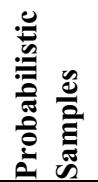 & 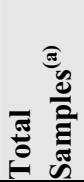 & 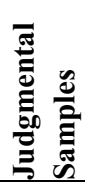 & 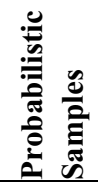 & 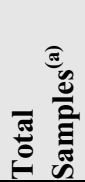 & 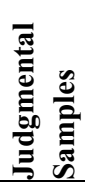 & 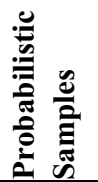 & 离 \\
\hline Event $1^{(\mathbf{b})}$ & 35 & 29 & 59 & 123 & 31 & 81 & 147 & 15 & 60 & 75 & 20 & 88 & 108 \\
\hline Event 2 & 45 & 37 & 73 & 155 & 41 & 101 & 187 & 15 & 60 & 75 & 20 & 88 & 108 \\
\hline Event 3 & 45 & 37 & 73 & 155 & 41 & 101 & 187 & 15 & 60 & 75 & 20 & 88 & 108 \\
\hline Event 4 & 36 & 48 & 65 & 149 & 60 & 101 & 197 & 15 & 60 & 75 & 20 & 88 & 108 \\
\hline Event 5 & 45 & 52 & 65 & 162 & 67 & 82 & 194 & 15 & 60 & 75 & 20 & 88 & 108 \\
\hline Total & 206 & 203 & 335 & 744 & 240 & 466 & 912 & 75 & 300 & 375 & 100 & 440 & 540 \\
\hline
\end{tabular}

(a) "Total samples" is the sum of referee samples, judgmental samples, and probabilistic samples.

(b) Event 1 is the Operational Readiness Inspection (ORI). 


\subsection{Experimental Design Details}

The details of each sample in each test should be stored in a test matrix to clearly specify the nature and location of each sample. It is not possible to complete all of the entries (e.g., the locations of judgmental and probabilistic samples, the personnel assigned to collect each sample) in such a table at this time. Some of this information cannot be filled out until the sample positions (both judgmental and probabilistic) are determined. However, a draft layout of such a table can be found in Appendix B. This table represents the samples that would be taken in the lobby during Test Event 1 (the Operational Readiness Inspection). Information about each sample could be stored within this table or a similar table or software package. The results from the culture analysis of each sample could also be stored in this table, making it an ideal source for the data needed for eventual statistical analyses of the data. 


\subsection{Experimental Design Limitations}

The scope of the INL Sample Collection Operational Test was limited because it is the first attempt to contaminate, sample, decontaminate, and re-sample a building in an operational environment. Concerns were expressed by the team planning the INL Sample Collection Operational Test that it should not attempt to do too much in a first such effort. This section discusses several ways in which the study was limited.

\subsection{Concentration Gradient}

One of the key aspects of the INL Sample Collection Operational Test is the concentration gradient. There is a possibility of three possible outcomes with the gradient, two of which are undesirable. The ideal outcome is that the gradient along the floor (first or second, depending on the test event) of the INL PBF-632 building ranges from highly contaminated in the area of contaminant release to no contamination at the other end of the building with a gradient of contamination occurring in the rooms in between. The two undesirable outcomes are that the contamination is evenly spread throughout the floor and is easily detectable in each room; or the contamination is confined to only the area of dissemination, and the other rooms are not contaminated. Because the experiment is dependent on a good gradient, it will be important to review at least some of the results (perhaps the referee samples) from the ORI (Test Event 1) before the second test event is started, so adjustments can be made if necessary. Also, it is hoped that air-flow modeling and tracer studies in the INL building before the testing will help define the characteristics necessary for a desirable gradient. However, if the gradient is not obtainable using these methods, a backup plan should be implemented that calls for multiple disseminations of varying concentrations throughout the floor to create the gradient.

\subsection{Aerosol Release}

While the experimental design for the INL Sample Collection Operational Test was designed to study the performance of probabilistic and judgmental sampling, it is important to remember that only aerosol disseminations are being studied. Therefore, all conclusions made concerning the sampling strategies should state these limitations. For example, one of the main goals of the INL Sample Collection Operational Test is to compare the ability of judgmental samples and probabilistic samples to detect contamination. It might be expected that judgmental samples ought to perform well in detecting an aerosol contaminant dispersed throughout a building via HVAC vents and return air pathways. An early draft of the experimental design description contained one test event with localized "hot spot" contamination of smaller areas of varying size in different rooms, potentially in locations that would not naturally be chosen by judgmental samples. Such a contamination scenario would have been more likely to show the advantages of larger numbers of probabilistic samples (compared to typically smaller numbers of judgmental samples) in detecting smaller areas of contamination in less likely locations. However, this contamination scenario was not included in a test event of the final experimental design because of issues about how to contaminate smaller areas with viable contaminant spores.

\subsection{Probabilistic Sampling of Horizontal Surfaces}

All probabilistic sampling for the experimental design of the INL Sample Collection Operational Test has been designed to sample only horizontal surfaces. A decision will need to be made if a sample

UNCLASSIFIED 
location has more than one possible horizontal surface to sample from. It may be decided to sample the highest vertical point of the sampling area without sampling anything on the ceiling. For example, if the vertical extension of a sample location has the floor, a desktop, and a ceiling vent, it will be decided to sample the desktop. Future versions of the VSP software (Matzke et al. 2007) will include the capability to add furniture to the probabilistic sampling area, so future experiments could be designed to take advantage of this feature. The VSP software already has the capability to sample from floors, walls, and ceiling of a room or building by "laying out" the room/building and then selecting "horizontal" samples from the "laid out" room/building. However, that capability requires larger numbers of samples to cover the increased surface area, and it was judged sufficient for the INL exercise to sample only horizontal surfaces on which aerosol-disseminated contaminant could settle.

\subsection{Limited Knowledge of Information Required to Calculate Numbers of Samples}

Many assumptions are necessary in making the various statistical confidence statements. These assumptions include the size of the contaminated area, the FNR, how much more likely a judgmental sample location is to contain detectable contamination relative to a probabilistic sample location, and the a priori probability of an area being contaminated. A limitation of the experimental design for the INL Sample Collection Operational Test is that previous research has not fully defined specific values for each of these assumptions. Reasonable ranges for each assumption were created using expertise from subject matter experts. Multiple implication statements were made with each number of samples considered. These implication statements look across the expected range of values for each assumption. These investigations were performed to minimize the limitation of not knowing the actual values of quantities involved in the assumptions.

\subsection{Comparing Sample-Collection Methods}

In general, the sample-collection methods to be used in the INL Sample Collection Operational Test (swab, wipe, vacuum) are each used in unique sampling situations such that there is little opportunity to compare results from one sampling method to results from another. In early planning of the experimental design, the statistical comparison of results obtained from side-by-side wipe and vacuum samples of nonporous surfaces was considered. This testing would have also included side-by-side sampling with the same sampling methods as a way of quantifying the variation in contamination and uncertainty in sampling and analytical processes. However, it was ultimately decided that this sort of investigation was not feasible because of 1) the pilot-study nature of the investigation and 2) the limitations on the numbers of samples that could be collected and analyzed within the available time for testing at the INL PBF-632 building.

\subsection{Comparing Judgmental and Probabilistic Samples to Referee Samples}

The experimental design was not constructed to enable direct comparison of results from judgmental and probabilistic samples to those from referee samples. The pattern of settling of the BG contaminant on surfaces in a given room of the INL PBF-632 building is expected to vary considerably within a room and from room to room. Hence, results from referee samples cannot be directly compared to results from judgmental and probabilistic samples because of the likelihood that locations where referee samples are

\section{UNCLASSIFIED}


collected will be contaminated to different extents than the locations where judgmental and probabilistic samples are collected. However, it is possible to use referee samples to give a general indication of the extent to which a given room was contaminated and to assess the relative levels of contamination from room to room. Thus, the referee samples will be useful in assessing how well an ideal gradient across each floor of the INL PBF-632 building (see Section 2.0) was achieved.

\subsection{Numbers of Test Events and Numbers of Samples}

Because of the period of time available for testing at the INL PBF-632 building, as well as the time and funding available for sample collection and analysis, the number of test events and the total number of samples per test event were limited. These limitations ultimately impact the ability to perform statistical analyses of the test data. However, the limitations on numbers of samples were accommodated by assigning fewer samples to be collected from rooms closer to the contaminant release locations (for overt Test Events 1, 2, and 3).

\subsection{Limitations in VSP Software}

Although the VSP software has had additional capabilities added in new versions over its 10-year history, it still has some limitations that impacted the calculation of numbers of samples associated with the experimental design for the INL Sample Collection Operational Test. The VSP limitations include:

- VSP creates probabilistic sampling plans that are based on the assumption that the probability of contamination is the same for each sample location.

- VSP can only account for the surface area covered by a sample when a $0 \%$ FNR is assumed. In that case, only one magnitude of surface area is allowed. If a positive FNR is specified, then VSP currently assumes "point samples." Not accounting for differences in surface area sampled is an unrealistic assumption when different sampling methods (such as swab, wipe, and vacuum) are used. Assuming point samples in the FNR $>0$ case may lead to larger numbers of samples than would otherwise be needed.

- The Bayesian sampling approach implemented in VSP for clearing uncontaminated or decontaminated areas currently only addresses the case where FNR $=0$. If the FNR is actually greater than zero, then the numbers of samples calculated for the FNR $=0$ case provide less protection. It also results in clearance statements of the form "X\% confidence that at least $\mathrm{Y} \%$ of the area does not contain detectable contamination," rather than the more desirable clearance statement " $\mathrm{X} \%$ confidence that at least $\mathrm{Y} \%$ of an area is uncontaminated."

\subsection{Conclusions Regarding Study Limitations}

The limitations identified and described in the preceding sections are not so severe that they compromise the ability to meet the objectives of the INL Sample Collection Operational Test. Rather, they should be considered in any future studies that extend the work of this first-of-kind study. 


\subsection{Summary and Recommendations for Any Future Studies}

Section 7.1 summarizes the work performed to generate the experimental design presented in this report for the INL Sample Collection Operational Test. Section 7.2 makes recommendations for any future studies that may be conducted.

\subsection{Summary}

This report documents the experimental design (including numbers of samples) developed for the INL Sample Collection Operational Test.

Two objectives were developed to guide the construction of the experimental design for the INL Sample Collection Operational Test. The first objective is to assess the relative abilities of judgmental and probabilistic sampling strategies to detect contamination (or the extent of contamination) in individual rooms or on a whole floor of the INL PBF-632 building. The second objective is to assess the use of traditional probabilistic sampling strategies and a Bayesian sampling strategy (which combines judgmental and probabilistic samples) to make clearance statements of the form " $\mathrm{X} \%$ confidence that at least $\mathrm{Y} \%$ of a room (or floor of the building) does not contain detectable contamination." These are referred to as $\mathrm{X} \% / \mathrm{Y} \%$ clearance statements. ${ }^{(a)}$

The experimental design described in this report includes five test events, the first of which is an ORI. The test events 1) vary the floor of the building on which the contaminant will be released, 2) provide for varying or adjusting the concentration of contaminant released to obtain the ideal concentration gradient across a floor of the building, and 3) investigate overt as well as covert release of contaminants (i.e., the responders either know or do not know the release point of the contaminant). The ideal contaminant gradient would have high concentrations of contaminant in rooms near the release point, with concentrations decreasing toward zero (i.e., not contaminated) in rooms at the opposite end of the building floor. Such a gradient is ideal because it would provide a range of contamination levels to challenge the sampling, sample extraction, and analytical methods.

Test Event 1 is an Operational Readiness Inspection to confirm that the whole testing process is ready for testing and to make adjustments if needed. Test Events 2 and 3 are overt scenarios in which the locations of contaminant release are known to those selecting the specific locations of judgmental and probabilistic samples and to the sampling teams. Test Events 4 and 5 are covert scenarios in which the locations of contaminant release are not known to these participants.

For each of the five test events, the specified floor of the INL PBF-632 building will be contaminated with BG. The BG contaminant will be disseminated from a point-release device located in the room specified in the experimental design for each test event. Then judgmental and probabilistic samples will be collected according to the pre-specified sampling plan. Judgmental samples will be selected based on professional judgment and prior information. Probabilistic samples will be selected with a random aspect and in sufficient numbers to provide desired confidence for detecting contamination or clearing

(a) The $\mathrm{X} \% / \mathrm{Y} \%$ clearance statements are based on the statistical theory for $\mathrm{X} \% / \mathrm{Y} \%$ tolerance intervals (see Hahn and Meeker 1991).

\section{UNCLASSIFIED}


uncontaminated (or decontaminated) areas. Following sample collection for a given test event, the INL PBF-632 building will be decontaminated using $\mathrm{Cl}_{2} \mathrm{O}$ gas.

For possibly contaminated areas (which may be individual rooms or the whole floor of the INL PBF632 building), the numbers of probabilistic samples were chosen to provide $95 \%$ confidence of detecting contaminated areas of specified sizes. The numbers of judgmental samples were chosen based on guidance from experts in judgmental sampling. For rooms that may be uncontaminated following a contamination event, or for whole floors after decontamination, the numbers of judgmental and probabilistic samples were chosen using a Bayesian approach that combines judgmental and probabilistic samples to make a clearance statement of the form " $95 \%$ confidence that at least $99 \%$ of the room (or floor) does not contain detectable contamination." The experimental design also provides for making $95 \% / Y \%$ clearance statements using only probabilistic samples, where $\mathrm{Y}<99$.

For each test event, the numbers of samples were selected for a minimal plan (containing fewer samples) and a preferred plan (containing more samples). The preferred plan is recommended over the minimal plan for the following reasons. The larger numbers of characterization samples increase the probability of detecting contamination if 1) it occurs in a smaller area, and/or 2) the FNR is higher. The larger numbers of clearance samples 1) increase the percentage of an area (floor or rooms) that can be declared not contaminated with a given confidence, and/or 2) protect against judgmental sample locations being equally likely $(1 \times)$ to contain detectable contamination as probabilistic sample locations, versus the assumption that judgmental sample locations are three times as likely $(3 \times)$ to contain detectable contamination as probabilistic sample locations in the Bayesian approach to clearance sampling.

The preferred plan specifies a total of 1452 samples, 912 after contamination and 540 after decontamination. The minimal plan specifies a total of 1119 samples, 744 after contamination and 375 after decontamination. If the advantages of the "after decontamination" portion of the preferred plan are judged to be small compared to the "after decontamination" portion of the minimal plan, it is an option to combine the "after contamination" portion of the preferred plan (912 samples) with the "after decontamination" portion of the minimal plan (375 samples). This hybrid plan would involve a total of 1287 samples.

There were some limitations of the experimental design for the INL Sample Collection Test, which are briefly summarized below (see Section 6 for more detained discussions).

- Concentration Gradient: All five test events relied on releasing the contaminant as an aerosol from a room at one end of either the first or second floor of the INL PBF-632 building. An ideal distribution gradient would vary from highly contaminated in the vicinity of the contaminantrelease location to uncontaminated at locations farthest on a given floor from the release location. If a gradient close to ideal is not achieved, it would limit the ability to achieve some of the objectives.

- Aerosol Release: Considering only aerosol releases meets the objectives of this particular study, but limits the ability to make conclusions about other types of contaminant releases. In particular, it limits the ability to compare probabilistic and judgmental samples when contamination occurs in "hot spots" (i.e., smaller areas of contamination surrounded by uncontaminated, or very lowly contaminated, areas).

\section{UNCLASSIFIED}


- Probabilistic Sampling of Horizontal Surfaces: The numbers of probabilistic samples for the experimental design were chosen assuming that only horizontal surfaces would be sampled. This reduced the number of samples required to detect contamination or clear an area, which was required to meet limitations on the time and personnel available for sampling. Sampling only horizontal surfaces is a limitation of the study to the extent that non-horizontal surfaces could be contaminated with a different chance than horizontal surfaces. This possibility was deemed unlikely for the aerosol dissemination method to be used.

- $\quad$ Limited Knowledge of Information Required to Calculate Numbers of Samples: Several input parameters are necessary to calculate the numbers of probabilistic samples needed to detect contamination or to clear an uncontaminated (or decontaminated) area. These include the size of the contaminated areas to be detected, the FNR, how much more likely it is that a judgmental sample location contains detectable contamination compared to a probabilistic sample location (required in the Bayesian approach), and the a priori probability of an area being contaminated. Note that the FNR includes all "inefficiencies" in sample collection, sample recovery, and analytical methods. Because good estimates of these input parameters were not available, it was necessary to perform calculations over a range of parameter values judged to be reasonable.

- Comparing Sample Collection Methods: The experimental design does not provide for statistically comparing sample collection methods (swab, wipe, vacuum). It was considered possible to compare wipe and vacuum methods for non-porous surfaces, but doing so was considered a lower priority given the number of additional samples that would have been required. Also considered was the collection of some side-by-side samples using the same sampling method as a way to quantify the combined uncertainties in "nearby sampling", sample extraction, and analytical. This was also considered a lower priority given the additional number of samples that would have been required.

- Comparing Judgmental and Probabilistic Samples to Referee Samples: The experimental design was not constructed to enable direct comparison of results from judgmental and probabilistic samples to those from referee samples. Results from referee samples cannot be directly compared to results from judgmental and probabilistic samples because it is likely that referee sample locations will be contaminated to different extents than judgmental and probabilistic sample locations. However, it is possible to use referee samples to obtain a general indication of the extent to which a given room was contaminated and to assess the relative levels of contamination from room to room.

- Numbers of Test Events and Numbers of Samples: Because of the period of time available for testing at the INL PBF-632 building as well as the time and funding available for sample collection and analysis, the number of test events and the total number of samples per test event were limited. These limitations ultimately impact the ability to perform statistical analyses of the test data. However, the limitations on numbers of samples were accommodated by assigning fewer samples to be collected from rooms closer to the contaminant release locations (for overt Test Events 1, 2, and 3).

- Limitations in VSP Software: The VSP software (Matzke et al. 2007) was well suited for use in calculating numbers of samples for characterization and clearance in the INL Sample Collection Operational Test. However, VSP has some limitations, as follows.

\section{UNCLASSIFIED}


1) VSP creates probabilistic sampling designs that are based on the assumption that the probability of contamination is the same for each sample location.

2) The VSP does not provide for different sampling methods covering different surface areas, such as occurs with swab, wipe, and vacuum samples.

3) When the FNR is greater than zero, VSP assumes point samples (with negligible surface area), which yields larger numbers of samples than would otherwise be required.

4) The Bayesian sampling approach implemented in VSP for clearing uncontaminated or decontaminated areas currently only addresses the case where FNR $=0$. If the FNR is actually greater than zero, then the numbers of samples calculated provide less protection. This also results in clearance statements of the form " $\mathrm{X} \%$ confidence that at least $\mathrm{Y} \%$ of the area does not contain detectable contamination," rather than the more desirable statement " $\mathrm{X} \%$ confidence that at least $\mathrm{Y} \%$ of an area is uncontaminated."

It is important to note that these limitations are not so severe that they compromise the ability to meet the objectives of this study. Hence, the experimental design and numbers of referee, judgmental, and probabilistic samples specified in this report provide a good statistical foundation for achieving the objectives of the INL Sample Collection Operational Test.

\subsection{Recommendations for any Future Studies}

The following specific recommendations are made for any future testing that may be conducted at the INL PBF-632 building or other real-world facilities.

- Other Contamination Scenarios: Other contamination scenarios that may be possible in a realworld environment should be investigated in any future work. For example, "hot-spot" scenarios in which contaminated areas are surrounded by uncontaminated areas should be tested using a range of sizes for contaminated areas. This is a fundamentally different type of contamination scenario than the aerosol release scenario considered in this report. Hot-spot contamination is harder to detect and would more readily show the advantages of probabilistic sampling over judgmental sampling, especially if the hot spots of contamination are located (e.g., placed by a terrorist or disgruntled employee) in places that are not typically sampled by judgmental sampling.

- $\quad$ Contributors to False Negative Rate (FNR): To address congressional and GAO concerns (see Section 1.1) about making defensible conclusions based on negative results, it is extremely important to have good estimates of FNRs. The FNR is likely to be different for each sample collection, recovery, and analytical method combination. The FNR will also depend on the level of contamination - the FNR increases as the level of contamination decreases.

- Information to Calculate Numbers of Samples: For any future studies, better estimates are needed for input parameters used in calculating the required numbers of samples. In addition to the FNR discussed in the previous bullet, other parameters include the size of contaminated areas to be detected, how much more likely a judgmental sample location is to be contaminated than a probabilistic sample location, and the a priori probability that an area of interest contains detectable contamination. The last two items are required in the Bayesian approach that combines judgmental and probabilistic sampling.

\section{UNCLASSIFIED}


In general, it is also recommended that statisticians be involved in planning, experimental and sampling design, and data analyses of future validation work such as is described in the Interagency

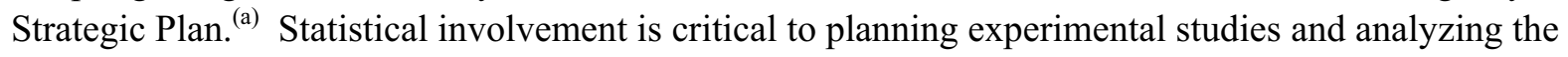
data that result from them. It helps ensure that resources are used efficiently, testing and analytical uncertainties are accounted for, and that conclusions can be made with the desired statistical confidence. Statistical planning combined with proper statistical analysis of data leads to defensible conclusions that satisfy the research objectives.

(a) Interagency Strategic Plan for Validation of Environmental Sampling Methods Used in Detection and Cleanup of B. Anthracis Contamination in Facilities, June 29, 2007. 


\subsection{References}

Bowen MW and CA Bennett. 1988. Statistical Methods for Nuclear Material Management. NUREG/CR-4604, U.S. Nuclear Regulatory Commission, Washington, DC.

Government Accountability Office (GAO). 2005a. Anthrax Detection: Agencies Need to Validate Sampling Activities in Order to Increase Confidence in Negative Results (Report to the Chairman, Subcommittee on National Security, Emerging Threats, and International Relations, House Committee on Government Reform, House of Representatives). GAO-05-251, United States Government Accountability Office, Washington, DC, March 2005.

Government Accountability Office (GAO). 2005b. Anthrax Detection: Agencies Need to Validate Sampling Activities in Order to Increase Confidence in Negative Results, (Testimony before the Chairman, Subcommittee on National Security, Emerging Threats, and International Relations, House Committee on Government Reform, House of Representatives). GAO-05-493T, United States Government Accountability Office, Washington, DC, April 2005.

Gilbert RO. 1987. Statistical Methods for Environmental Pollution Monitoring. Van Nostrand Reinhold, New York, NY.

Hahn GJ and WQ Meeker. 1991. Statistical Intervals, A Guide to Practitioners. John Wiley \& Sons, Inc., New York, NY.

Matzke BD, JE Wilson, LL Nuffer, ST Dowson, RO Gilbert, NL Hassig, JE Hathaway, CJ Murray, LH Sego, BA Pulsipher, B Roberts, and S McKenna. 2007. Visual Sample Plan Version 5.0 User's Guide. PNNL-16939, Pacific Northwest National Laboratory, Richland, WA. Available at:

http://dqo.pnl.gov/vsp/pnnl16939.pdf.

Sego LH and JE Wilson. 2007. Accounting for False Negatives in Hotspot Detection. PNNL16812, Pacific Northwest National Laboratory, Richland, WA.

Sego LH, KK Anderson, and BD Matzke. 2007. An Environmental Sampling Model for Combining Judgment and Randomly Placed Samples. PNNL-16636, Pacific Northwest National Laboratory, Richland, WA. 


\section{Appendix A: Numbers of Probabilistic Samples}

Figures A.1 through A.12 display the numbers of probabilistic samples calculated for confidence levels ranging from $50 \%$ to $95 \%$, circular contaminated areas ranging from 1 foot to 10 feet in diameter, and false-negative rates ranging from $0 \%$ to $50 \%$. Only combinations of these factors that result in 100 or less samples for a typical room in the INL PBF-632 building or 500 or less samples for a single floor are displayed. Odd-numbered figures display numbers of samples for a typical room, while even numbered figures display numbers of samples for a single floor. 


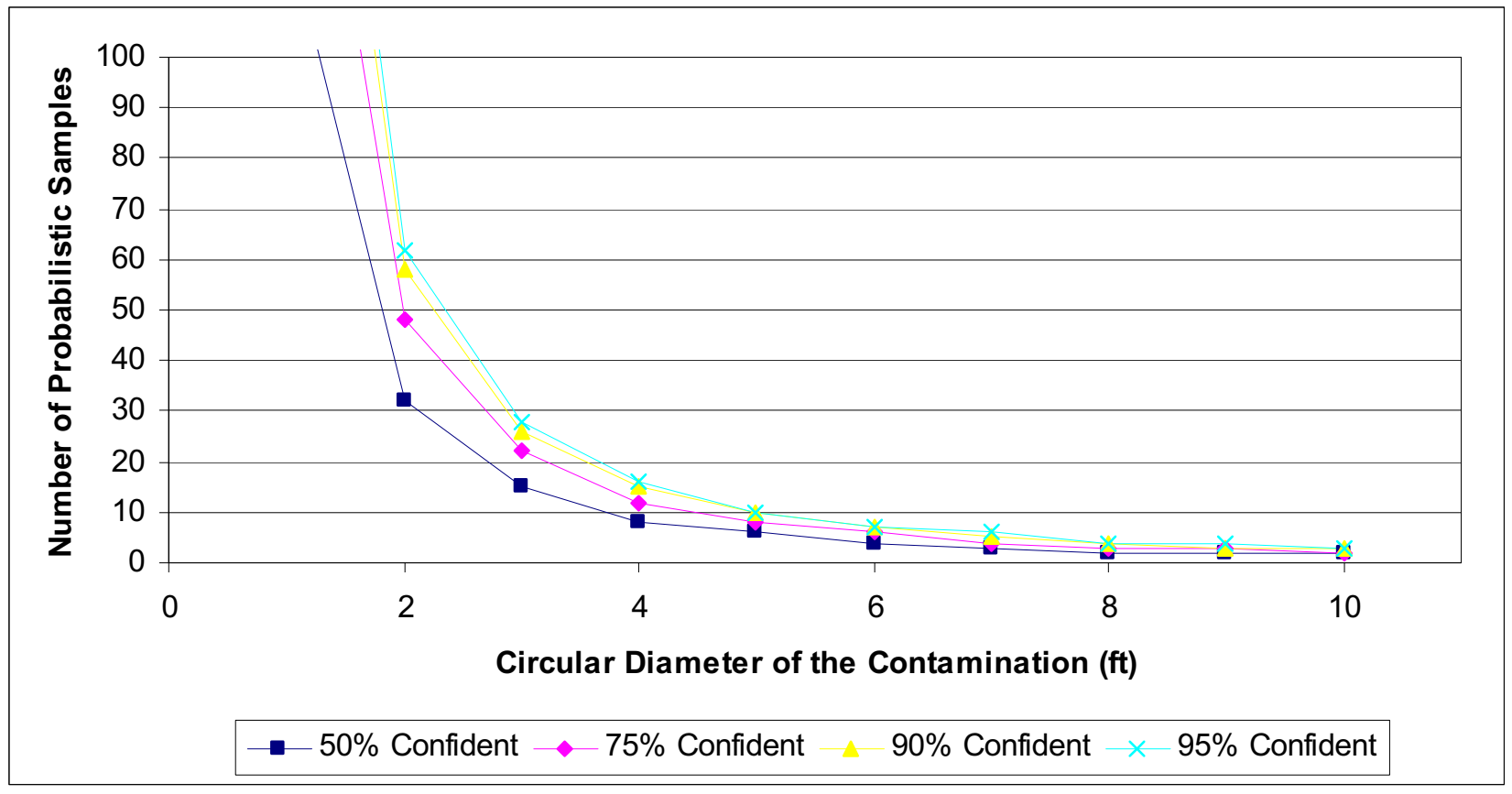

Figure A.1. Number of Probabilistic Samples Required to Detect with $0 \%$ False Negative Rate a Circular Contaminated Area of a Given Diameter with a Given Confidence (represented by the colored lines) within a Typical Room of the INL PBF-632 Building

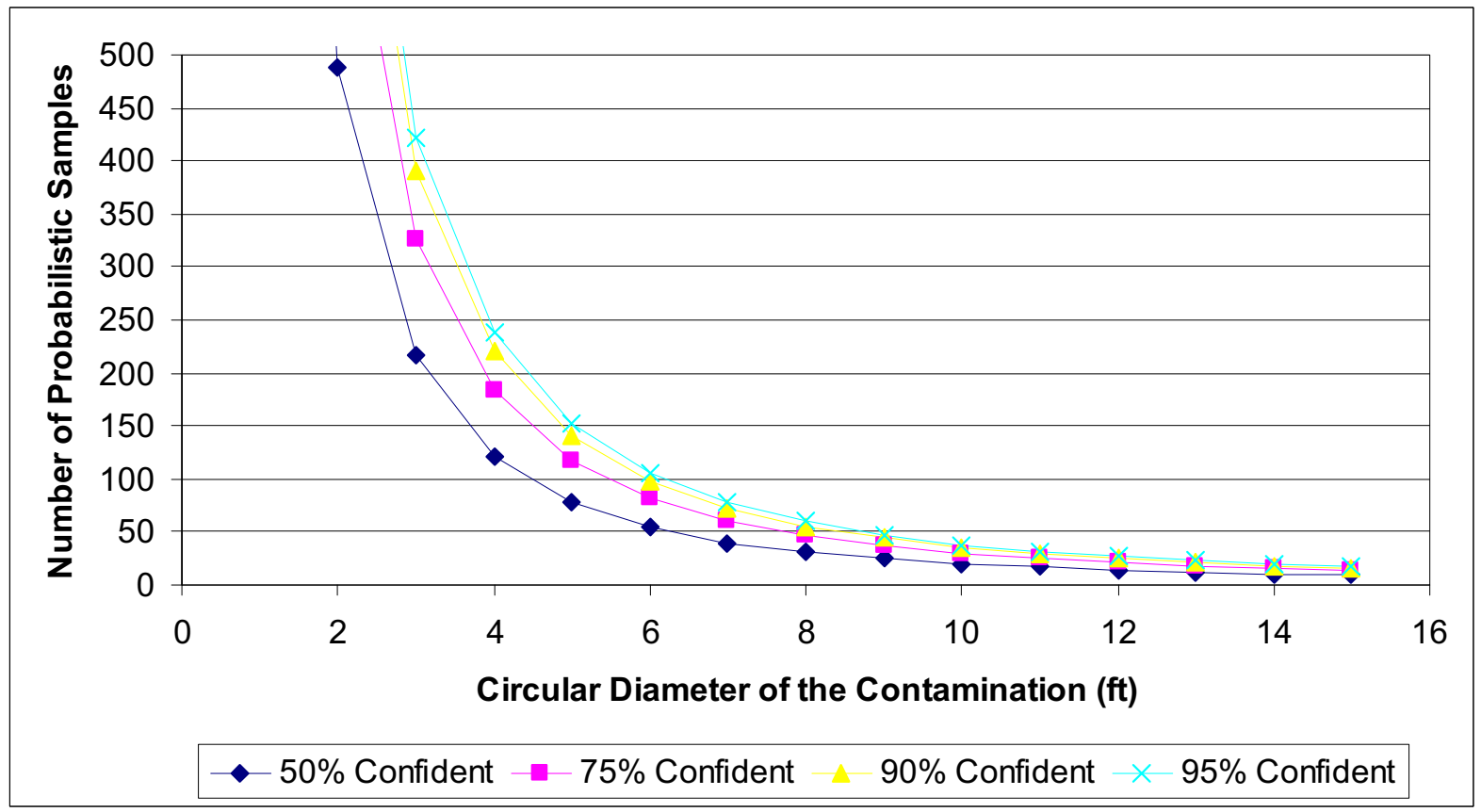

Figure A.2. Number of Probabilistic Samples Required to Detect with 0\% False Negative Rate a Circular Contaminated Area of a Given Diameter with a Given Confidence (represented by the colored lines) within a Single Floor of the INL PBF-632 Building

\section{UNCLASSIFIED}




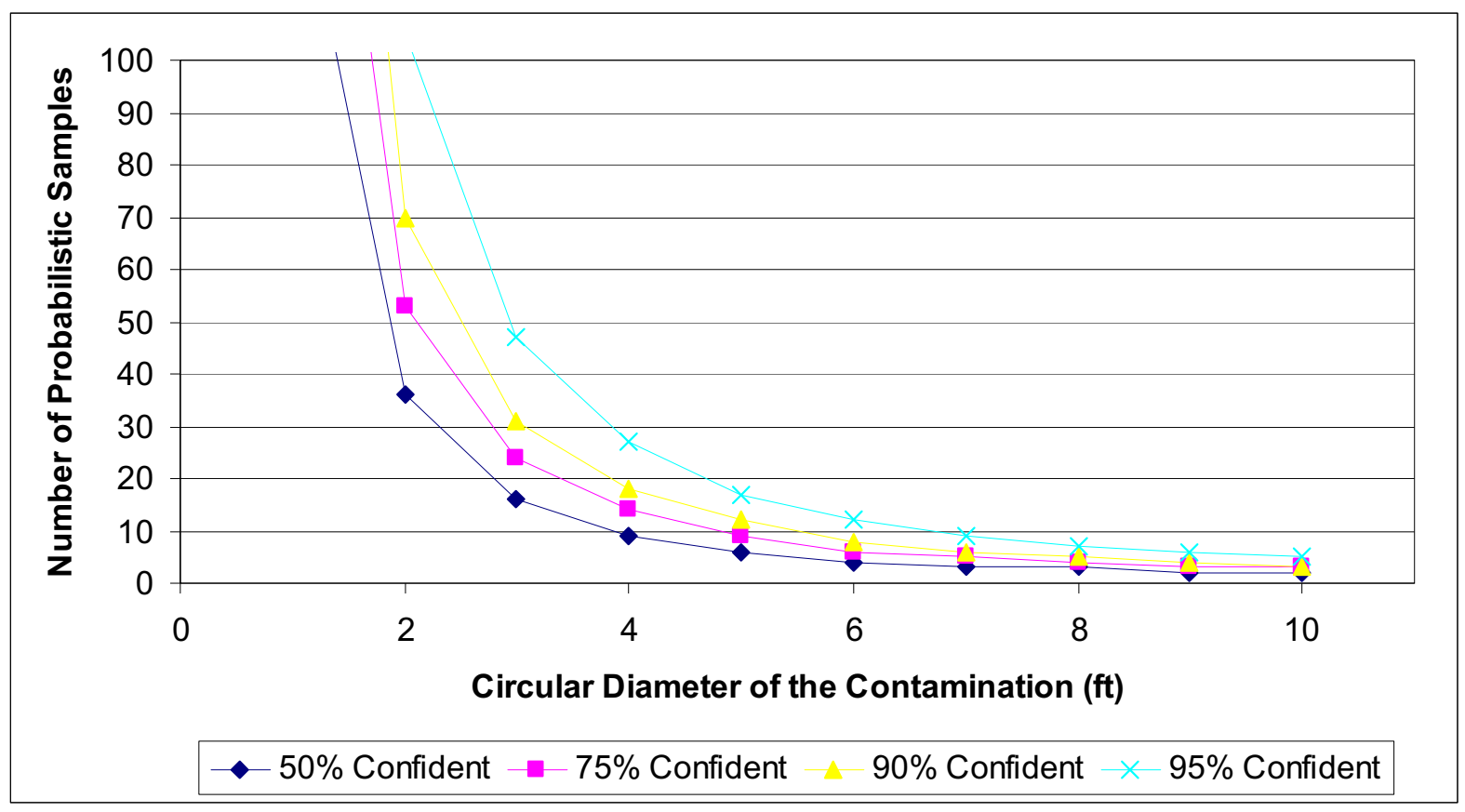

Figure A.3. Number of Probabilistic Samples Required to Detect with $10 \%$ False Negative Rate a Circular Contaminated Area of a Given Diameter with a Given Confidence (represented by the colored lines) within a Typical Room of the INL PBF-632 Building

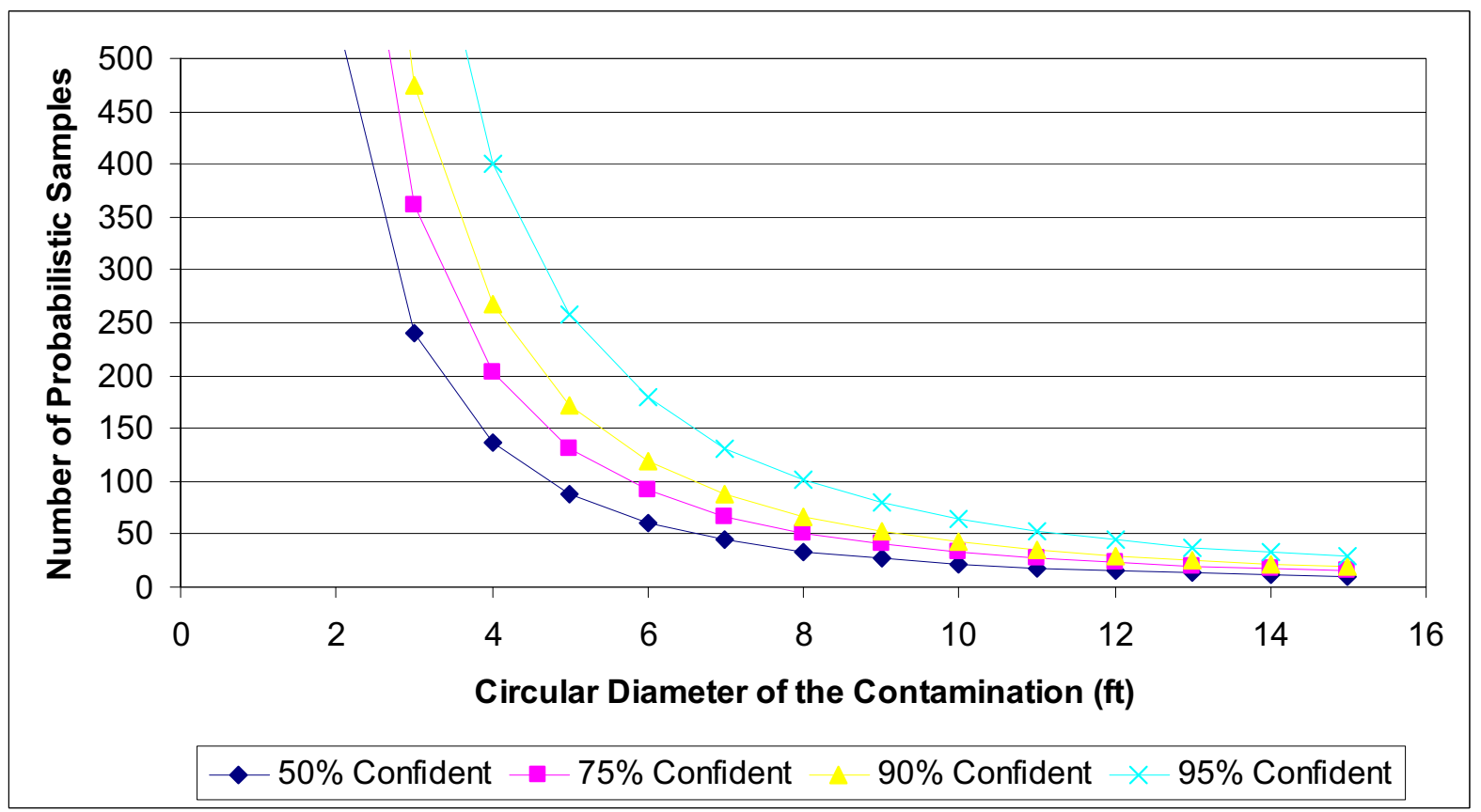

Figure A.4. Number of Probabilistic Samples Required to Detect with $10 \%$ False Negative Rate a Circular Contaminated Area of a Given Diameter with a Given Confidence (represented by the colored lines) within a Single Floor of the INL PBF-632 Building 


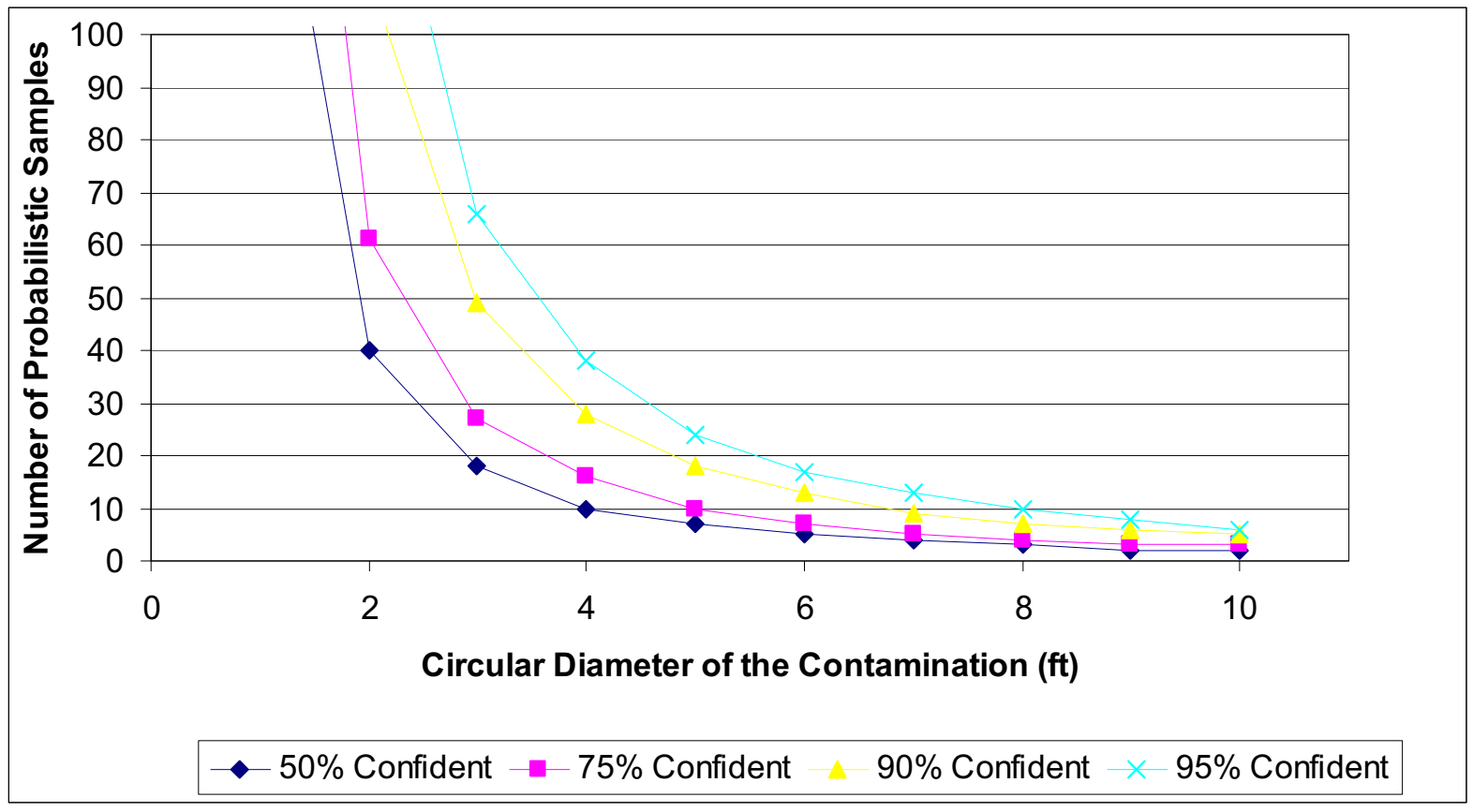

Figure A.5. Number of Probabilistic Samples Required to Detect with $20 \%$ False Negative Rate a Circular Contaminated Area of a Given Diameter with a Given Confidence (represented by the colored lines) within a Typical Room of the INL PBF-632 Building

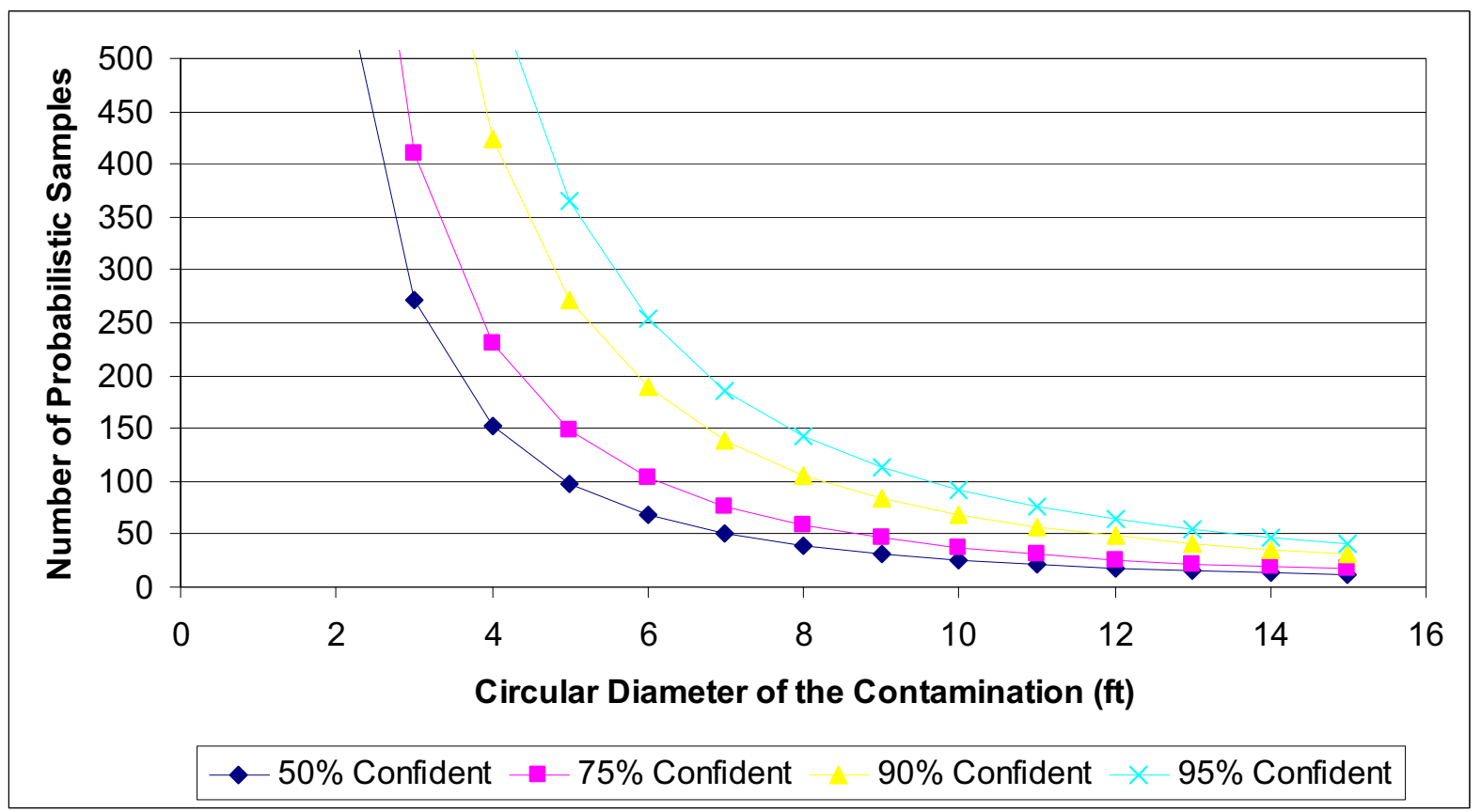

Figure A.6. Number of Probabilistic Samples Required to Detect with 20\% False Negative Rate a Circular Contaminated Area of a Given Diameter with a Given Confidence (represented by the colored lines) within a Single Floor of the INL PBF-632 Building 


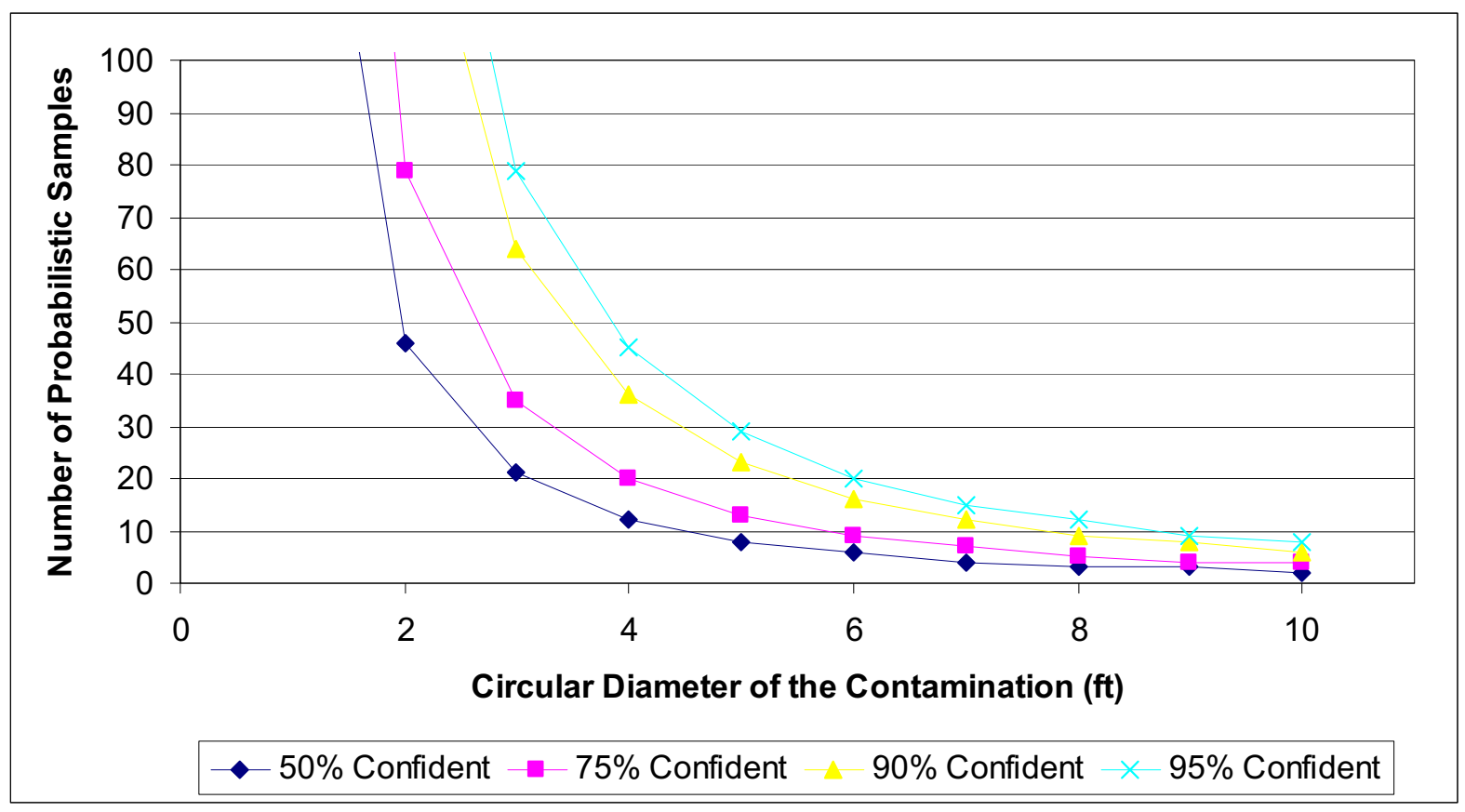

Figure A.7. Number of Probabilistic Samples Required to Detect with $30 \%$ False Negative Rate a Circular Contaminated Area of a Given Diameter with a Given Confidence (represented by the colored lines) within a Typical Room of the INL PBF-632 Building

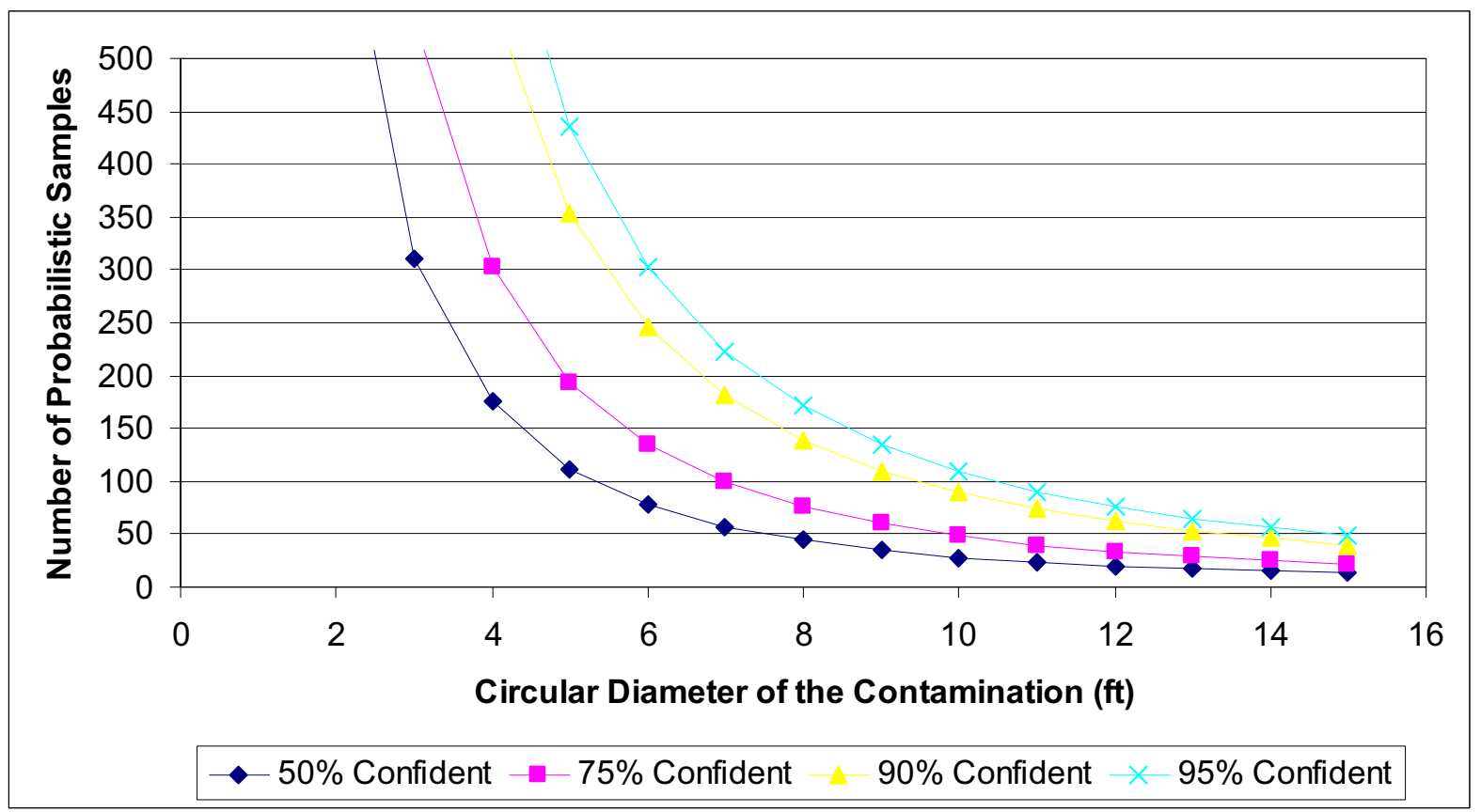

Figure A.8. Number of Probabilistic Samples Required to Detect with 30\% False Negative Rate a Circular Contaminated Area of a Given Diameter with a Given Confidence (represented by the colored lines) within a Single Floor of the INL PBF-632 Building 


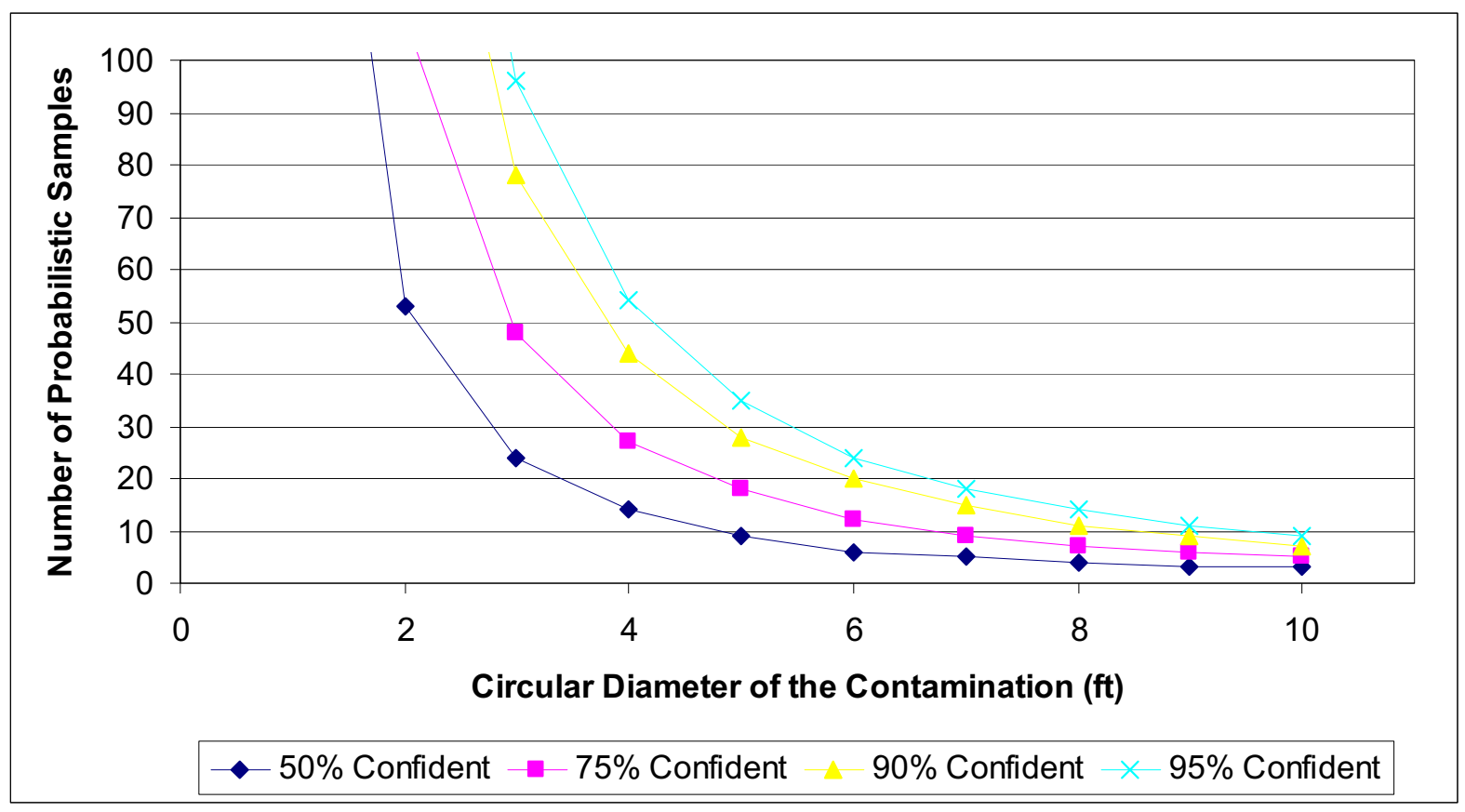

Figure A.9. Number of Probabilistic Samples Required to Detect with $40 \%$ False Negative Rate a Circular Contaminated Area of a Given Diameter with a Given Confidence (represented by the colored lines) within a Typical Room of the INL PBF-632 Building

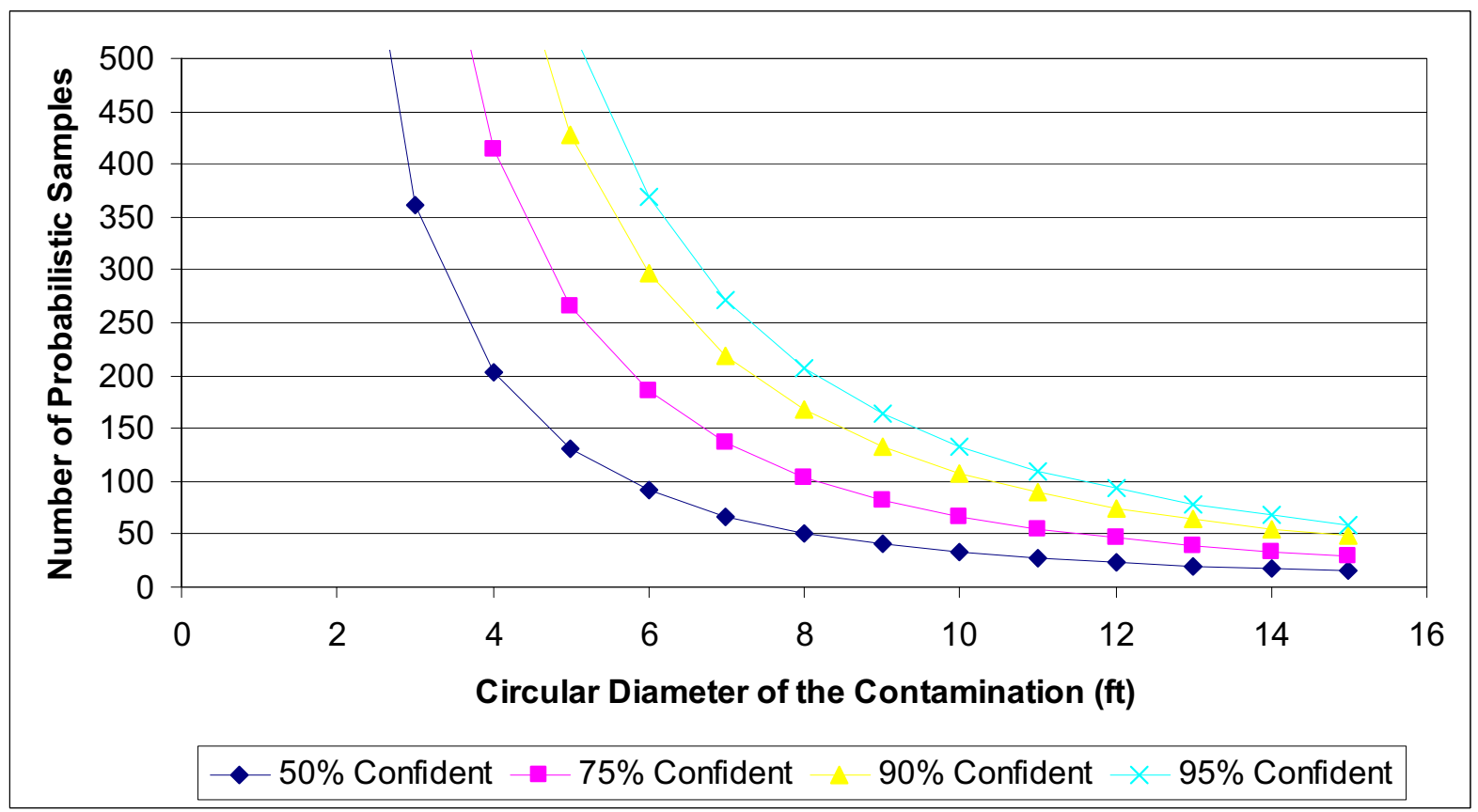

Figure A.10. Number of Probabilistic Samples Required to Detect with 40\% False Negative Rate a Circular Contaminated Area of a Given Diameter with a Given Confidence (represented by the colored lines) within a Single Floor of the INL PBF-632 Building 


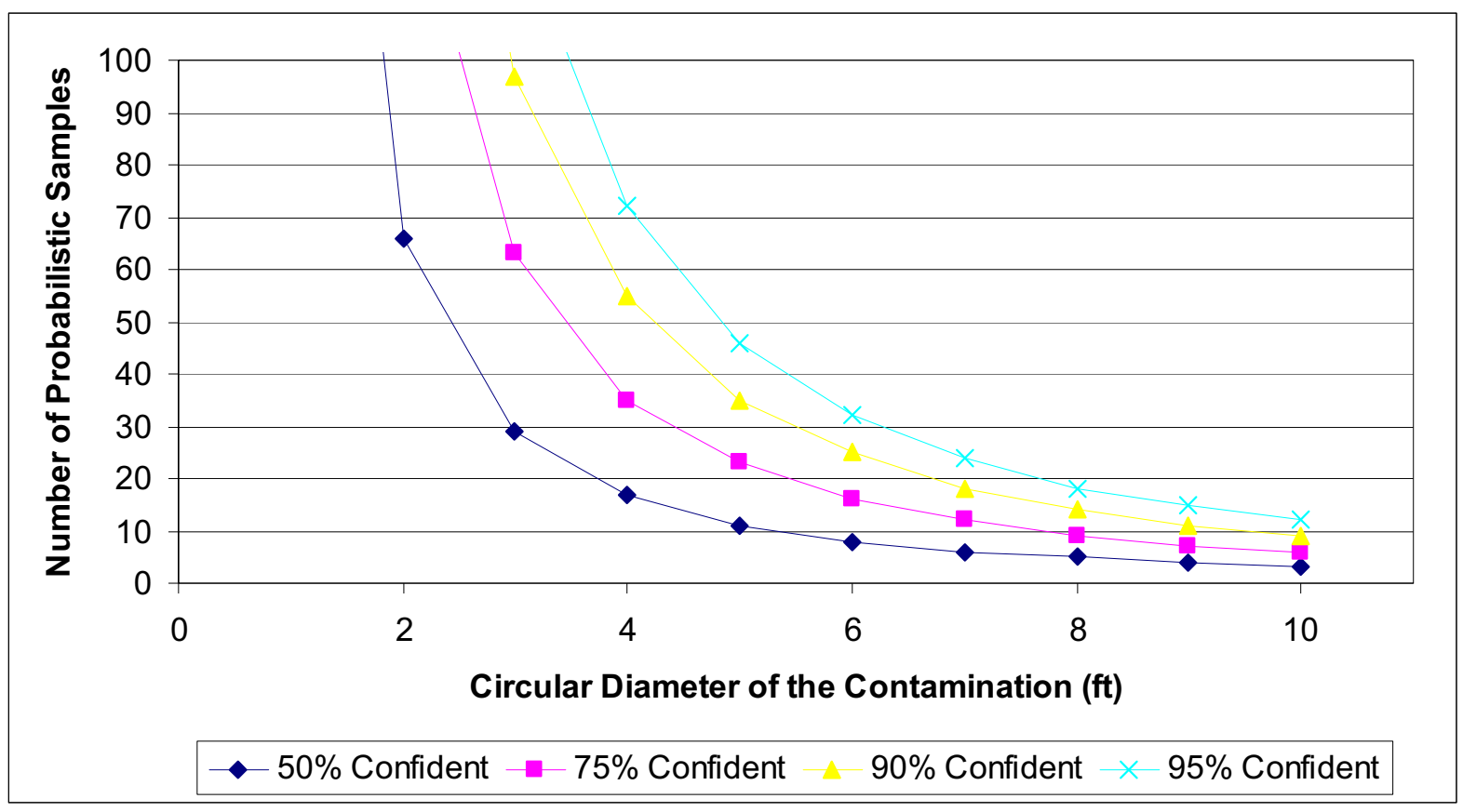

Figure A.11. Number of Probabilistic Samples Required to Detect with 50\% False Negative Rate a Circular Contaminated Area of a Given Diameter with a Given Confidence (represented by the colored lines) within a Typical Room of the INL PBF-632 Building

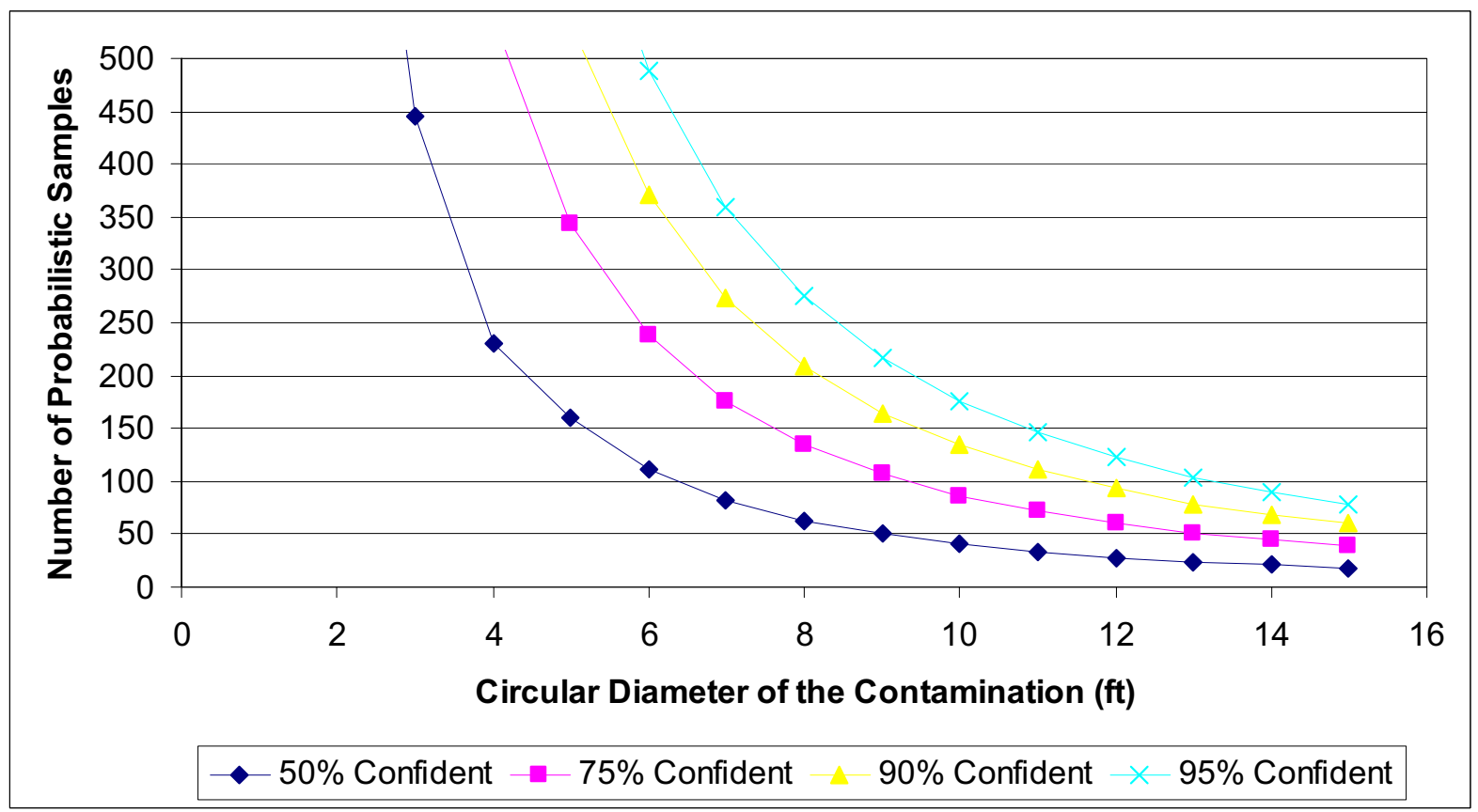

Figure A.12. Number of Probabilistic Samples Required to Detect with 50\% False Negative Rate a Circular Contaminated Area of a Given Diameter with a Given Confidence (represented by the colored lines) within a Single Floor of the INL PBF-632 Building 


\section{Appendix B: Details to be Contained in the Eventual Complete Test Matrix}

Table B.1 illustrates the details to be contained in a test matrix prepared for each test event in the experimental design for contamination and decontamination testing in the PBF-632 building at the Idaho National Laboratory (INL). 


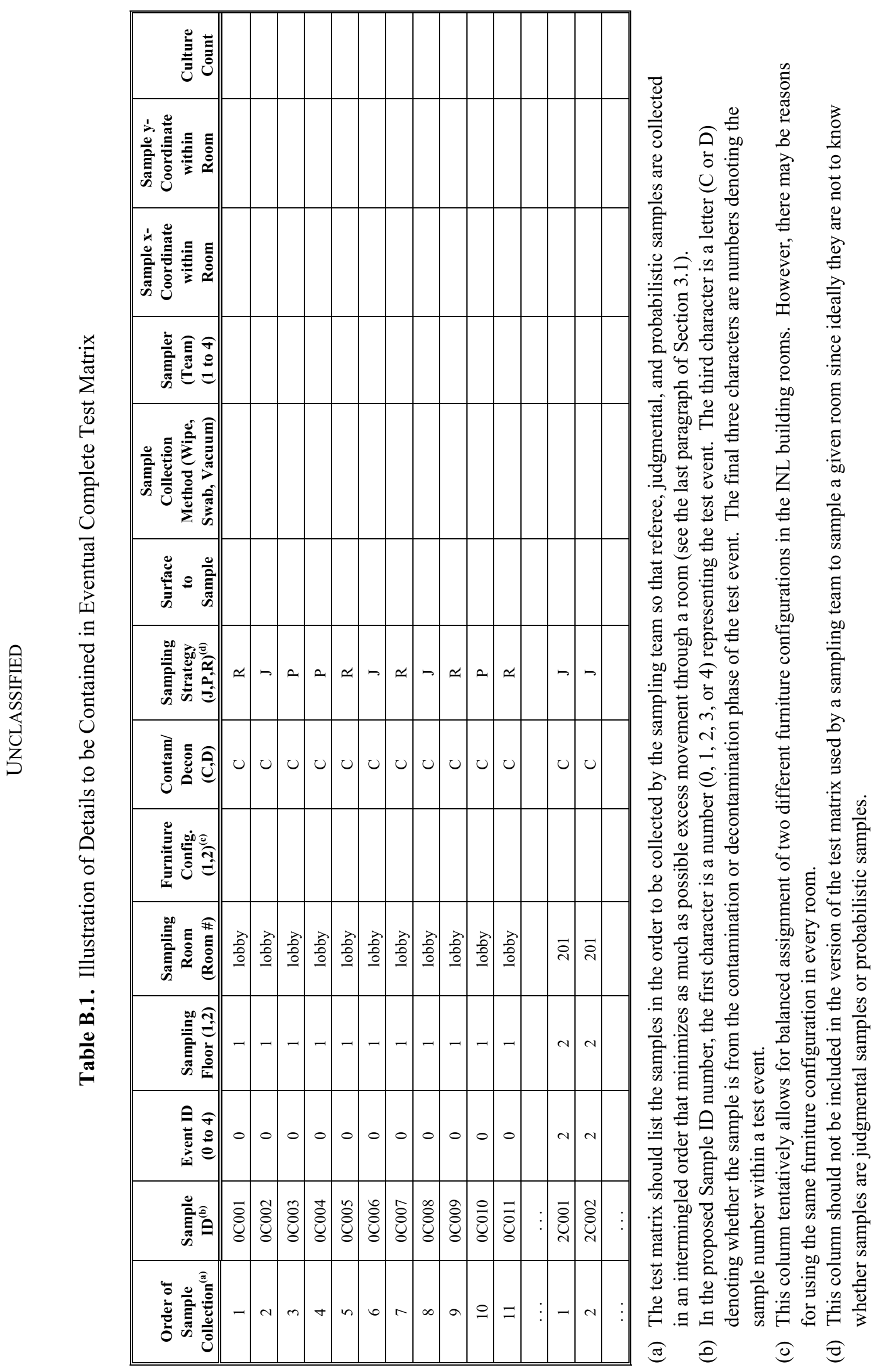

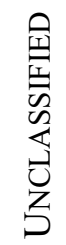




\section{Electronic Distribution List}

No. of

\section{Copies}

4 Department of Homeland Security

Lance Brooks (lance.brooks@dhs.gov)

Bert Coursey (bert.coursey@dhs.gov)

Randy Long (randolph.long@dhs.gov)

Sara Warnick (sara.warnick@associates.dhs.gov)

5 Environmental Protection Agency

Shatzi Fitz-James (fitz-james.schatzi@epa.gov)

Dino Mattorano (mattorano.dino@epa.gov)

Tonya Nichols (nichols.tonya@epamail.epa.gov)

Shawn Ryan (ryan.shawn@epa.gov)

Oba Vincent (vincent.oba@epa.gov)

2 Joint Program Executive Office for Chemical and Biological Defense

Kristin Korte (kristin.korte@jpeocbd.osd.mil)

Michael Walter (michael.walter@jpeocbd.osd.mil)

3 National Institute of Standards \& Technology

James Filliben (filliben@nist.gov)

Barbara Jones (barb.jones@nist.gov)

Andrew Persily (andrew.parsily@nist.gov)

1 Johns Hopkins University Applied Physics

Laboratory

Dorothy Canter (dorothy.canter@jhuapl.edu)

1 Idaho National Laboratory

Michael Carpenter (michael.carpenter@inl.gov)

1 Signature Science

Molly Isbell (misbell@signaturescience.com)

1 Federal Bureau of Investigation

Doug Anders (douglas.anders@ic.fbi.gov)

Doug Beecher (douglas.beecher@ic.fbi.gov)
No. of

\section{Copies}

4 Center for Disease Control and Protection

Matthew Arduino (marduino@cdc.gov)

Ken Martinez (kmartinez@cdc.gov)

Stephen Morse (sam1@cdc.gov)

Angela Weber (aweber@cdc.gov)

1 Bob Murtha

Murtech

bmurtha@murtech.us

\section{Internal Distribution}

Pacific Northwest National Laboratory

Brett Amidan (brett.amidan@pnl.gov)

Brett Matzke (brett.matzke@pnl.gov)

Greg Piepel (greg.piepel@pnl.gov)

Brent Pulsipher

(brent.pulsipher@pnl.gov)

Landon Sego (landon.sego@pnl.gov)

Information Release 